Historical Perspective of Clean Cities and Alternative Fuels Data Center Trends

J.K. O'Connor
Technical Report NREL/TP-540-41069

September 2007 


\section{Historical Perspective of Clean Cities and Alternative Fuels Data Center Trends}

\section{J.K. O'Connor}

Prepared under Task Nos. FC07.0023, BB07.9021
Technical Report NREL/TP-540-41069

September 2007

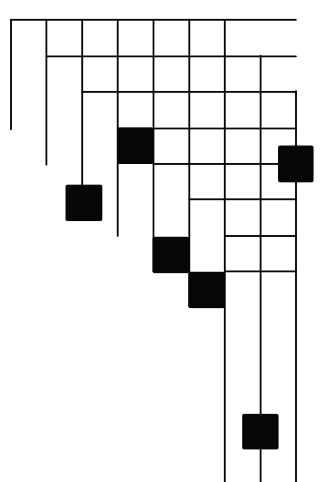




\section{NOTICE}

This report was prepared as an account of work sponsored by an agency of the United States government. Neither the United States government nor any agency thereof, nor any of their employees, makes any warranty, express or implied, or assumes any legal liability or responsibility for the accuracy, completeness, or usefulness of any information, apparatus, product, or process disclosed, or represents that its use would not infringe privately owned rights. Reference herein to any specific commercial product, process, or service by trade name, trademark, manufacturer, or otherwise does not necessarily constitute or imply its endorsement, recommendation, or favoring by the United States government or any agency thereof. The views and opinions of authors expressed herein do not necessarily state or reflect those of the United States government or any agency thereof.

Available electronically at http://www.osti.gov/bridge

Available for a processing fee to U.S. Department of Energy and its contractors, in paper, from:

U.S. Department of Energy

Office of Scientific and Technical Information

P.O. Box 62

Oak Ridge, TN 37831-0062

phone: 865.576 .8401

fax: 865.576 .5728

email: mailto:reports@adonis.osti.gov

Available for sale to the public, in paper, from:

U.S. Department of Commerce

National Technical Information Service

5285 Port Royal Road

Springfield, VA 22161

phone: 800.553.6847

fax: 703.605.6900

email: orders@ntis.fedworld.gov

online ordering: http://www.ntis.gov/ordering.htm 


\section{Contents}

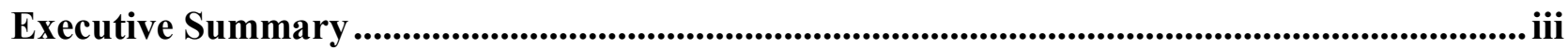

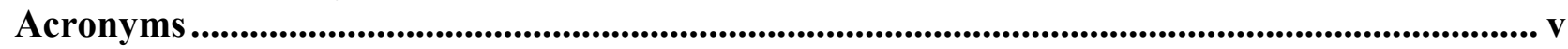

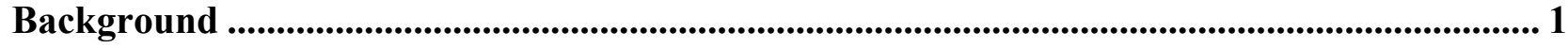

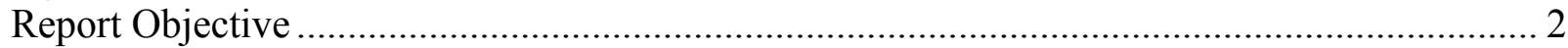

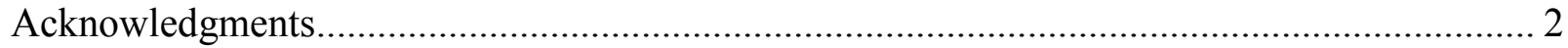

Light-Duty Original Equipment Manufacturer Vehicle Offerings.............................................. 3

Original Equipment Manufacturer Models Offerings 1991 to 2006 ..................................... 3

Original Equipment Manufacturer Offerings by Fuel Type, 1991 to 2006 ............................ 4

Recent Trends in Alternative Fuel Vehicle/Hybrid Electric Vehicle Offerings ........................ 8

Fueling Station Analysis ...................................................................................................................... 12

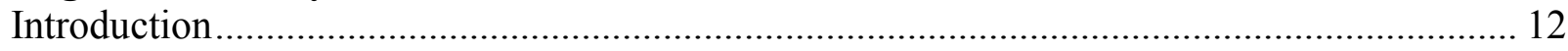

Fueling Station Database Validation ......................................................................... 12

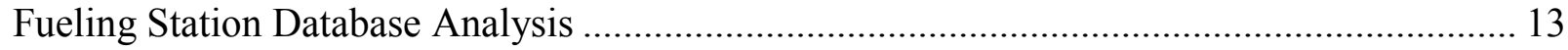

Public/Private Refueling Site Analysis ................................................................. 14

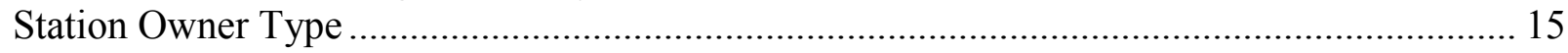

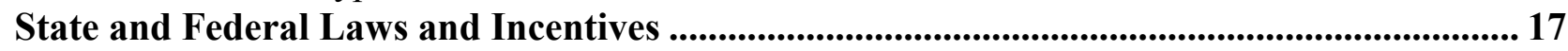

The Clean Cities Program..................................................................................................... 22

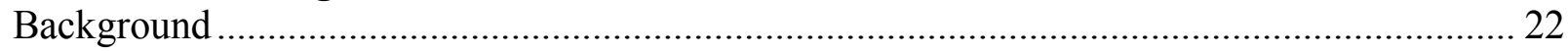

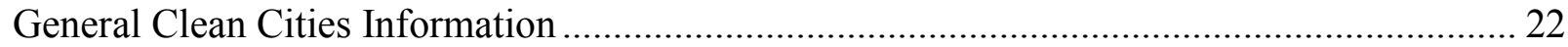

The National Alternative Fuels and Clean Cities Hotlines .................................................... 24

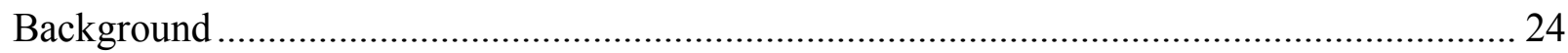

Hotline Request Processing and Evaluation - the Details ............................................... 26

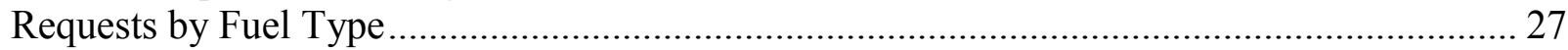

Sources of Requests Received by the Hotline/Technical Response Service ......................... 29

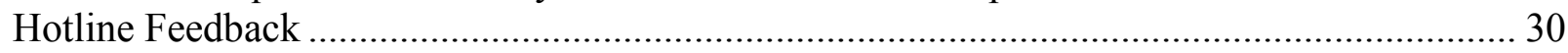

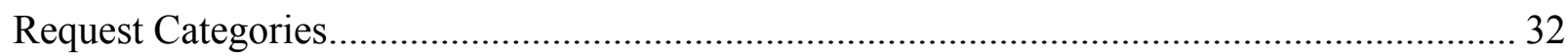

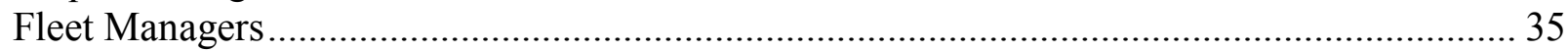

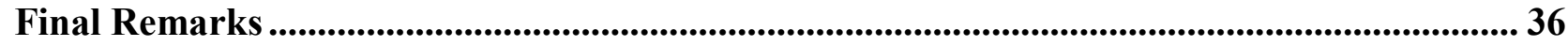

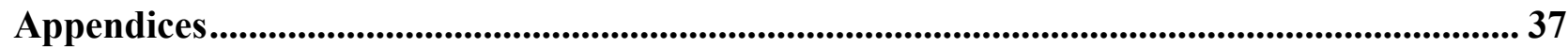

Appendix I. Raw Data Used To Generate Some Original Equipment Manufacturer Figures by

Models Offered and Fuel Type ......................................................................... 37

Appendix II. Original Equipment Manufacturer Charts Showing Models Offered by Fuel Type

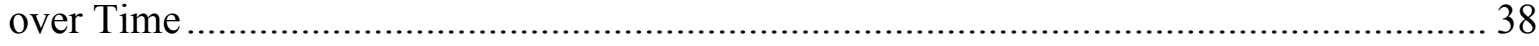

Appendix III. Laws and Incentives-Supplemental Information....................................... 41

Appendix IV. Map of Clean Cities Coalitions................................................................. 42

Appendix V. Supplementary Hotline State and Country Usage Information......................... 43

Appendix VI. Organization Type of Hotline Users ............................................................ 45 


\section{Figures}

Figure 1

Figure 2

Figure 3A

Figure 3B

Figure 4

Figure 5

Figure 6

Figure 7

Figure 8

Figure 9

Figure 10

Figure 11

Figure 12

Figure 13

Figure 14

Figure 15

Figure 16

Figure 17

Figure 18

Figure 19

Figure 20

Figure 21

Figure 22

Figure 23

Figure 24

Figure 25

Figure 26

Figure 27

Figure 28

Figure 29

Figure 30

Figure 31

Figure 32

Figure 33

Figure 34

Figure 35

Figure 36

Light-Duty OEM AFV/HEV Models Offered 1991-2006 . . . . . . . . . . . . . . . . . . . .

AFV/HEV Models Offered by OEMs 1991-2006 . . . . . . . . . . . . . . 4

AFV/HEV Models by OEM/Fuel Type 1991-2006 (\# of models) . . . . . . . . . . 5

AFV/HEV Models by OEM/Fuel Type 1991-2006 (percentage) . . . . . . . . . . 5

AFV/HEV Models by Fuel Type/OEM 1991-2006 (\# of models) . . . . . . . . . . 6

AFV/HEV Models by Fuel Type/OEM 1991-2006 (percentage) . . . . . . . . . . . 7

OEM AFV/HEV Models Available $2006 \ldots \ldots \ldots \ldots \ldots \ldots \ldots \ldots \ldots \ldots$

AFV/HEV LDV Model Offerings by Fuel Type 1998-2006 . . . . . . . . . . . . 8

AFV vs. Hybrid OEM Models 2000-2006 . . . . . . . . . . . . . . . . . . . 9

OEM AFV/HEV Models By Vehicle Type 1991-2006 . . . . . . . . . . . . . . . 9

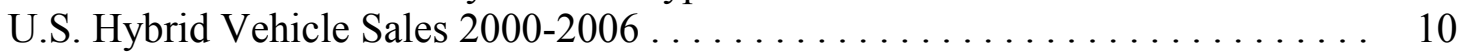

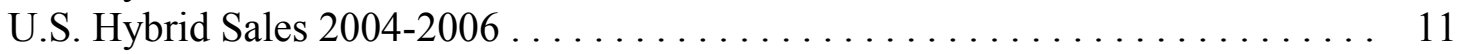

AFV Refueling Sites by Fuel Type $1998-2006 \ldots \ldots \ldots \ldots \ldots \ldots \ldots \ldots \ldots$

Refueling Sites By Fuel Type $2006 \ldots \ldots \ldots \ldots \ldots \ldots \ldots \ldots \ldots \ldots \ldots$

E85, Biodiesel, \& CNG Station Trends 1998-2006 . . . . . . . . . . . . . . 15

Public/Private Proportions of Refueling Stations by Fuel Type in 2006 . . . . . . . 15

2006 Alternative Fuel Stations by Ownership Type . . . . . . . . . . . . . . 16

Federal and State Laws and Incentives by Incentive Type (2006) . . . . . . . . . 18

Laws \& Incentives by Regulation Type (2006) . . . . . . . . . . . . . . . . . . . . . 19

Laws \& Incentives By Fuel/Technology (2006) . . . . . . . . . . . . . . . . . . . . . . . . . . . . . . . . . . .

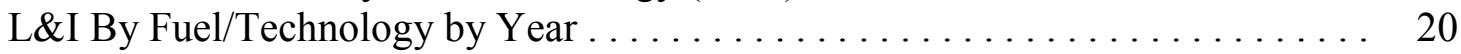

Laws \& Incentives by User Type (2006) . . . . . . . . . . . . . . . . . 21

Population Covered by Clean Cities Coalitions (2000 Census Data) . . . . . . . 23

States with $>2$ Clean Cities Coalitions . . . . . . . . . . . . . . . . . 23

Hotline/TRS Requests $($ FY92-06) . . . . . . . . . . . . . . . . . . . . . 24

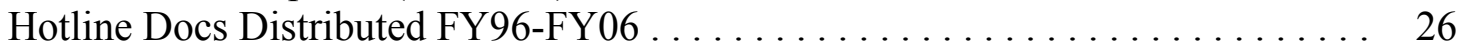

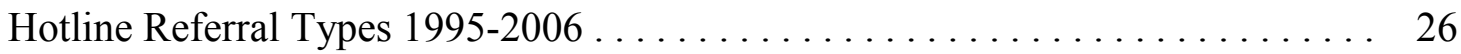

Hotline Fuel Type Requests (FY95-05) (annual) . . . . . . . . . . . . . . . 27

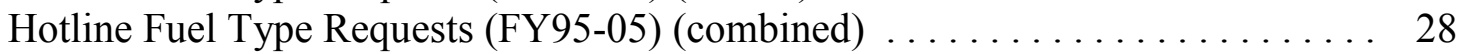

Hotline Fuel Type Requests FY05 . . . . . . . . . . . . . . . . . . . . . 29

TRS Requests by Fuel Type FY06 . . . . . . . . . . . . . . . . . . . . . . 29

Sources of Requests Received at the Hotline By Fiscal Year (FY97-FY06) . . . . . 30

Hotline Operator/Operations Feedback 1996-2005 . . . . . . . . . . . . . . . 31

Were Hotline Expectations Met? (User Feedback FY96-05) . . . . . . . . . 31

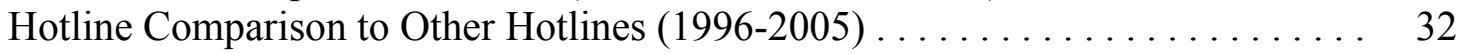

Grades on Documents Distributed to Hotline Users (1996-2005) . . . . . . . . . 32

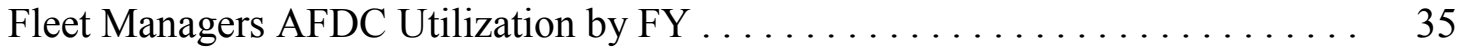

\section{Tables}

Table 1 Top 20 Most Popular Hotline Request Categories (FY 1991-2006) . . . . . . . 33

Table 2 Top 20 Most Popular Hotline Request Categories (FY 2005-2006) . . . . . . . . 34 


\section{Executive Summary}

This document draws on the wealth of information housed in the U.S. Department of Energy's (DOE) Alternative Fuels Data Center (AFDC) at the National Renewable Energy Laboratory. Trends and analyses are examined from data as far back as 1991. The findings of those trends and salient features are summarized. The AFDC is available at www.eere.energy.gov/afdc/.

\section{Original Equipment Manufacturer Vehicle Offerings}

- Ford, General Motors, and DaimlerChrysler (the U.S. "Big Three" original equipment manufacturers [OEMs]) have offered about $80 \%$ of all alternative fuel vehicle (AFV) and hybrid electric vehicle (HEV) models since 1991.

- The Big Three concentrated on compressed natural gas (CNG) and flexible-fuel vehicles (FFVs) during the 1990s, and offered some liquefied petroleum gas (LPG) vehicles.

- Only Honda and General Motors offered CNG models in 2006.

- The Big Three AFV models of 2006 focused on FFVs; an estimated 6 million FFVs were on the roads in 2006.

- Toyota and Honda entered the HEV market in 2000 with the Honda Insight and the Toyota Prius. HEV sales were about 254,000 in 2006, according to Energy Futures.

- Ford made the first Big Three entry into the HEV market with the Escape model in 2005.

- Neither Toyota nor Honda has ever offered an FFV model.

- In 2006 no OEM made an LPG model, and only Global Electric Motorcars made an electric vehicle $(\mathrm{EV})$, its neighborhood electric vehicle.

\section{Alternative Fuel Vehicle Refueling Stations}

- CNG sites peaked in 1999 and have been in steady decline since.

- Ethanol (E85 - a blend of 85\% ethanol and 15\% gasoline) stations demonstrated dramatic growth between 2004 and 2006.

- The growth of biodiesel fueling opportunities mirrored that of E85 between 2004 and 2006.

- E85 stations surpassed the CNG station total in 2006 and biodiesel stations are expected to exceed the number in 2007.

- LPG stations have always reflected the greatest number of fueling opportunities, but the fuel's use for motor vehicles has been difficult to segregate from its other uses.

- EV charging sites continue to be available, especially in Arizona, California, and New York.

- E85, biodiesel, EV, and LPG fueling facilities are generally open to the public.

- $\mathrm{LNG}, \mathrm{CNG}$, and hydrogen stations are less likely to be publicly available.

\section{Laws and Incentives}

- Eighty percent of federal alternative fuel laws and incentives (L\&I) appear as tax incentives and grants.

- Tax incentives and grants account for more than half of all combined federal and state L\&I that have been enacted. 
- When laws and incentives are classified by regulation type, about $60 \%$ are for vehicle acquisition requirements, fuel tax breaks, and vehicle registration requirements.

- There has recently been a sharp increase in L\&I related to ethanol and biodiesel, most likely stemming from the Energy Policy Act of 2005 and the increased popularity of these fuels.

- When classifying by user type, fully one-third of all L\&I are aimed at fleets; another onesixth of the current L\&I benefit individual consumers.

\section{The Clean Cities Program}

- Officially started in September 1993; Atlanta, Georgia, was the first Clean Cities coalition.

- At the end of FY 2006, there were 90 coalitions with more than 4,400 stakeholders.

- The geographic area covered by Clean Cities coalitions includes about two-thirds of the U.S. population, based on the 2000 U.S. Census.

- The three states with the greatest population (California, Texas, and New York) have more than $25 \%$ of the coalitions $(26 / 90)$.

- Fourteen states have state-wide coalitions.

- Five states (Alaska, Mississippi, Montana, Nebraska, and South Dakota) currently have no Clean Cities coalitions.

\section{National Alternative Fuels and Clean Cities Hotlines}

- The National Alternative Fuels Hotline began answering queries in 1991; the Clean Cities Hotline came online in 1993.

- The Hotlines have handled more than 95,000 requests through FY 2006.

- More than 1 million documents have been distributed in response to Hotline requests.

- At its peak in FY 2000, the Hotline handled almost 11,000 requests.

- With the consolidation of DOE's Hotlines to the Energy Efficiency and Renewable Energy Information Center (IC) in FY 2006, the Hotline Service was converted to a Technical Response Service to handle only higher level inquiries passed on by the IC.

- Before FY 2000, almost two-thirds of people heard about the Hotline through the Internet. After FY 2000, the proportion increased to $90 \%$.

- In 2005 requests for information about ethanol, biofuels, and biodiesel reached about $60 \%$ of all requests when a request was classified by fuel type.

- CNG interest dropped from 16\% of fuel requests in FY 2004 to 9\% in FY 2005; biodiesel requests increased from $18 \%$ to $29 \%$ in the same time period.

- More than one-third of all fuel type requests were about ethanol in FY 2004 and FY 2005.

- Hotline requests received electronically doubled in proportion (about $20 \%$ to $40 \%$ ) from FY 1997 to FY 2005.

- From direct user feedback received over the years, the Hotline has received very high grades for its operators, the service provided, and the responses having met or exceeded expectations. 


\section{Acronyms}

$\begin{array}{ll}\text { AFDC } & \text { Alternative Fuels Data Center } \\ \text { AFV } & \text { alternative fuel vehicle } \\ \text { AGA } & \text { American Gas Association } \\ \text { AMFA } & \text { Alternative Fuels Motor Act of } 1988 \\ \text { CNG } & \text { compressed natural gas } \\ \text { DOE } & \text { U.S. Department of Energy } \\ \text { E85 } & \text { fuel blend of } 85 \% \text { ethanol with 15\% gasoline } \\ \text { EPAct } & \text { Energy Policy Act } \\ \text { EV } & \text { electric vehicle } \\ \text { FEG } & \text { Fuel Economy Guide } \\ \text { FFV } & \text { flexible-fuel vehicle } \\ \text { FY } & \text { fiscal year } \\ \text { GEM } & \text { Global Electric Motors } \\ \text { HEV } & \text { hybrid electric vehicle } \\ \text { IC } & \text { Energy Efficiency and Renewable Energy Information Center } \\ \text { L\&I } & \text { laws and incentives } \\ \text { LDV } & \text { light-duty vehicle } \\ \text { LPG } & \text { liquefied petroleum gas } \\ \text { MY } & \text { model year } \\ \text { NAFH } & \text { National Alternative Fuels Hotline } \\ \text { NBB } & \text { National Biodiesel Board } \\ \text { NEV } & \text { neighborhood electric vehicle } \\ \text { NEVC } & \text { National Ethanol Vehicle Coalition } \\ \text { NREL } & \text { National Renewable Energy Laboratory } \\ \text { OEM } & \text { original equipment manufacturer } \\ \text { SUV } & \text { sport utility vehicle } \\ \text { TEDB } & \text { Transportation Energy Data Book } \\ \text { TRS } & \text { Technical Response Service } \\ & \end{array}$




\section{Background}

Alternatives to gasoline and diesel fuels have been investigated and used for more than a century; however, not since the electric automobiles of the late 1800s and early 1900s have any serious challenges been posed to the gasoline or diesel internal combustion engine. In the lightduty vehicle (LDV) sector, gasoline use has predominated, especially stimulated by Henry Ford's mass production of the gasoline-powered Model As and Ts that propelled the industry for the next century. The LDV industry continues to be dominated by the gasoline internal combustion engine. However, because of our nation's growing demand for petroleum in the transportation sector, the increasing instability of supply guarantees, and the rising global demands for oil by developing nations, alternatives to a petroleum-based transportation industry are being vigorously explored in both the industrial and the governmental sectors.

The prime legislative mover that led to the current alternative fuel movement began with the 1988 Alternative Motor Fuels Act (AMFA). AMFA contained provisions to formally establish an Alternative Fuels Data Center (AFDC). According to the National Highway Traffic Safety Administration in its discussion of AMFA:

The AFDC was created to facilitate the directives of AMFA. The purpose of the AFDC is to gather and analyze information on the fuel consumption, emissions, operation, and durability of alternative fuel vehicles, and to provide unbiased, accurate information on alternative fuel vehicles to government agencies, private industry, research institutions, and other related organizations.

AMFA provided incentives for the original equipment manufacturers (OEMs, i.e., Chrysler [now DaimlerChrysler], Ford, and General Motors) through corporate average fuel economy credits. Follow-on legislative activities mandated the use of alternative fuel vehicles (AFVs) in increasing proportions over time by federal, state, and fuel provider fleets as a result of the national Energy Policy Act of 1992 (EPAct). EPAct further expanded the requirements for data and information to support regulated fleets and established the requirements for a voluntary program, which led to the Clean Cities Program. Additional federal executive orders added strength to this legislation by mandating the use of the alternative fuel in vehicles, in the case of non-dedicated fuel systems.

Since its inception in the fall of 1990, the AFDC has played a major role in tracking information about alternative fuels and AFVs. The AFDC has made information available to industry, government, and the public about AFVs offered each model year. Through a variety of cooperative and subcontracted efforts, a database of alternative fuel refueling sites with mapping capabilities has also been offered from 1991 to the present. In addition, information about industry-related laws and incentives (L\&I) has been made available on federal and state levels since the mid-1990s.

The AFDC is available to the public through the AFDC Web site, which offers a wealth of additional information, including a clean fleet guide for fleet managers, fuel property comparison charts, a variety of toolkits (e.g., the E85 Fleet Toolkit and the Hybrid Vehicle Toolkit), alternative fuels training, educational resources, related links, industry contacts, frequently asked questions, a searchable document database, and a link to the Clean Cities Web site, which offers 
all programmatic details about Clean Cities and its contributions to reducing our dependence on imported petroleum. The information in the AFDC and Clean Cities Web sites can be found at http://www.eere.energy.gov/afdc/ and www.eere.energy.gov/cleancities/, respectively. Information about EPAct regulations and implementation can be found at www.eere.energy.gov/vehiclesandfuels/epact.

\section{Report Objective}

This report uses the wealth of information contained in the AFDC databases to assess and describe historical trends in the alternative fuels industry. The objectives of this report are to:

- Document the development of the alternative fuels industry as reflected in AFDC data.

- Analyze information and trends from the AFDC that may prove valuable in understanding past perspectives that could help advance the current and newly emerging technology market.

The prime indicators of growth, interest, and emphasis in the alternative fuels industry can be found by exploring historical trends as reflected in OEM vehicle model data and AFV fueling station growth and decline.

The report analyzes information from the following AFDC databases:

- OEM Vehicle Offerings - primarily LDV information

- AFV Refueling Stations

- Laws and Incentives

- National Alternative Fuels Hotline and Clean Cities Hotline Caller/Requester, Request, and User Feedback Databases

- Clean Cities Coalition Information

\section{Acknowledgments}

The AFDC has been supported by DOE's Clean Cities activity within the FreedomCAR and Vehicle Technologies Program. Additional funding has been provided by FCVT's EPAct Regulated Fleet activities for resources of particular relevance to regulated fleets. In addition to the support from the U.S. Department of Energy, the AFDC has benefited from contributions of data, information, and feedback from countless industry groups and individuals in the alternative fuels community. 


\section{Light-Duty Original Equipment Manufacturer Vehicle Offerings}

\section{Original Equipment Manufacturer Models Offerings 1991 to 2006}

The AFDC has made OEM product offerings available since 1991, beginning with the 65 methanol flexible-fuel vehicle (FFV) Ford Tauruses and Chevy Luminas offered that year at four federal fleet locations in partial response to AMFA 1988. These were not the first AFVs tested and analyzed at the federal level. From 1985 through 1987 Lawrence Berkeley National Laboratory, Argonne National Laboratory, and Oak Ridge National Laboratory also collected performance data about M85 and M88 FFVs as part of the Alternative Fuels Utilization Program. Those beginnings, AMFA 1988, and EPAct 1992, along with a few presidential executive orders, launched the foray into a host of LDV alternative fuel and vehicle combinations from 1991 to present.

Since 1991, 390 AFV and 31 hybrid-electric vehicle (HEV) models have been offered by all OEMs combined. Recent trends will be subsequently examined, but the Big Three U.S.

automakers (DaimlerChrysler, Ford, and General Motors) have accounted for four of five vehicle models offered since 1991 (see Figure 1). Ford has led the way with one-third of all models offered by all manufacturers. Entering into the alternative fuels and $\mathrm{HEV}$ arena beginning in 1998, Toyota and Honda have accounted for about one of 10 models offered. Additional discussion on these generalities will follow as more details are provided in later charts.

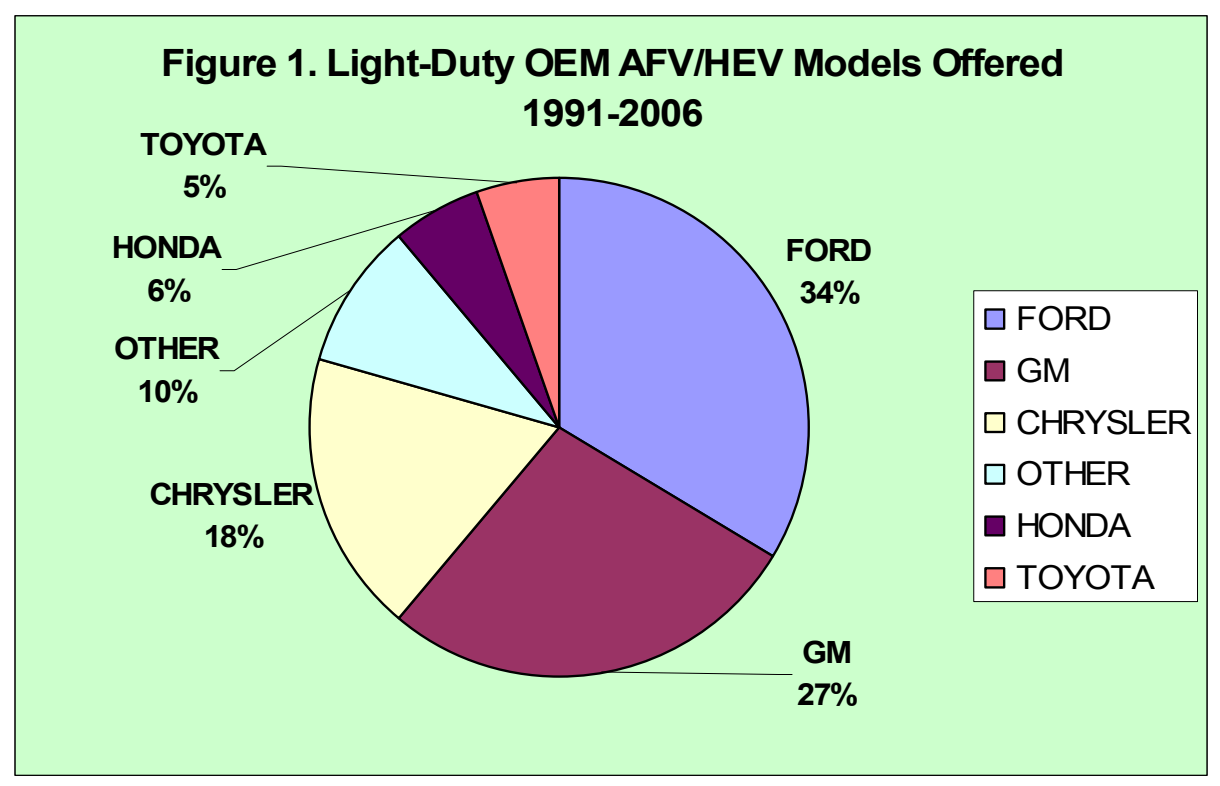

Figure 2 is a follow-on chart that presents a historical timeline detailing the number of models offered by each OEM. Ford showed steady growth in its offerings of compressed natural gas (CNG) vehicles and FFVs through 2004, having peaked in 1999 with 19 models. Ford's dramatic decline in the number of models offered between 2004 and 2005 represents its decision to no longer offer CNG vehicles. In 2005 Ford made its entry in the hybrid market with the Escape, and continues to offer FFVs. 


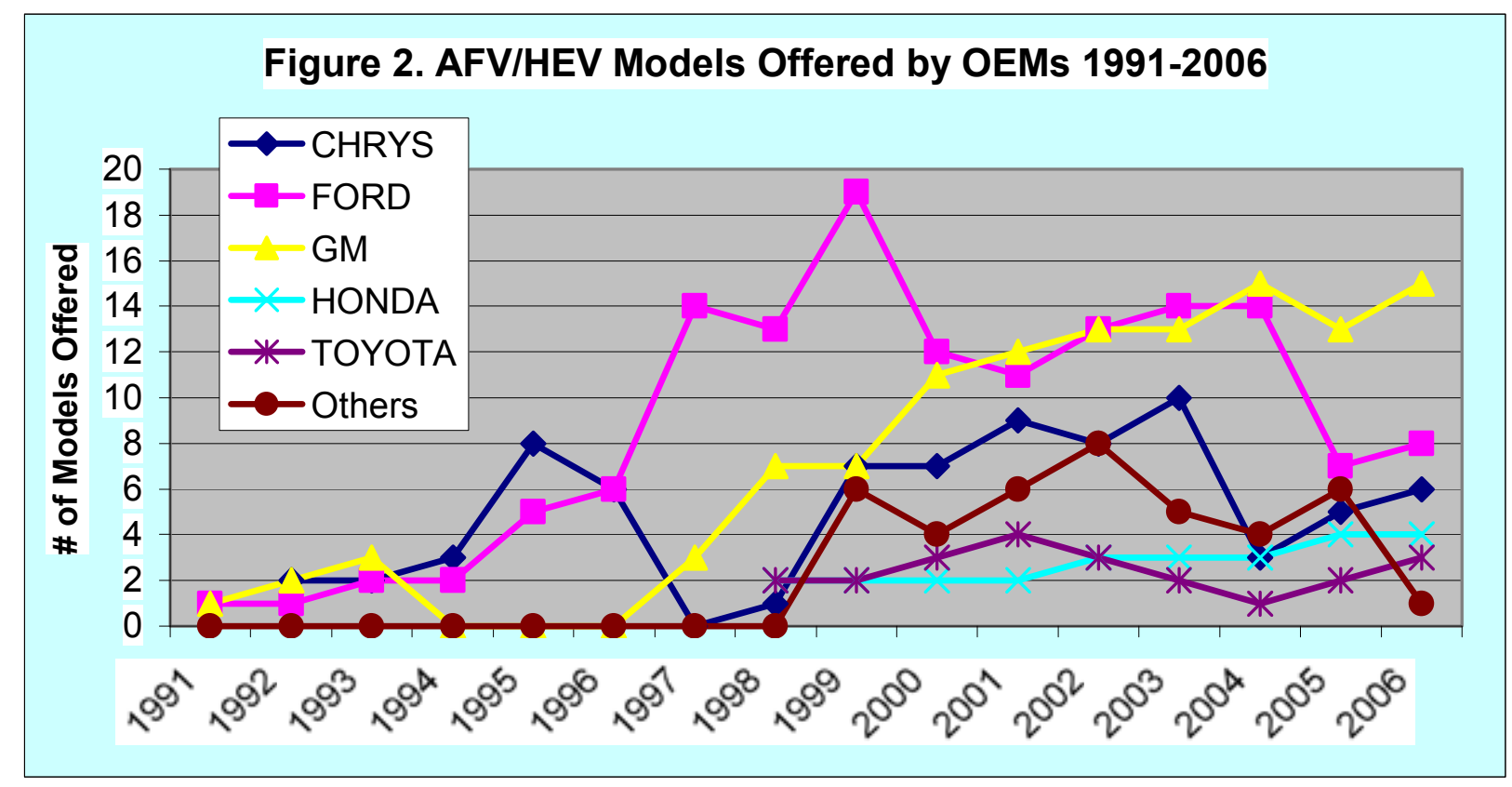

Because of negative publicity that seemed to be related to CNG tank cylinder problems (later determined not to be the cause), GM pulled out of the AFV market for a three-year period from 1994 to 1996. Since that time GM has demonstrated a diversified commitment to alternative fuels and the Clean Cities Program, and sales of all the AFVs have experienced steady growth since 1996. GM was the last U.S. OEM to produce a CNG vehicle, having discontinued its CNG models after MY 2006. Honda, with its Civic GX, is the only other manufacturer offering a CNG model in 2006.

DaimlerChrysler has also been a major contributor to the alternative fuels market, with its peak offerings in the 1999 to 2003 timeframe, when it manufactured CNG, E85, and electric vehicles (EVs). By 2006 DaimlerChrysler offerings were limited to a variety of FFV models.

Honda and Toyota have been in the AFV and HEV markets since 1998. Both have had entries in the CNG market (Toyota's Camry and Honda's Civic GX), but only Honda's Civic GX remains. Honda and Toyota have also had EVs in the market, but now concentrate their offerings in the HEV arena. The Honda Insight and the Toyota Prius HEVs first hit the market in the 2000 model year. The Toyota Prius sedan sales far outstripped the two-seater Insight, which was discontinued in 2006. The first sport utility vehicle (SUV) hybrids were the Ford Escape (the first U.S. OEM hybrid) and the Toyota Highlander, offered initially in 2005.

\section{Original Equipment Manufacturer Offerings by Fuel Type, 1991 to 2006}

Our analysis continues with the examination of the fuel types of the models offered by the OEMs. We've seen that the Big Three have offered the greatest number of models since 1991, but is there a difference between the U.S. manufacturers and others, such as Toyota and Honda, with regard to fuels on which they've chosen to concentrate? Figure 3A shows the numerical distribution of models offered from 1991 to 2006 by manufacturer and vehicle fuel type. The Big Three have concentrated on CNG and E85 over the years. But we'll later present information that 
shows the decline in the interest of CNG as a fuel offering among the Big Three because of lack of infrastructure development and the incremental production costs of CNG vehicles. Honda and Toyota have concentrated on HEVs, EVs, and CNG vehicle offerings. Only Honda and GM remained in the light-duty CNG market in 2006. The "Other" category includes Mazda, Mercedes, Nissan, Quantum, and Solectria; only Nissan is still in the AFV ballgame in 2006 with an FFV offering.
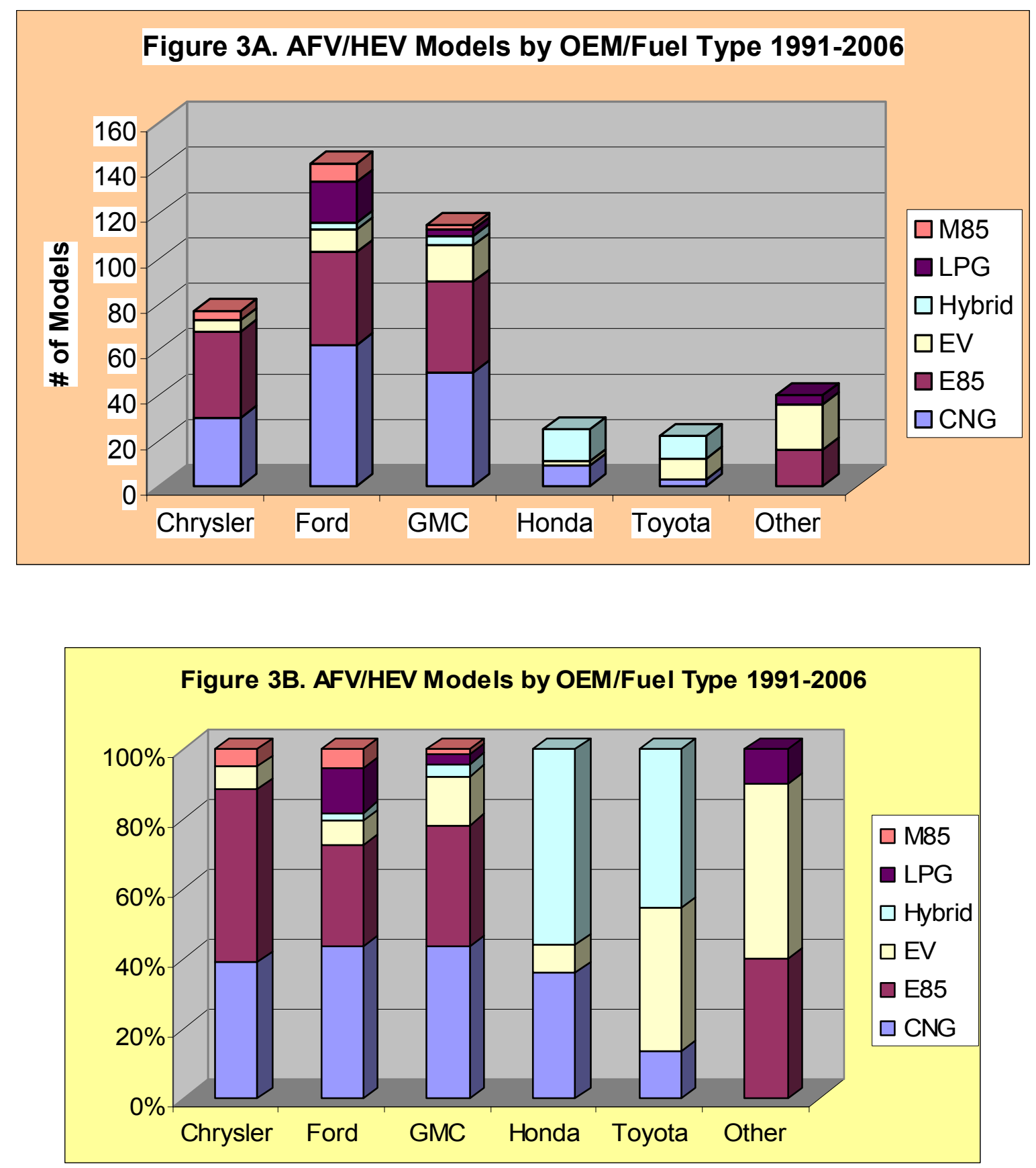

Figure $3 \mathrm{~B}$ is based on the same data as Figure 3A, but provides a clearer representation of the proportional distribution of vehicle/fuel type offered by each manufacturer from 1991 to 2006. 
More than anything this chart reflects the Big Three reaction to the demands placed on fleets to purchase AFVs as a result of EPAct 1992. Through the 1990s the only vehicles coming to the market were CNG, FFVs (E85 and M85), LPG, and EVs; the emphasis was on CNG and alcohol fuel vehicles. Hence, the Big Three not surprisingly show much greater proportions of CNG and FFV vehicles than the latecomers - Honda and Toyota — who introduced the first hybrids in 2000 .

Because CNG and E85 were the primary vehicle fuel choices through most of the 1990s, it is not unexpected to find that the greatest number of model choices over the years concentrated on these two fuels. Where Figures 3A and 3B show the number of vehicle models offered by fuel choice and OEM, Figure 4, a reversal of the axes in Figures 3A and 3B, is provided here to provide a better visualization of the fuel emphases shared by the OEMs since 1991, rather than the OEM offerings by fuel type. Figure 4 clearly shows the emphasis that the OEMs have historically placed on CNG and E85. Appendix I provides the raw data that were used to generate Figures 1 to 4 .

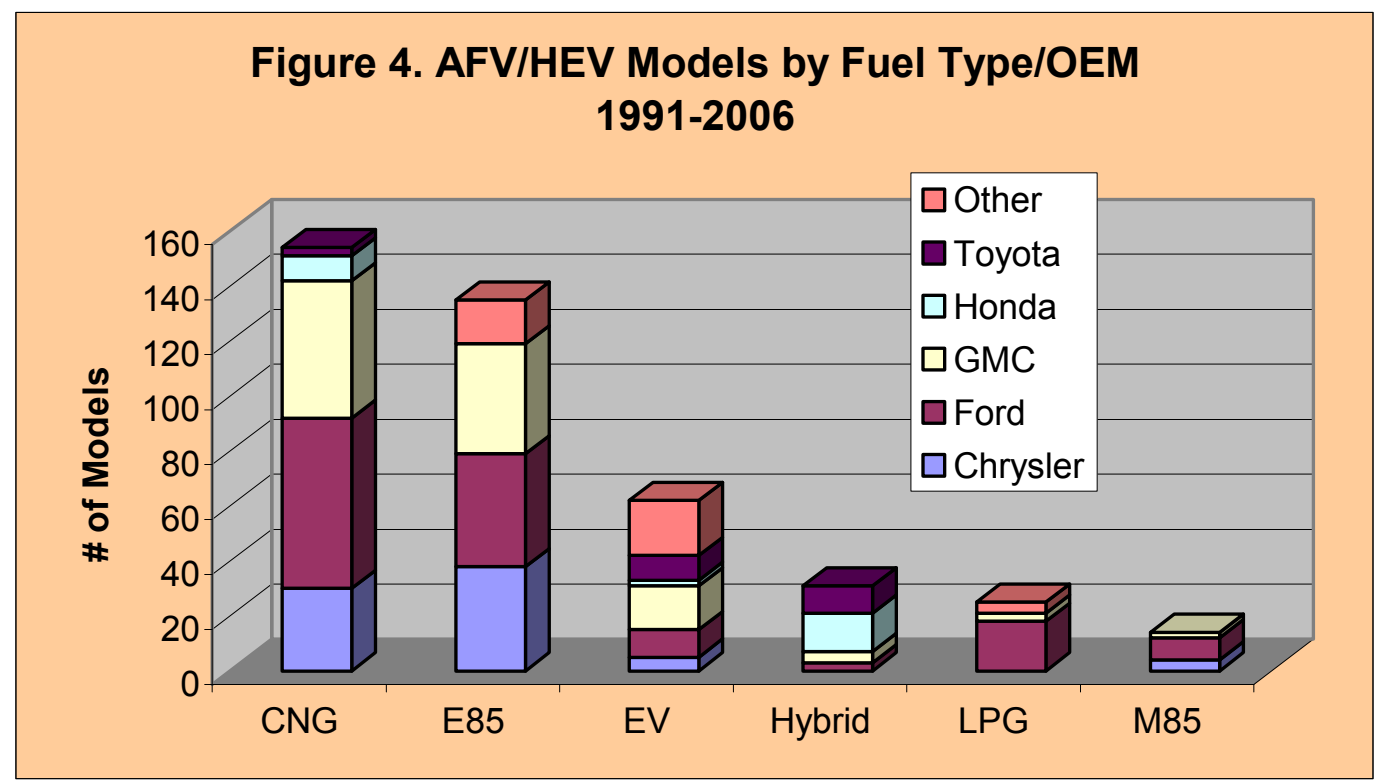

Figure 5 represents the proportional distribution of fuel types offered by OEMs from 1991 to 2006. The figure further shows that Toyota and Honda have dominated the HEV market over time and the Big Three have dominated the CNG and E85 markets, as well as the early LDV M85 and LPG markets, which are no longer players in the light-duty AFV sector. All OEMs have participated in the development of the EV market, but that role has diminished in 2006 to a neighborhood electric vehicle (NEV) niche, dominated by Global Electric Motorcars (GEM), LLC, a DaimlerChrysler company. 


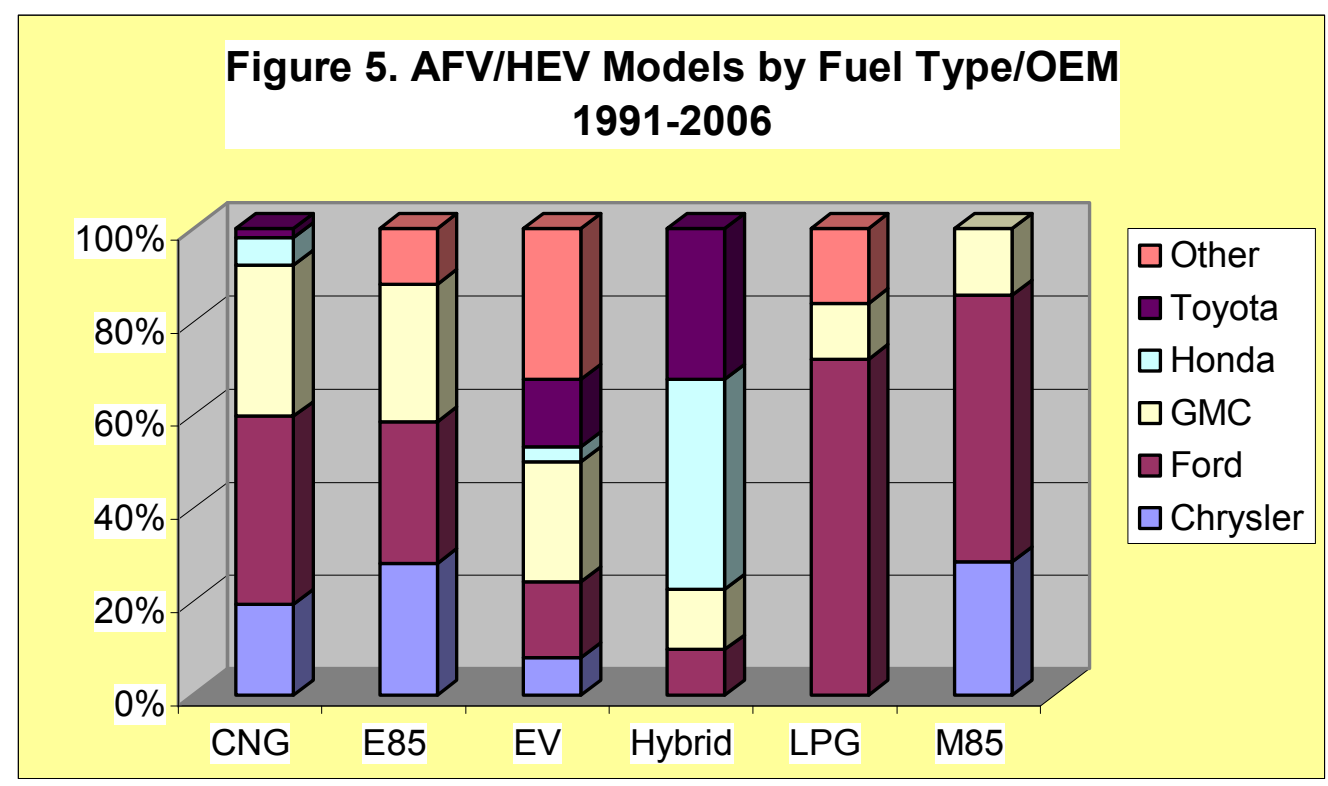

So far we've looked at aggregate data spanning 1991 to 2006 . But what does the AFV market look like in 2006? To determine this, we'll examine 2006 OEM models offered by fuel type, as shown in Figure 6. This picture represents a significant deviation from the full historical offerings of Figure 3A. First, no OEM in MY 2006 offered an EV, M85, or LPG vehicle; only GM and Honda offered CNG vehicle models. The rest are E85 FFVs and HEVs. Chrysler's six models are all E85; 75\% of Ford's eight vehicles are FFVs. In 2006 GM is the only OEM to offer all three vehicle fuel types and leads the way with 15 models. Toyota was $100 \%$ committed to the hybrid line in 2006. Neither Honda nor Toyota has ever offered an alcohol fuel or LPG vehicle.

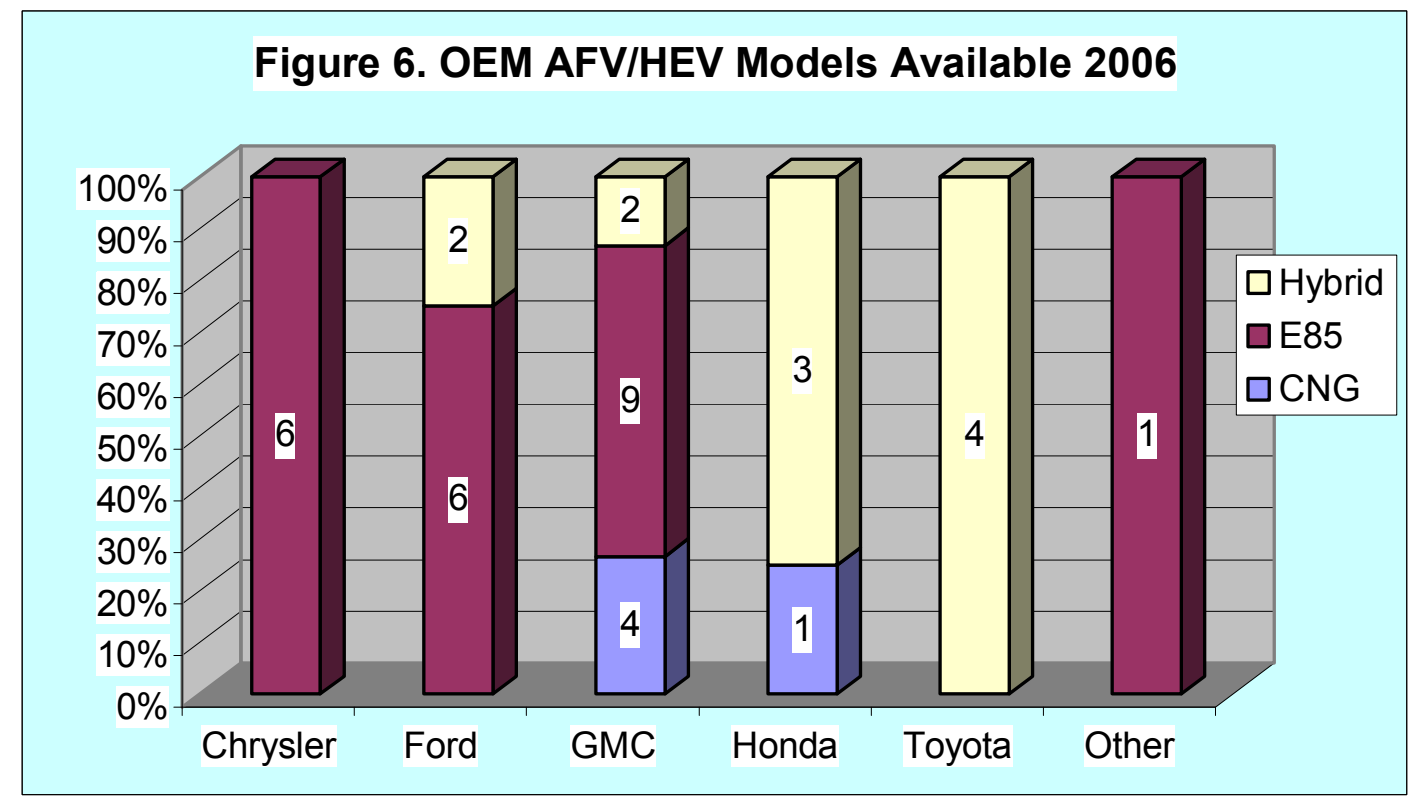




\section{Recent Trends in Alternative Fuel Vehicle/Hybrid Electric Vehicle Offerings}

Four additional charts shed light on the more recent trends of vehicle offerings in the AFV/HEV arenas. First, in Figure 7, we'll analyze vehicle fuel type trends from 1998 to 2006. The following information is noteworthy:

- $\quad$ E85 model offerings showed a relatively steady growth from 1998 to 2006.

- Hybrid models (10) in 2006 are double the number of CNG models offered (five).

- Only hybrid and E85 models are showing growth trends.

- In 2005 and 2006, no LPG or EV models were offered.

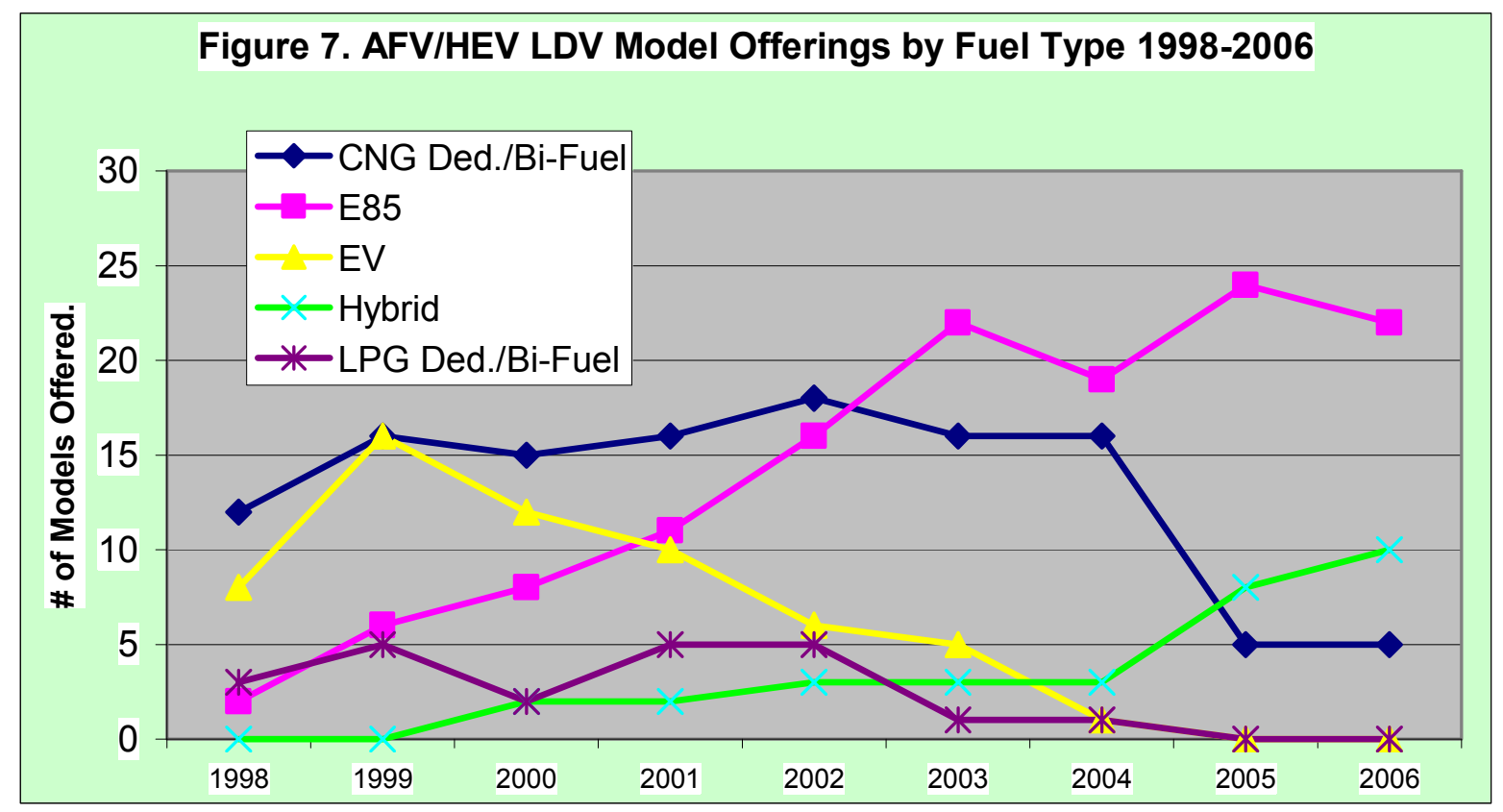

Figure 8 combines all AFV models and compares AFV models offered with HEV models from 2000 to 2006. Whereas AFV offerings reached their peak in 2002 with 45 models, the HEV market has shown significant growth from 2004 to 2006. Depending on the infrastructure growth for E85 and market demand for HEVs, the HEV model offerings might well surpass the number of FFV (E85) models offered in the not-too-distant future.

We've looked at vehicle models offered by OEMs with regard to fuel type over time. But what kinds of vehicle types (autos, pickups, vans, SUVs) in the light-duty arena have been offered by the OEMs from 1991 to 2006 ? Figure 9 provides the answers.

Some notable trends are:

- Autos and pickups continue to dominate today's market with more than $70 \%$ of the vehicle offerings in 2006.

- SUVs show significant proportionate growth since 2002 and now garner about onefourth of the offerings by all OEMs. 
- The interest in vans has dropped since the higher concentrations of CNG van offerings in the 1999 to 2003 timeframe; vans now represent only 5\% of the 2006 model offerings.

Details of models offerings by specific OEM are offered in Appendix II.
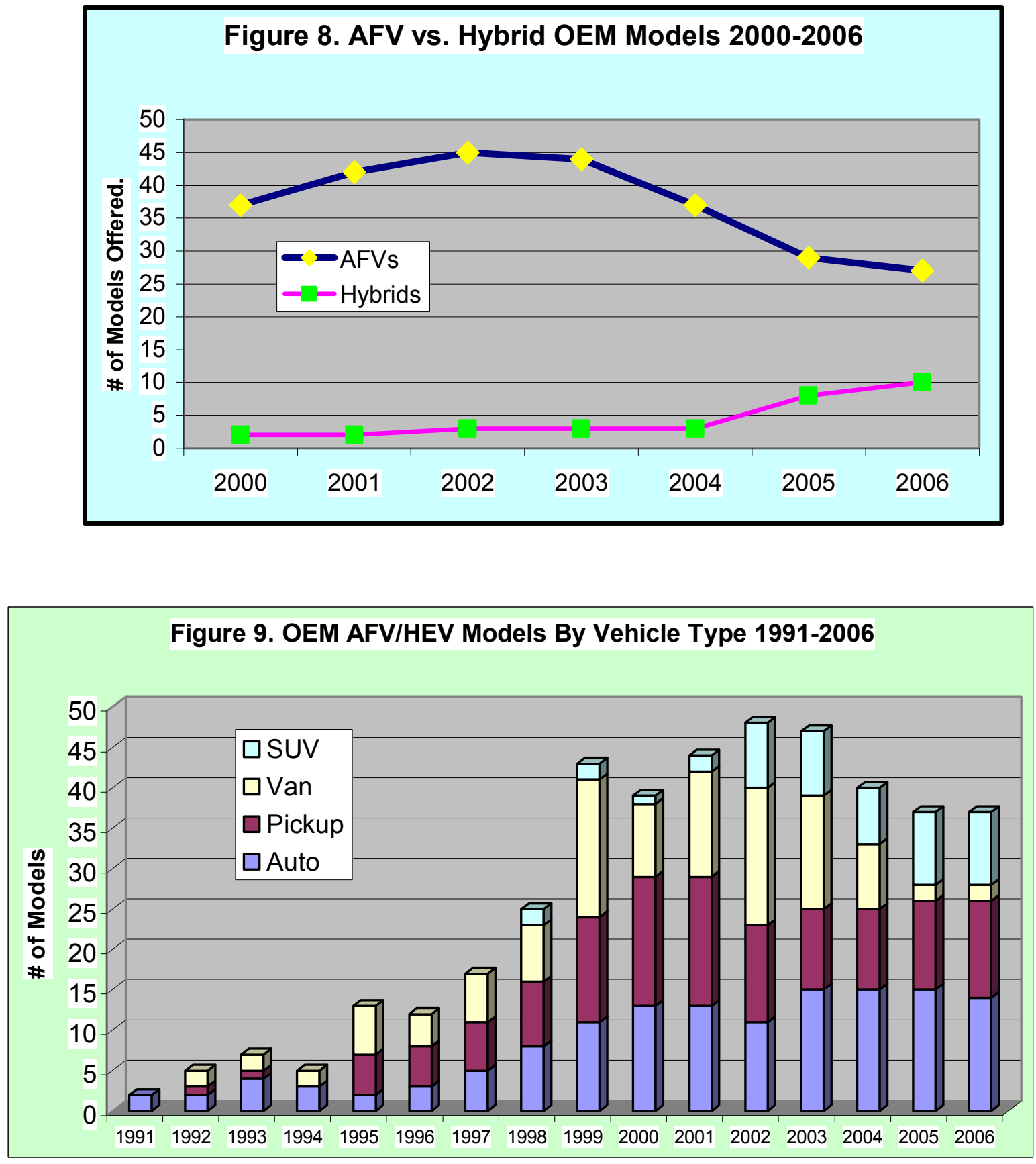

\section{Hybrid Sales Growth}

As shown in Figure 10, HEV sales have experienced dramatic exponential growth, both in numbers and in the increasing diversity of vehicle models coming online. Since their 
introduction in 2000 with the Honda Insight and Toyota Prius, total hybrid sales are approaching 650,000; at least 10 hybrids are now on the market from Ford, Honda, and Toyota. In 2006, annual sales figures are expected to be somewhere between 230,000 and 250,000 units.

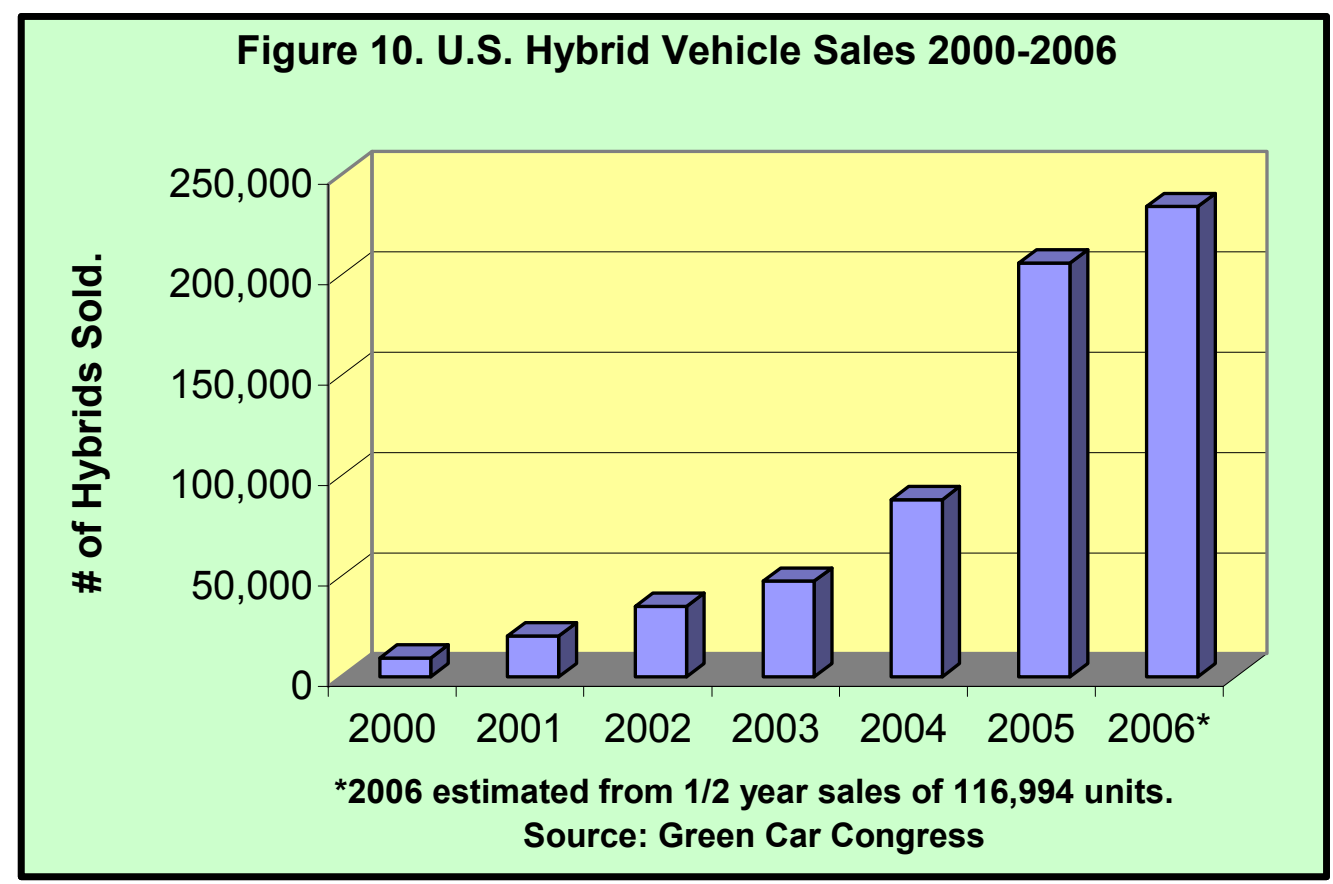

The Green Car Congress (www.greencarcongress.com) provides monthly updates on the number of hybrids sold by manufacturer and model. Figure 11 from the Green Car Congress provides a picture of the growth of HEV sales from 2004 to 2006. On a monthly basis, hybrid sales have steadily increased since February 2006; August sales reached the highest ever at 26,189 units, representing $1.8 \%$ of all LDVs sold in that month. Toyota's Prius and Camry hybrids garnered three-fifths of the hybrid sales in August 2006.

Parenthetically, EPAct 2005, Section 706, establishes a "Joint Flexible Fuel/Hybrid Vehicle Commercialization Initiative" under which "The Secretary shall establish a program to improve technologies for the commercialization of--

(1) a combination hybrid/flexible fuel vehicle; or

(2) a plug-in hybrid/flexible fuel vehicle."

As a result of this stimulus (paragraph [1] above), Ford is already developing an FFV option to the HEV Escape vehicle. At the 2006 Washington, D.C., auto show, Ford unveiled, with great fanfare, its prototype for an E85-powered Escape Hybrid vehicle. Ford's overall marketing plans for this vehicle are as yet unclear. 
Figure 11.

US Hybrid Sales 2004-2006

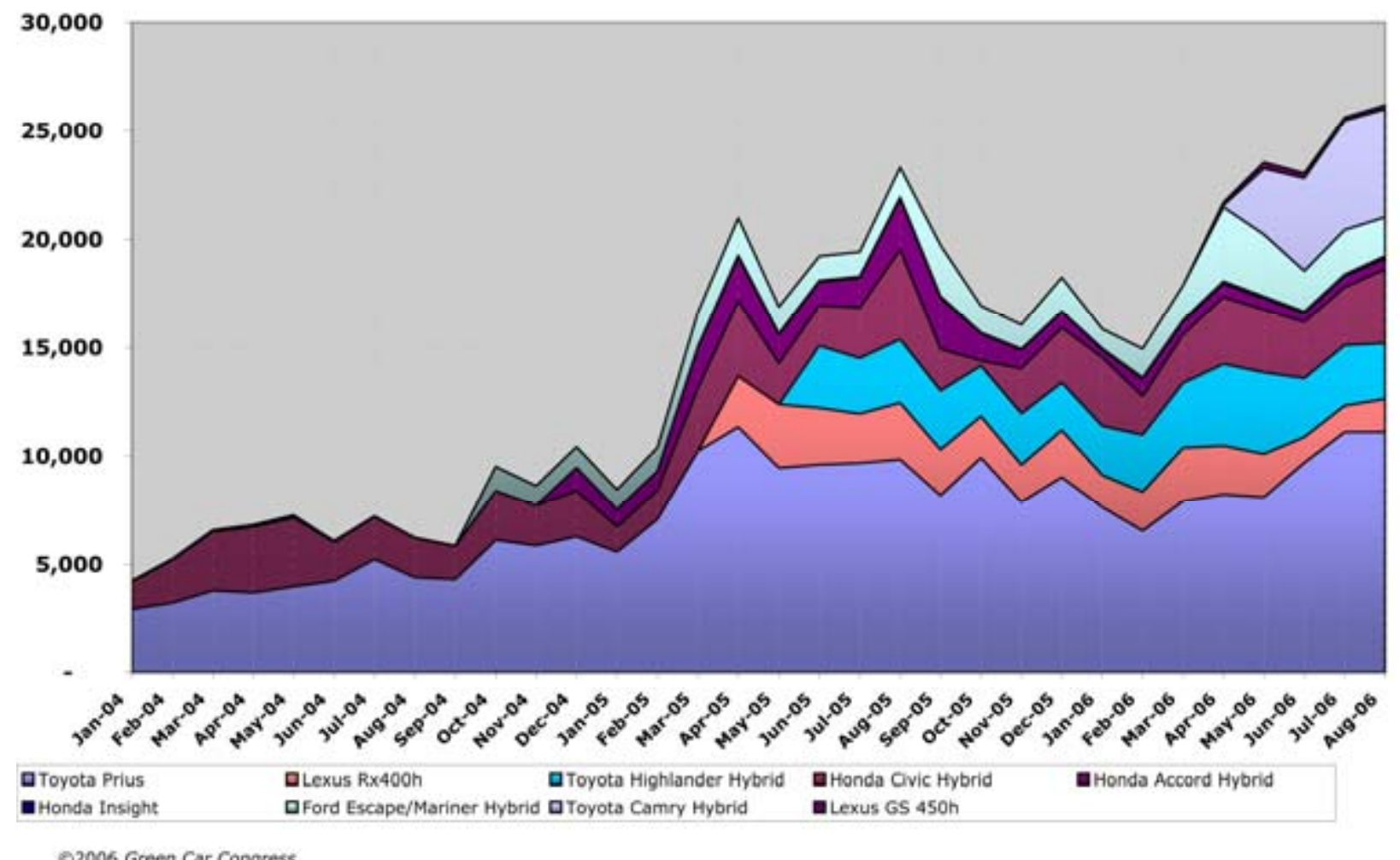

Q2006 Green Car Congress

Used with permission of Green Car Congress. 


\section{Fueling Station Analysis}

\section{Introduction}

The growth of the alternative fuels industry has, in some ways, been mirrored by the rise (and fall in some cases) of the number of fueling stations it has created. The growth of fueling stations will now be examined to see what can be learned about their effects on the alternative fuels industry. For the most part, the historical data have been taken from the data published in the Transportation Energy Data Book (TEDB) by Oak Ridge National Laboratory; the source of this information is the AFDC at NREL. The reason for using the data published in TEDB is that they represent a published snapshot in time of the data from the AFDC. We have chosen to present fueling station data from 1998 as the most reliable set of data on fueling stations over time, because of the more rigorous data validation efforts that have taken place since that date.

\section{Fueling Station Database Validation}

NREL has been cognizant of the need to maintain data that have been verified and are as complete as possible under the constraints of reasonable resources applied to data quality assurance. Over the years NREL has employed various subcontractors to collect and validate fueling site data sources. All stations in the NREL database have been directly contacted, either by phone or e-mail, or through secondary sources to ensure that the stations are open and still distributing the noted alternative fuel for motor fuel use.

Differences in data sets between NREL and other sources and Web sites are noted and explained for the special cases of E85 and biodiesel fueling sites. The National Ethanol Vehicle Coalition (NEVC) maintains a state-by-state list of E85 fueling stations, showing a total count of 979 stations when visited on October 1, 2006. NREL's database included 906 stations on the same date. The primary difference between the NREL and the NEVC counts is that the NEVC reports planned stations in addition to those in actual service. In a similar fashion the National Biodiesel Board (NBB) maintains a list of stations offering biodiesel (B2-B100), as does NREL. As NEVC does with E85, NBB includes planned stations.

Verifying the stations offering LPG (propane) as a motor fuel has always been difficult. The original database of more than 5,000 LPG sites offering LPG motor fuel came from a directory of LPG stations published by the National Propane Gas Association in the mid-1990s. Over time, NREL's investigations into these stations have shown that many have discontinued the practice of offering LPG as a motor fuel. In the early to mid-1990s the LP Gas Association estimated that 10,000 propane stations offered propane as a motor fuel, although this complete list of stations was never published for verification.

Regarding natural gas fueling facilities, NREL subcontracted with the American Gas Association (AGA) from the early to mid-1990s for use of its published stations offering CNG. The list was limited to AGA members and suffered somewhat from a lack of annual station verification. NREL felt more confident once the stations were directly contacted on an annual basis beginning in the late 1990s. 


\section{Fueling Station Database Analysis}

Because of the increasing confidence of data integrity from the late 1990s, the analysis of stations offering alternative fuels is made beginning with 1998 and extending through 2006. The data are reported on a fiscal year (October 1 to September 30) basis. Figure 12 summarizes the growth of alternative fuel refueling sites from 1998 to 2006. LPG sites are not included for two reasons: (1) to report the data would diminish the graphical representation of the other refueling sites; and (2) no OEMs are manufacturing LPG vehicles (and the number of LPG vehicles generally stems from estimates made by the Energy Information Administration in the early to mid-1990s with revisions as appropriate). And there have never been any reliable methods to estimate national use of LPG, except from the vehicle estimates. One could raise a similar question about including electric sites in the graph, but the argument for including these sites is that they are verifiable, although the use of the sites is not determinate and only NEVs are currently being manufactured and sold by one OEM (GEM), as noted above. The electric charging sites are predominantly in California, Arizona, and New York.

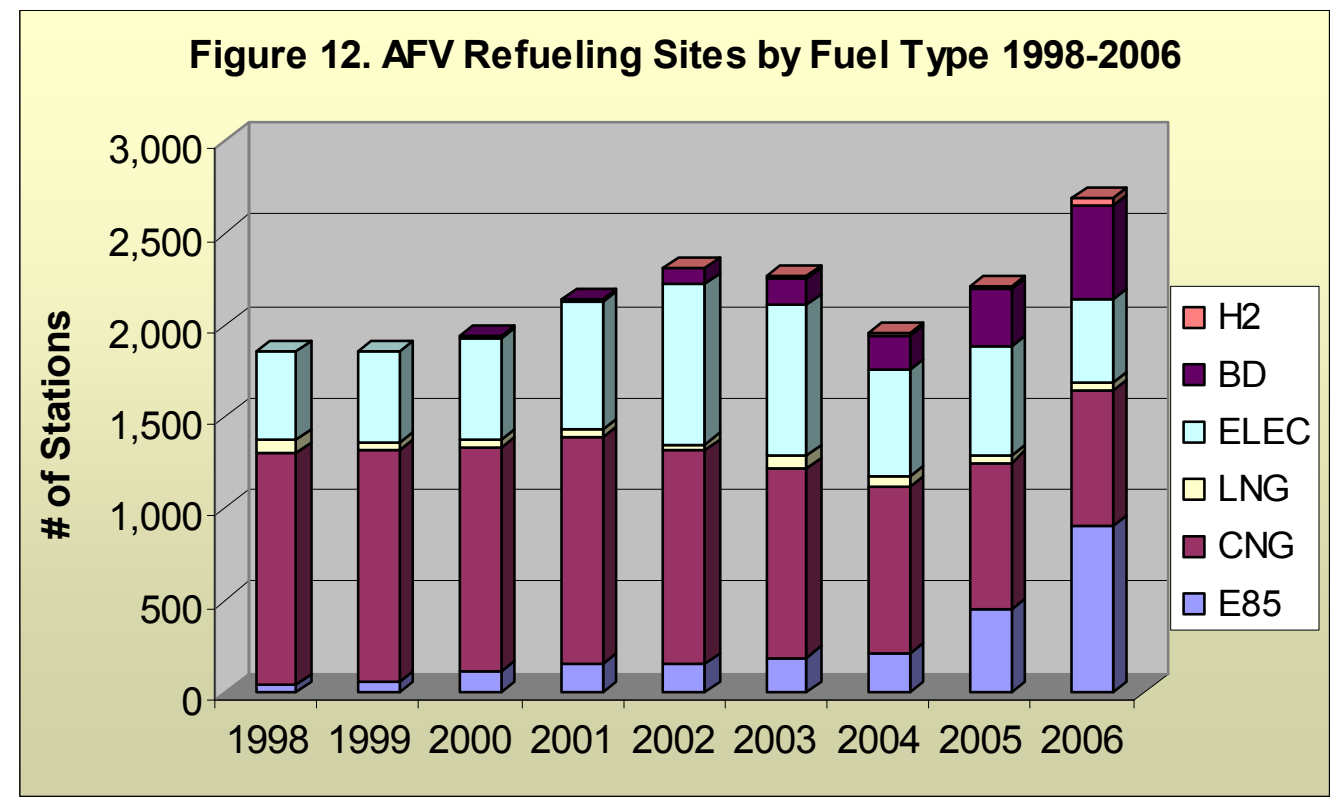

One of the most apparent features of the data presented in Figure 12 shows the steady decline of CNG sites since 1998 and dramatic increase of ethanol sites, especially from 2004 to 2006. The significant growth of the biodiesel sites reflects the growth and use of biodiesel as an alternative fuel, predominantly in the heavy-duty industry today. Of course, the 6 to 7 million ethanol vehicles on the roads in the United States today and EPAct 2005 (which established the Renewable Fuels Standard to produce 7.5 billion gallons of ethanol by 2012) easily justify the growth of E85 refueling sites. The number of stations offering biodiesel might be expected to experience more rapid growth in the next five years because biodiesel is more commonly sold as a low-level blend of $2 \%$ to $5 \%$; sales in the $20 \%$ blend have also increased in popularity. Anchor fleet stations for CNG (mostly in the heavy-duty and public transportation markets such as taxis and airport shuttles sectors) are on the increase, but the steady decline of CNG stations in general derives from very few OEMs presently offering light-duty CNG vehicles. 
Figure 13 shows the total number of U.S. refueling stations in 2006, including LPG. By NREL's best authentication processes, there were 5,256 alternative fuel refueling sites in the United States as of September 30, 2006. LPG sites represented about half of the sites, E85 about onesixth, CNG about one-seventh; biodiesel and electric sites fewer than one-tenth each, and LNG and hydrogen comprising fewer than $1 \%$ each of all sites.

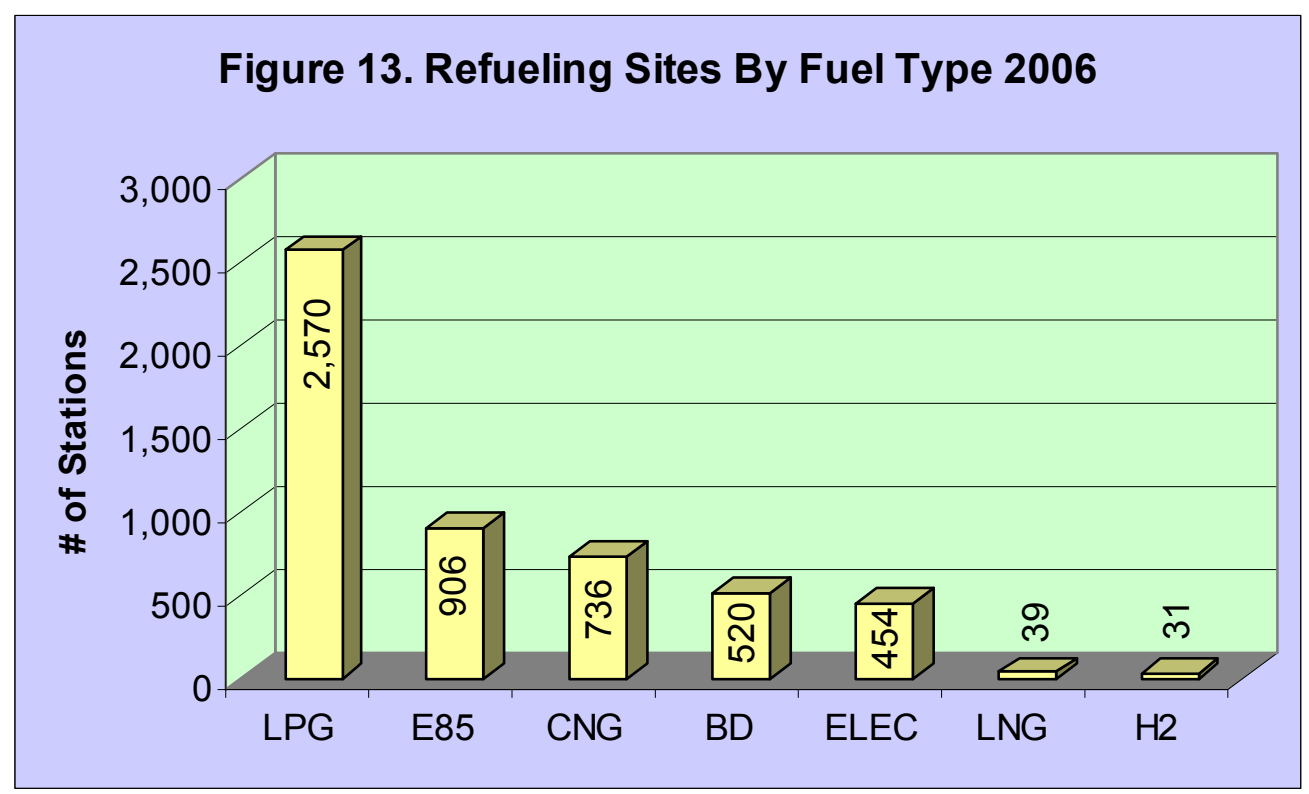

Figure 14 displays the comparative growth and decline of the E85, biodiesel, and CNG markets as represented by the number of stations from 1998 to 2006. Figure 14 illustrates the market trends previously alluded to: (1) the declining CNG market because of OEM lack of commitment to manufacture light-duty $\mathrm{CNG}$ vehicles; and (2) the legislatively stimulated and growing markets of E85 and biodiesel. In 2006, the number of E85 stations (906), growing by almost $85 \%$ from 2005 to 2006, surpassed the CNG station count (736), which once numbered more than 1,400 in the 1996 to 1997 timeframe according to the AGA data stored in the AFDC and reported in the TEDB. Based on trends indicated in Figure 14, the number of biodiesel stations will also surpass the number of CNG stations in 2006 or 2007.

\section{Public/Private Refueling Site Analysis}

Refueling stations may be open to the public part- or full-time, or they may be solely available to the owners of the station on private locations. Many stations on government property may also not be open to the public. Figure 15 offers the proportions of public to private stations by fuel type in 2006. The salient features of this figure are:

- Most LPG stations have always been open to the public.

- To service the millions of publicly owned FFVs on the road, E85 stations are most often open to the public.

- Almost $80 \%$ of electric charging sites have been open to the public historically.

- More than two-thirds of the biodiesel stations are open to the public as part of normal highway diesel service operations. 
- LNG, CNG, and hydrogen stations are more often located on private property to service large anchor niche market fleets, or fledgling prototype markets in the case of hydrogen.
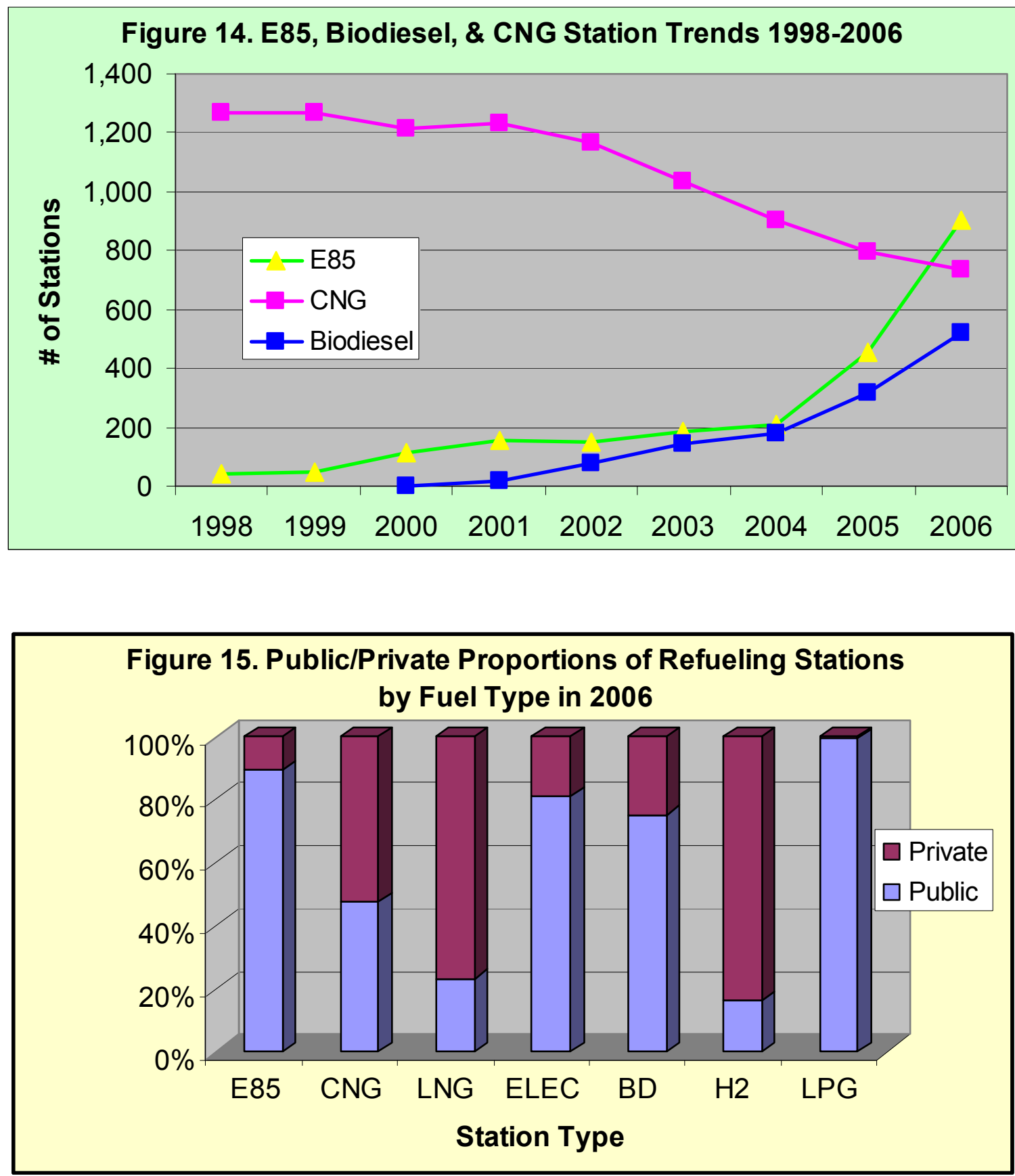

\section{Station Owner Type}

Alternative fuel station growth has been largely influenced by private entrepreneurs. Recent grant incentives for partially funding alternative fuel station capital investments have also contributed to station openings. Figure 16 clearly shows that $80 \%$ of all alternative fuel refueling 
stations are privately owned; another $10 \%$ are owned by the government, and the rest by a utility or some joint ownership venture. Although $80 \%$ of the stations are privately owned nationwide, $85 \%$ of all alternative fuel stations are open to the public, largely influenced by the significant proportions of the LPG, E85, and biodiesel stations open to the public as noted in Figure 15.

\section{Figure 16. 2006 Alternative Fuel Stations by} Ownership Type

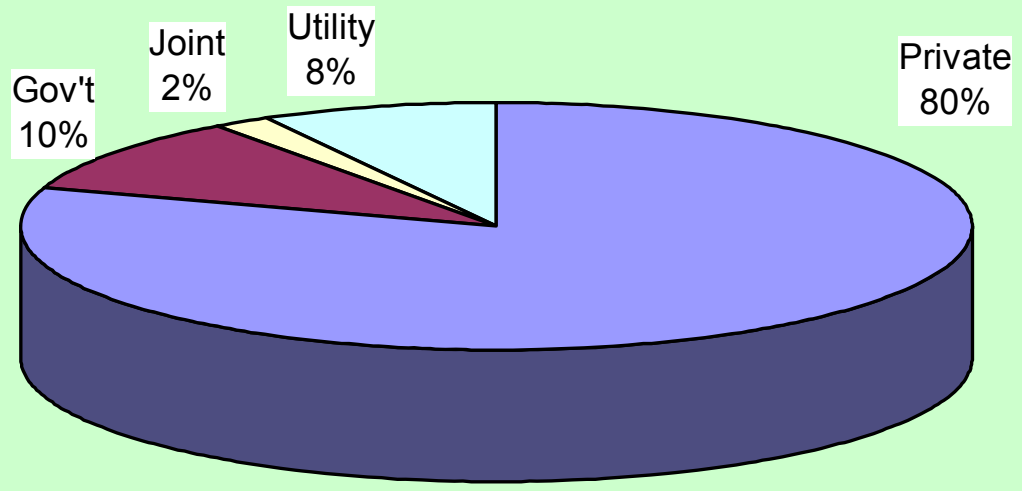




\section{State and Federal Laws and Incentives}

Because of the demand for information about L\&I at the state and federal levels, legislative actions have been tracked and made available to the public in the AFDC. Over the past decade, NREL has maintained data on federal and state L\&I through a subcontracting process.

This section is offered primarily to show the breadth and depth of the information that is offered within the AFDC. It is not intended to analyze the specific contents of passed legislation, but to discuss the robust ways the data are organized, categorized, and made available to the public. The information on the Web is divided into federal and state-by-state bases, and is further made available by the following classifications:

- Incentive type (grants, tax incentives, loans, rebates, etc.)

- Regulation type (acquisition requirements, fuel taxes, etc.)

- Technology/fuel type (general alternative fuels, biodiesel, ethanol, hydrogen, etc.)

- User type (fleet manager, alternative fuel producer/dealer/OEM, etc.)

- Multi-parameter search capability (refinements of above).

Hundreds of L\&I have been enacted at the federal and state levels. The AFDC provides information on all currently active legislation and regulations. The details of any searches on the Laws and Incentives Web site, for the first four specific categories noted above, results in a table that details the number of regulatory activities that have been enacted at the federal and state-bystate levels for each option in the selected category. Once a search is made, the user may click on any number in the summary table to view the details of the legislated activity. Searches may be conducted at: www.eere.energy.gov/afdc/laws/incen laws.html. One piece of legislation may fall into several categories. That is, for example, the user may see the same legislative activity referenced in the details of different searches within the same state or category.

We will now examine summary information about the number of L\&I that are currently categorized in one of the searchable areas: incentives types, regulation types, technology/fuel types, and user types.

Figure 17 shows the proportions of incentive types that have been used to stimulate and grow the alternative fuels market. Tax incentives and grants have led the way with more than half (54\%) of all legislative activity of these types at the combined federal and state levels. At the federal level, the importance that legislators placed on tax incentives and grants as the primary medium for advancing alternative fuels is noted in that four of five incentives were related to tax reductions or grant programs. At the state level, technical assistance and exemptions were found to be important incentive types. Currently 317 laws or regulations deal with various incentive types. Of these, one-eighth have been passed at the federal level and seven-eighths at the state level. Only two states have no current legislation or regulations pertaining to at least one of the incentive types in Figure 17. California, Connecticut, New York, and Texas all have more than 10 laws or regulations related to one of the listed incentive types. 


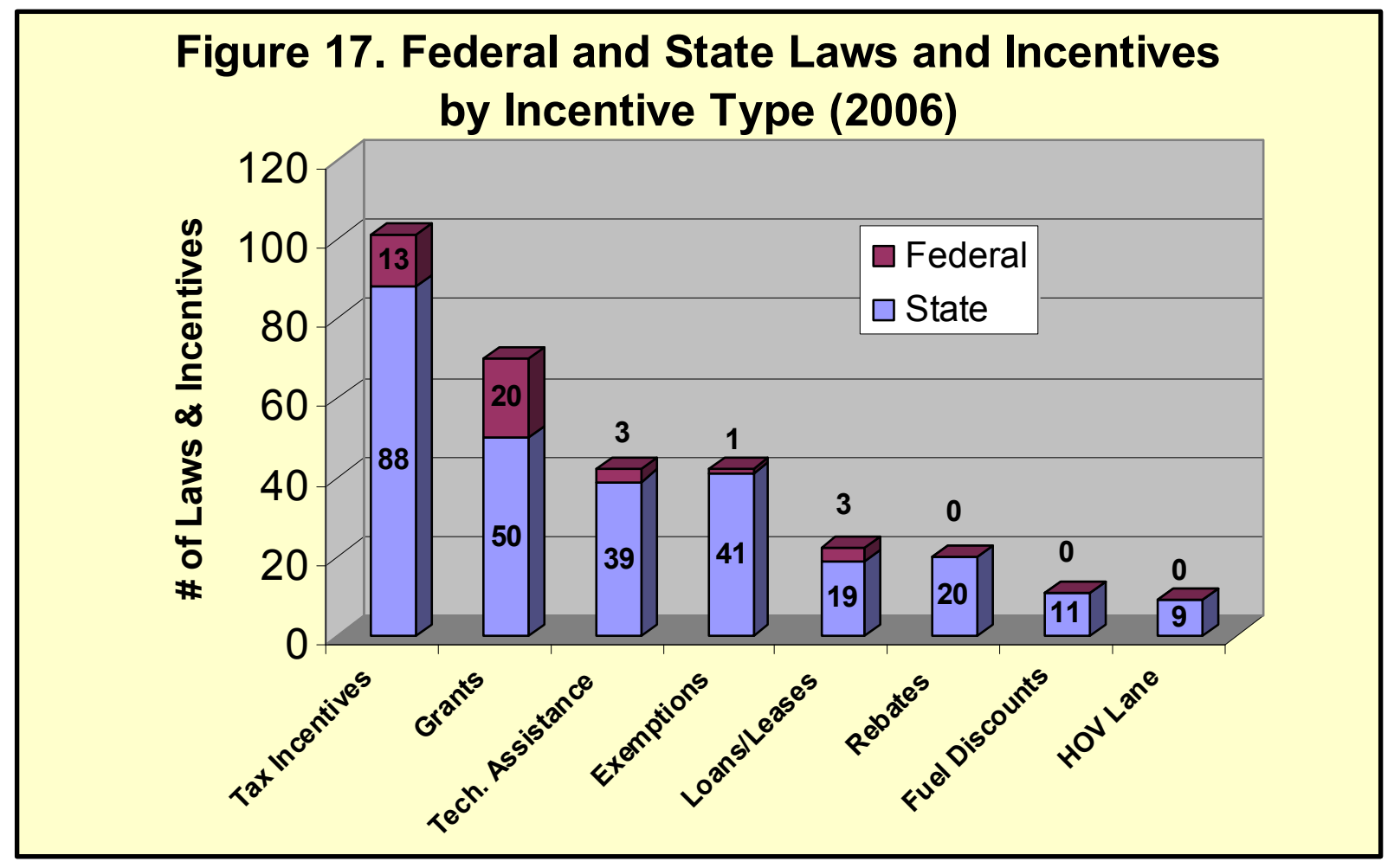

The second way the AFDC has classified legislation is by the regulation type or sectors affected by adopted legislation. Figure 18 presents the data on federal and state activities that have been specifically enacted to affect particular areas listed on the chart. In general the federal regulations have concentrated most of their efforts on vehicle acquisition requirements (EPAct 1992 especially focused on acquisition requirements); five of the eight enactments fall into this category. State efforts have been heavily concentrated in three areas; $60 \%$ of L\&I affect acquisition requirements, fuel tax regulations, and vehicle registration.

Most legislative and regulatory activities were easily classifiable into multiple fuel/technology categories, as suggested by the data in Figure 19. AFDC personnel were able to categorize L\&I by fuel/technology type into 894 entries, of which 812 represented state activities and 82 , federal. (See supplemental tables in Appendix III.) General alternative fuel impacts led the way numerically, but we may safely assume that these laws and regulations would also result in being classified in one of the other specific alternative fuel/technology categorizations listed in Figure 19. Suffice it to say that there has been significant activity, and more overall specific fuel diversity at the state level than at the federal level; the most significant currently active laws and incentives affect EVs/NEVs, biodiesel, natural gas, and ethanol. Of course, the greater diversity of L\&I at the state level would be expected with 50 entities contributing. 
Figure 18. Laws \& Incentives by Regulation Type (2006)

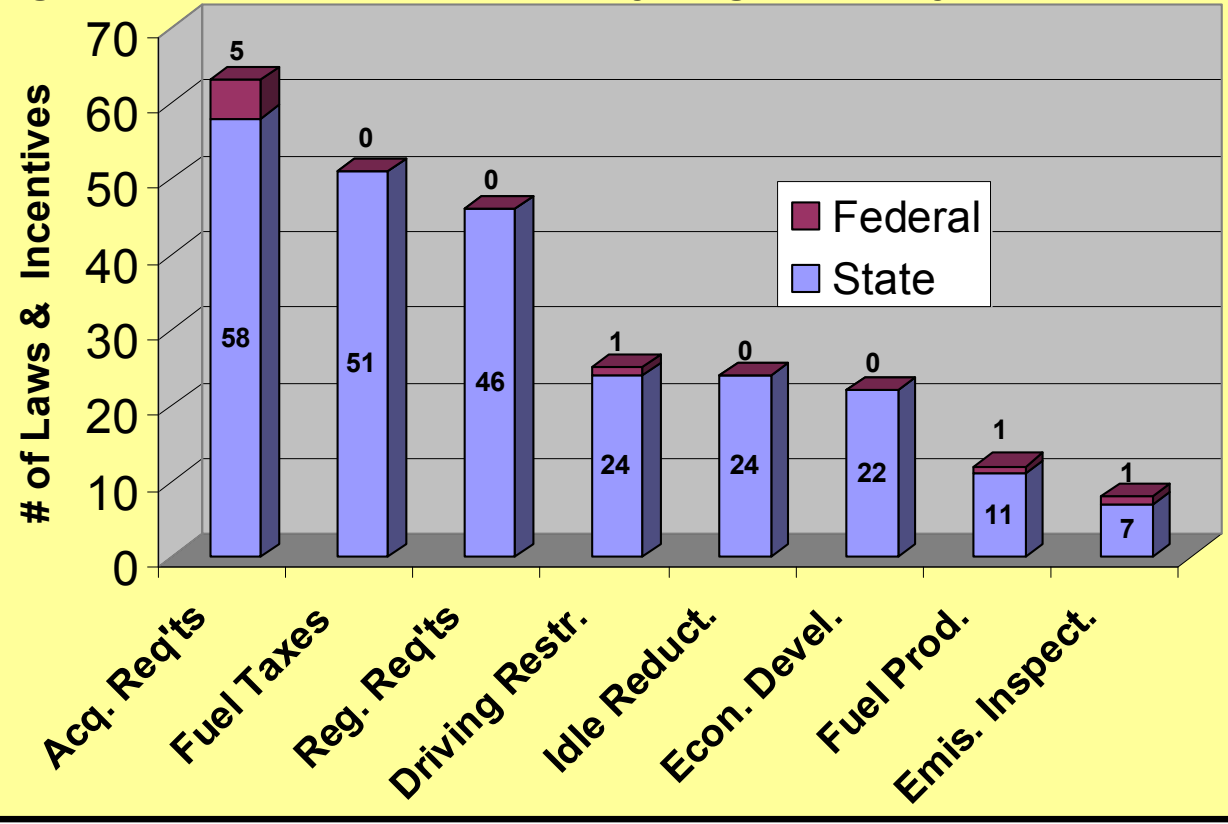

\section{Figure 19. Laws \& Incentives By Fuel/Technology (2006)}

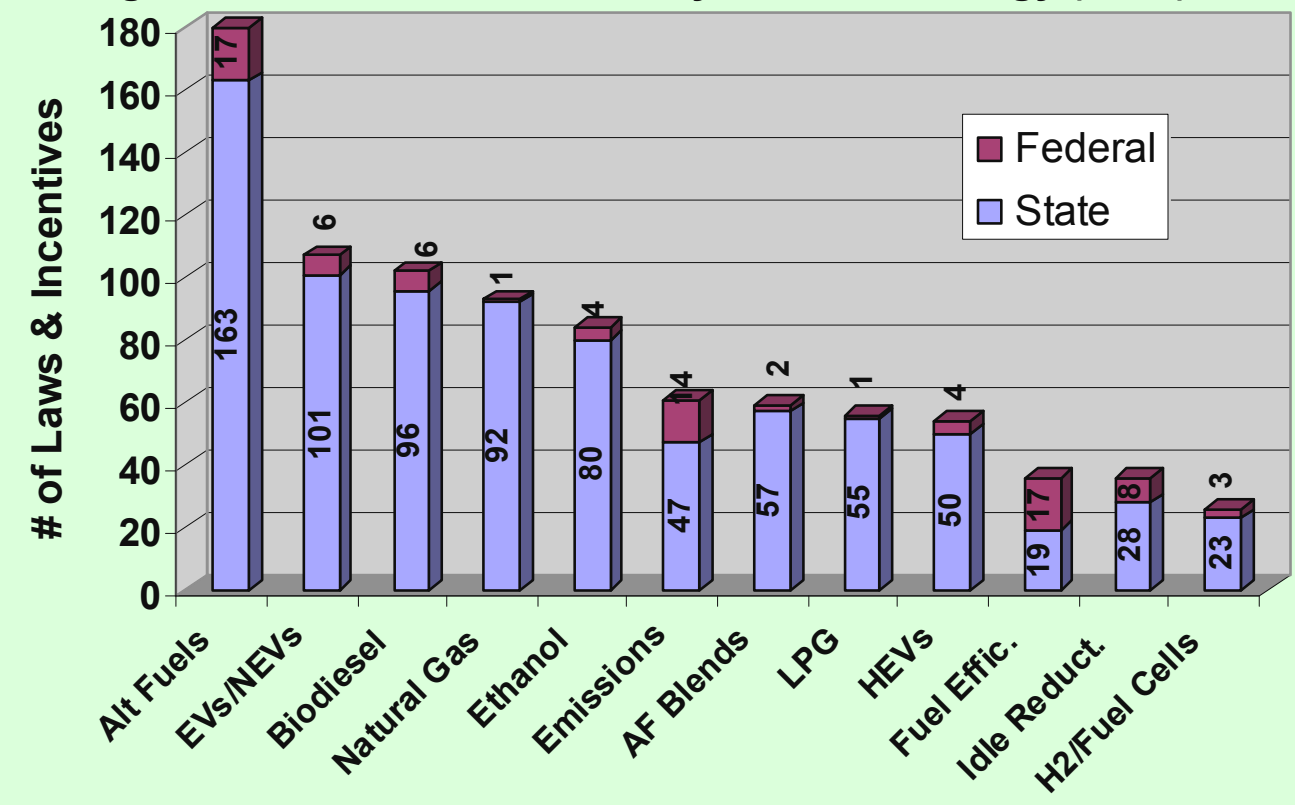


Figure 20 provides a detailed look at L\&I by fuel type/technology over time. The main points to be gleaned from this chart are:

- A general decline in L\&I related to natural gas.

- A sharp increase in L\&I related to ethanol and biodiesel that stems most likely from EPAct 2005 and the current growth in the popularity of these fuels.

- L\&I affecting idle reduction came on the books between 2004 and 2006.

- General L\&I covering all alternative fuels show gradual decline as L\&I become more fuel specific in recent years.

- And 2005 was a big year in total L\&I because of EPAct 2005.

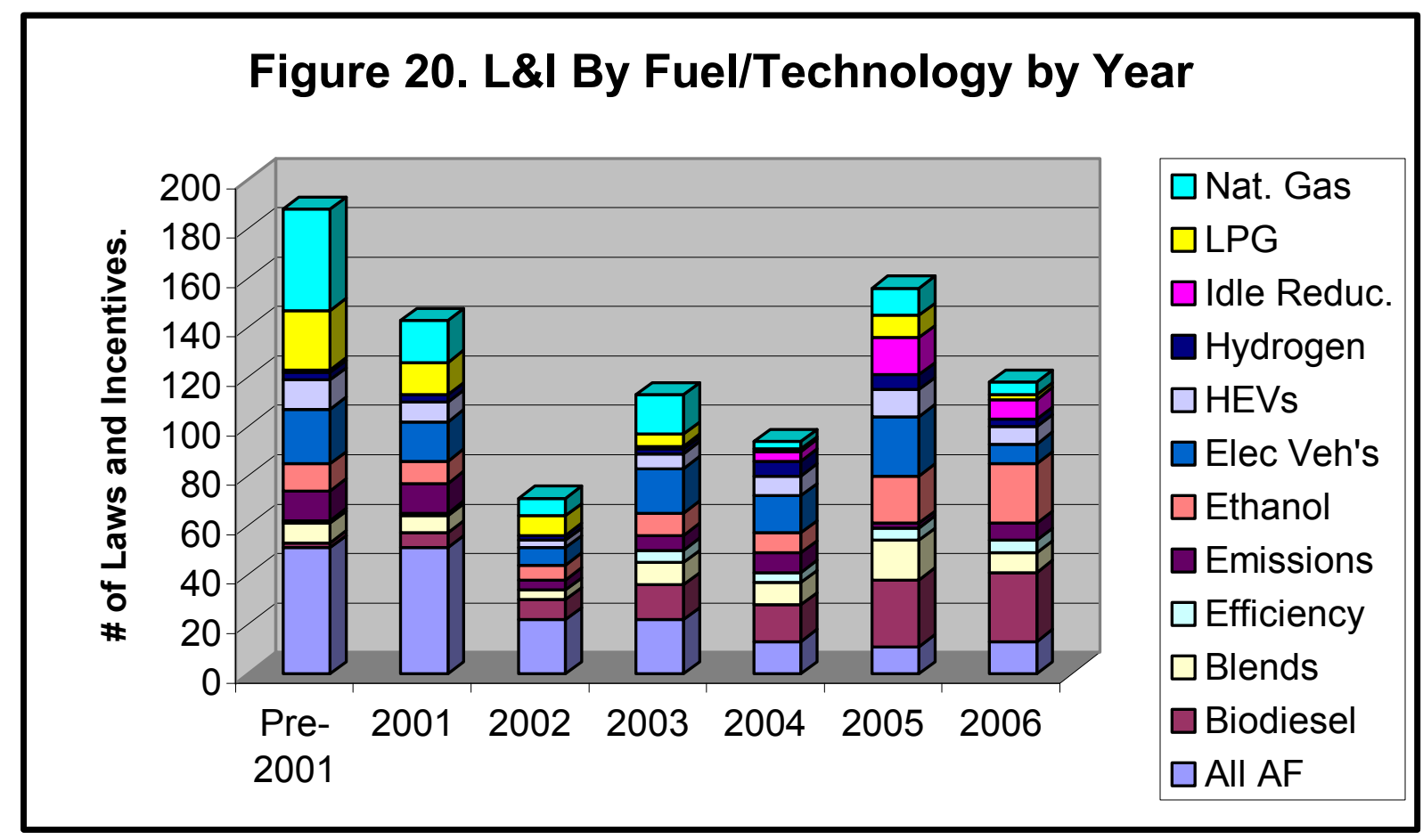

We will now examine the types of user groups for which L\&I have been enacted. Figure 21 shows that a great proportion of L\&I have been geared toward influencing or mandating fleet managers to purchase AFVs. Fully one-third of all L\&I are aimed at fleets. One-sixth of the current L\&I benefit individual consumers; one of eight provides some type of incentive or grant for infrastructure development. More than one-fourth of the L\&I benefit alternative fuel buyers, dealers, and producers.

Appendix III contains some additional detailed information on the states having the greatest number of L\&I and the general distribution of L\&I by type (incentive, regulation, technology, and user). 
Figure 21. Laws \& Incentives by User Type (2006)

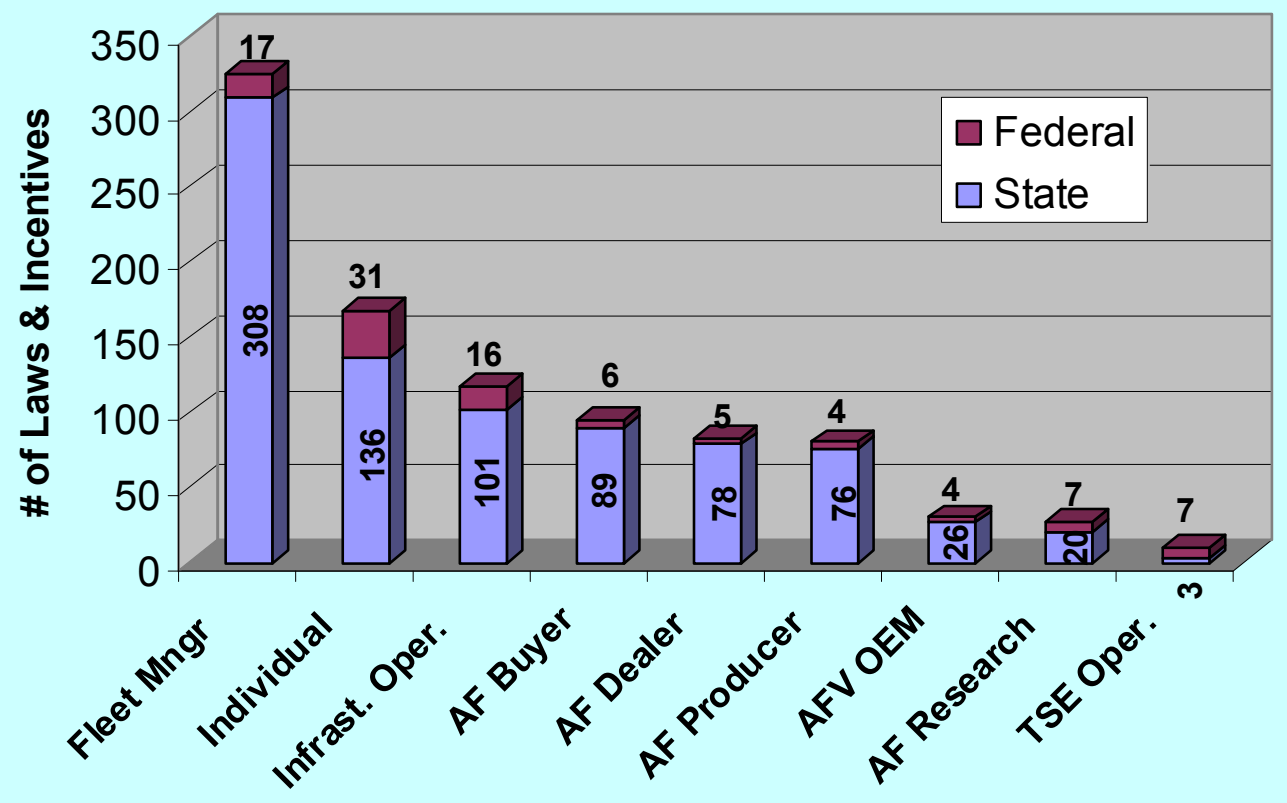




\section{The Clean Cities Program}

\section{Background}

The Clean Cities Program and its sponsoring offices within DOE (currently DOE's FreedomCAR and Vehicle Technologies Program) have funded NREL's AFDC since 1990. The Clean Cities activity commenced in September 1993 with the designation of Atlanta, Georgia, as the first Clean City. In addition to AFDC support, Clean Cities funding has provided significant support for the National Alternative Fuels Hotline (NAFH) and Clean Cities Hotline since inception. Data from the hotlines will be examined later in this document.

The Clean Cities Program is a voluntary public/private venture; 90 locations throughout the United States are currently designated as Clean Cities. Partnerships at the state and local levels form the foundation of Clean Cities (whose members are composed of state and local officials) and a diversity of industry and community organizations. Partnerships also take place at the national level through the program's close relationships with OEMs, fuel providers, and other federal agencies and national associations. Coalitions are technology and fuel neutral and position themselves to be credible players to attract strong project partners. These project partners can in turn recommend and adopt the fuels and technologies best suited to opportunities in their communities.

\section{General Clean Cities Information}

At the end of FY 2006, Clean Cities numbered more than 4,400 stakeholders in its 90 coalitions. A map of the Clean Cities coalition locations can be found in Appendix IV. Figure 22 shows the population coverage of Clean Cities coalitions, based on 2000 U.S. Census data. In 2005, the geographic coverage of the 90 Clean Cities coalitions included a population of almost 180 million people out of a U.S. population of some 281 million from the 2000 U.S. Census. This represents almost two-thirds of the U.S. population, affording the Clean Cities coalitions the ability to spread the word widely about AFVs and advanced technology vehicles. Because of the heavy proportion of population covered by Clean Cities, the growth of this coverage may well slow in the coming years. In addition, the Clean Cities Program funding has been limited in recent years, so the push to expand to more coalitions has not been a priority.

Figure 23 presents some interesting data which demonstrate that the strength of Clean Cities organizations, as measured by the number of coalitions in each state, is not necessarily proportionate to the population of the state within which coalitions have been formed. In Figure 23 the numbers on the bars represent the state population rank in the United States, so the three states with the greatest populations (California, Texas, and New York) would be expected to lead in the number of coalitions in that same rank order. The surprises come with the next three coalitions of Connecticut, Colorado, and Michigan, which have very low population rankings (especially Connecticut and Colorado), but high rankings in terms of the number of coalitions compared to the rest of the states. This demonstrates that some states can organize and network quite effectively despite their populations. However, 14 states have state-wide coalitions and, therefore, would have only one coalition to be counted. In 2006, only five states (Alaska, Mississippi, Montana, Nebraska, and South Dakota) have no Clean Cities coalitions. 
Figure 22. Population Covered by Clean Cities Coalitions (2000 Census Data)
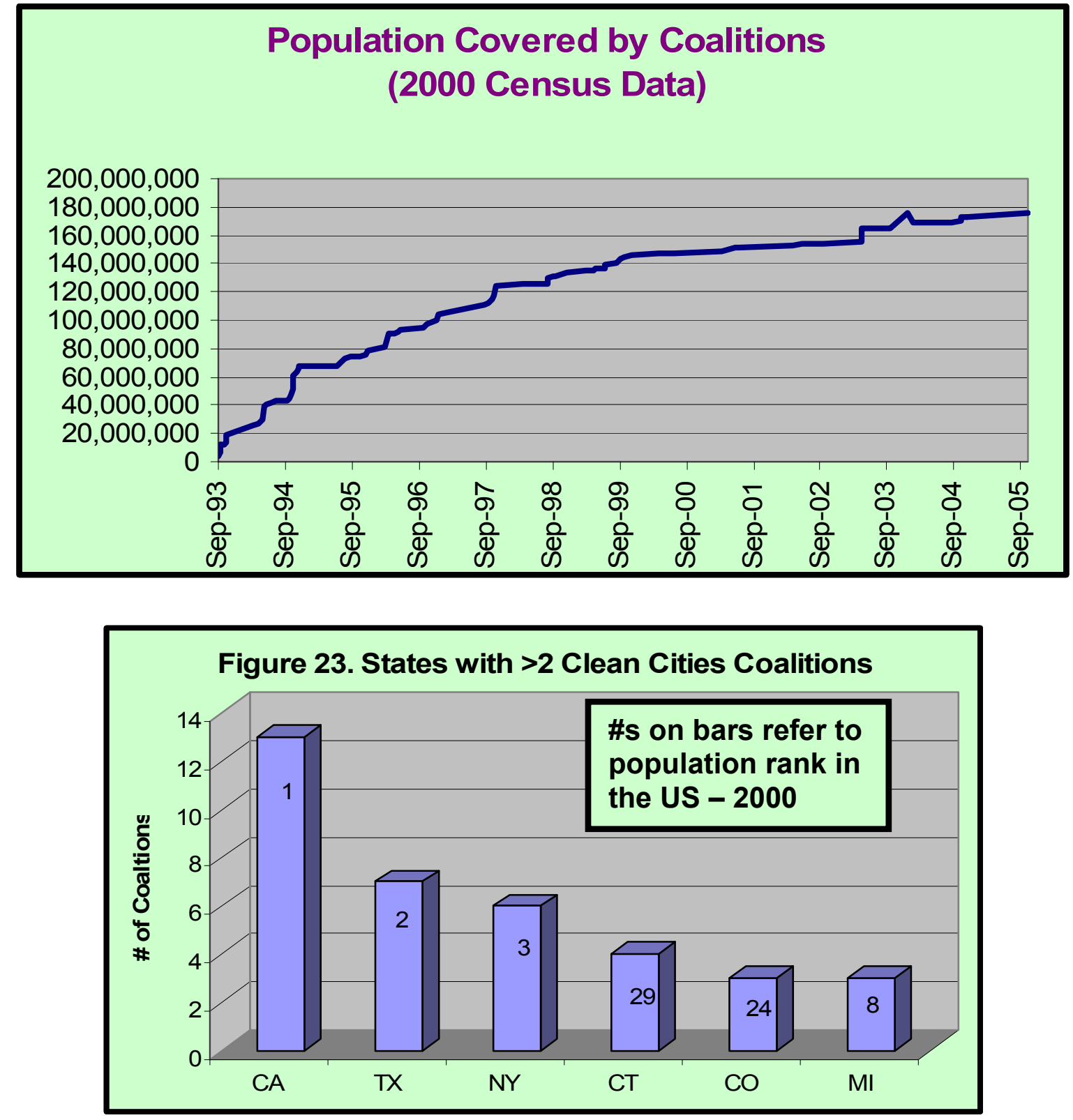

The bottom line is that the Clean Cities coalitions have been the vital outreach arm and active support branch of the national Clean Cities Program. Without these coalitions and their dedicated coordinators, there would be no Clean Cities Program. 


\section{The National Alternative Fuels and Clean Cities Hotlines}

\section{Background}

AMFA 1988 provided authority to establish the AFDC (created officially at NREL in the fall of 1990) and encouraged mechanisms to make information about alternative fuels available to the public. DOE was designated the government arm responsible to carry out both the provisions of AMFA 1988 and EPAct 1992, which added even more information dissemination responsibilities, lending justification to the important role the NAFH and Clean Cities Hotline have played since they were established in 1991 and 1993, respectively. The Hotlines, managed by NREL through a competitive subcontract, existed through the end of September 2005, when DOE consolidated its Hotline efforts with the formation of the Energy Efficiency and Renewable Energy Information Center (IC). The former Hotline service is now dedicated to providing only higher-level technical assistance as the Technical Response Service (TRS), responding mainly to questions forwarded by the IC that are above and beyond the expected expertise of that organization.

NREL has had the responsibility to gather and store information from the Hotline subcontractor about the users (generically the "callers") and the processed requests. Various FY beginning dates appear in the graphs because some data go back to the origin of the Hotlines, but Hotline data collection by NREL began in FY 1992, when it assumed managerial responsibility of the Hotline operation. Over the 15 years of the Hotline operations, more than 95,000 requests (Figure 24) were processed, resulting in more than 1 million documents (Figure 25) having been distributed since detailed document distribution statistics began to be maintained in 1995. These databases will now be analyzed to see what can be learned about the types of requests processed and the people who have used the system.

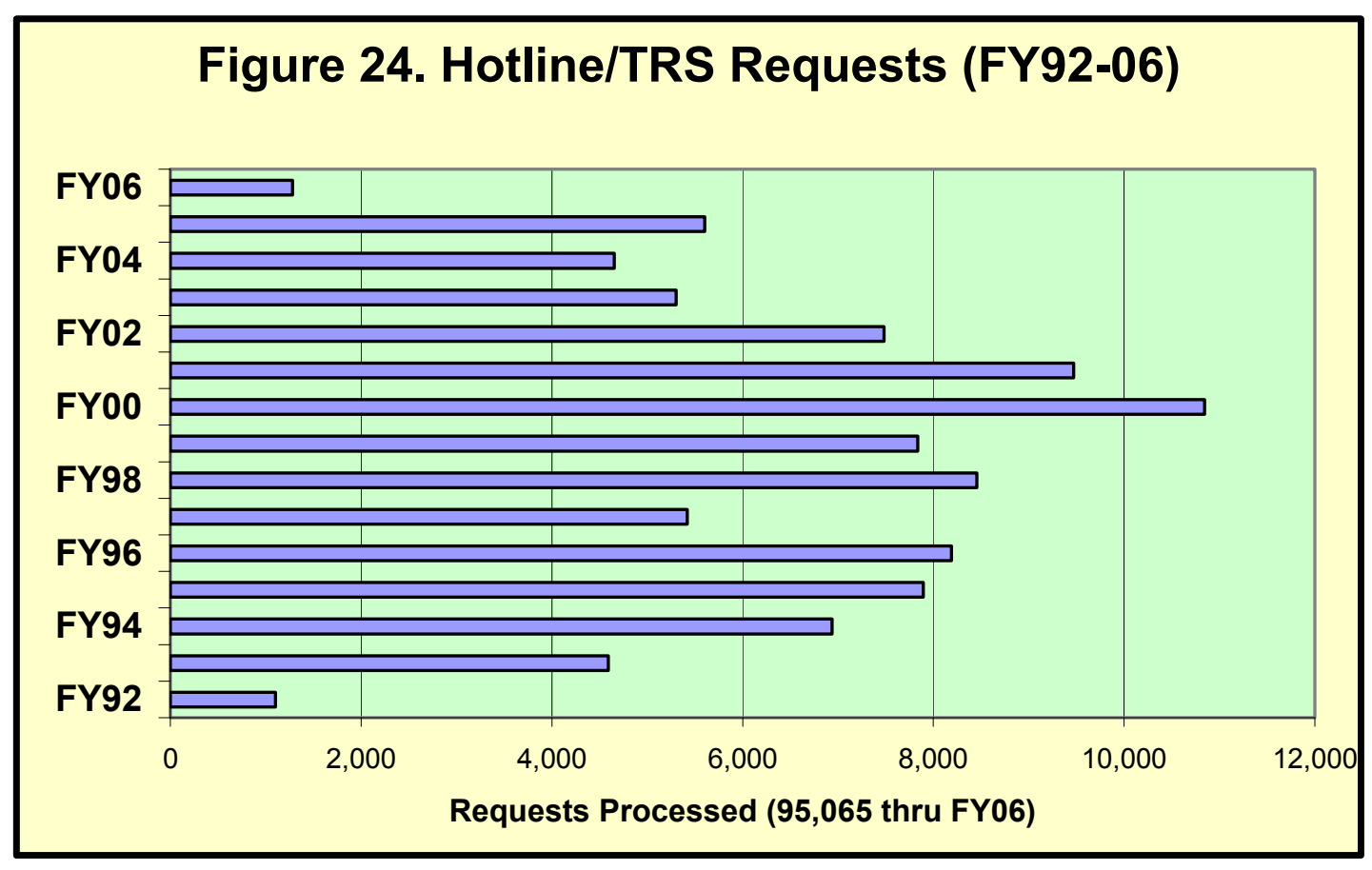


Hotline requests grew dramatically from its inception in 1992 through 1996, showed a significant decline in 1997 , then a resurgence in 1998. Requests peaked in 2000, declined significantly from 2000 to 2004 , increased slightly in 2005 , then dropped significantly in 2006. The explanations are:

- From 1992 to 1998 an anticipated increase in the toll-free 800 service was expected as the word spread and the increase in alternative fuels, vehicle models, and infrastructure continued to grow. We suspect that there really was not a decline in the number of requests handled in FY 1997, but that the reporting of all requests may have lapsed toward the end of FY 1997 when the Hotline was in a transition to a new subcontractor.

- By 1998, the number of people and organizations becoming Web savvy was increasing rapidly so inquiries, as anticipated and expected, began to be answered using Web information and its increasing search engine capabilities, making it easier for users to ask their questions over the Web, with no additional (Hotline) intervention necessary.

- The pickup in request processing from 1999 to 2002 can be explained by a large number of requests for copies of the Fuel Economy Guide (FEG), which were processed by the Hotline during those years.

- The number of requests continued to drop in 2003 and 2004 as the FEG distribution system was automated and moved away from Hotline handling.

- The slight resurgence in requests in 2005 stemmed from questions related to the newly passed EPAct 2005 legislation.

- FY 2006 began the new TRS. This meant that all requests first went to the IC, which only forwards to the TRS those inquiries that are at a technical level not expected to be answered by the IC. So, the sharp decrease in request processing in FY 2006 was fully expected.

Figure 25 presents the picture for documents distributed from FY 1996 to FY 2006. The peaks from 1999 to 2002 included distribution of more than 400,000 copies of the FEG. In 2003 the distribution of FEGs was automated and no longer handled by the Hotline. In FY 2006, the Hotline service changed to the TRS, as discussed above, so documents were distributed only by the IC.

How did people learn about the Hotline? Figure 26 answers that question. Over the years $64 \%$ of the way people learned about the Hotline was through the Internet. This percentage has increased to $90 \%$ since FY 2000. Newsletters and industry publications have accounted for one-sixth of the referrals historically. 

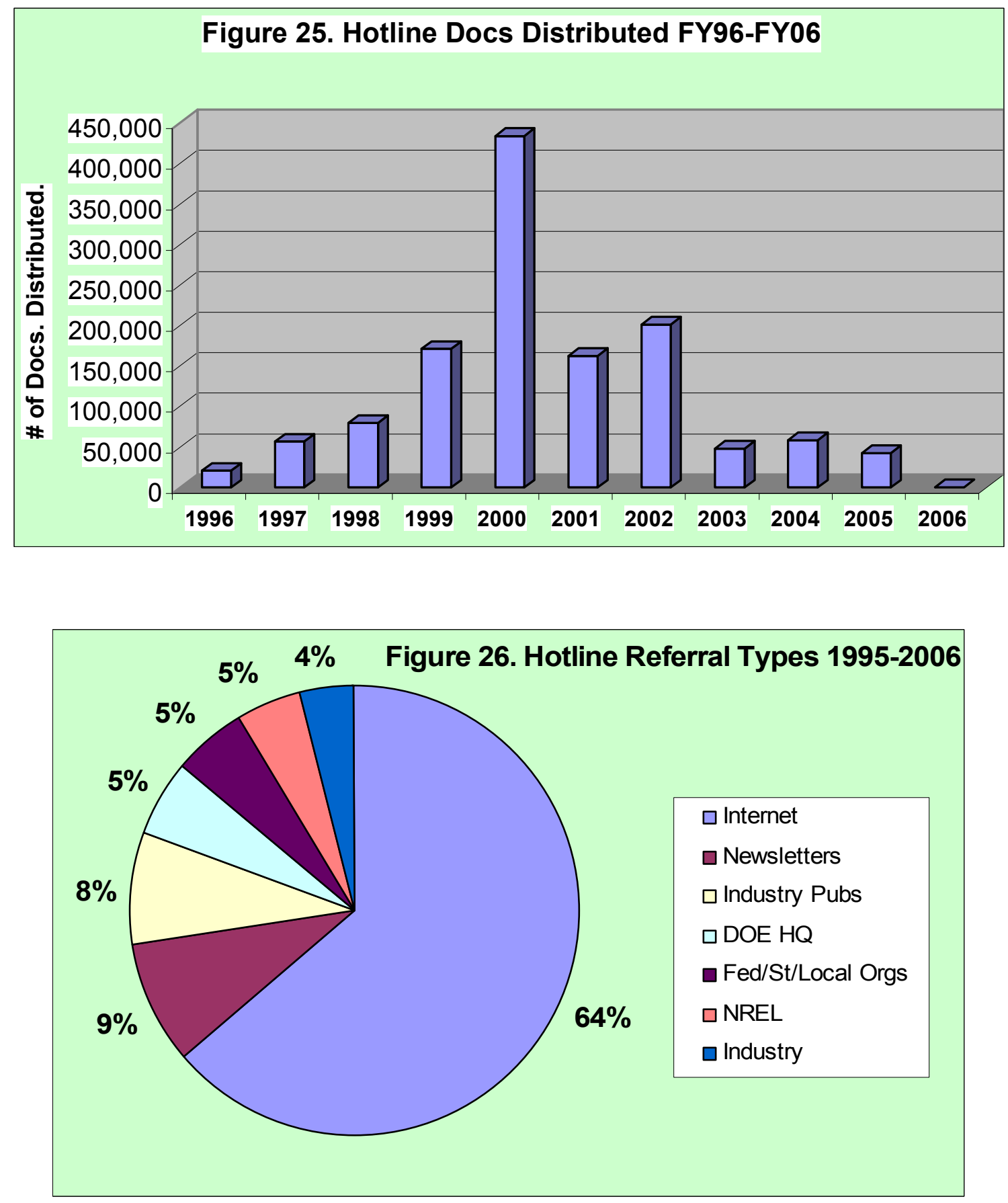

\section{Hotline Request Processing and Evaluation - the Details}

We will now examine the details of the Hotline operation, mostly from FY 1995 to FY 2005, as these are the full years for which data were collected and stored electronically from the Hotline. The details include:

- Fuel type requests

- Sources of requests - how received and by whom

- Hotline feedback 
- Request types - most popular topics

- Fleet managers in database

- State and country Hotline usage - Appendix V.

\section{Requests by Fuel Type}

Figure 27 presents the details of Hotline requests each year, classified by the caller's fuel interest.

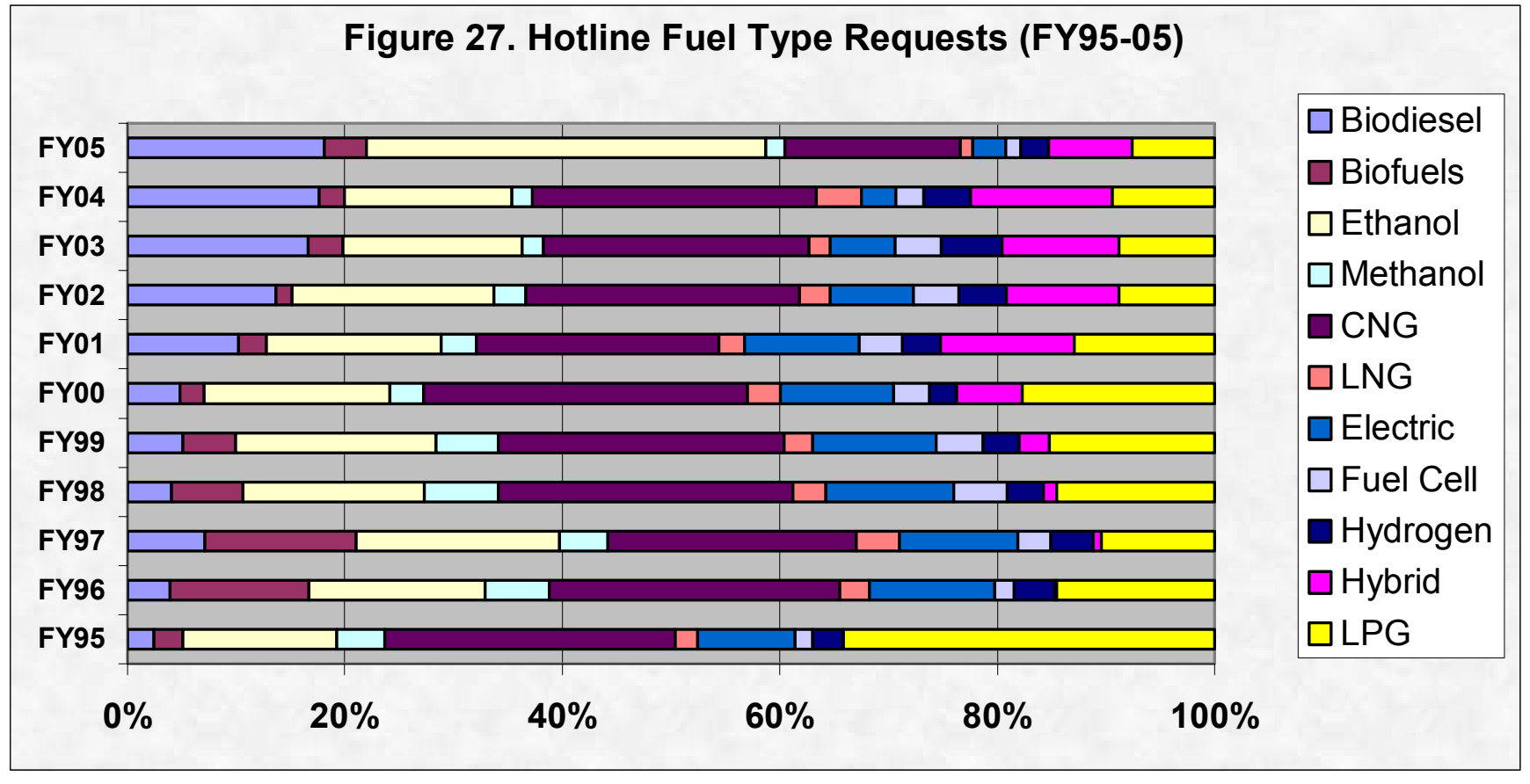

The distribution of fuel interest from FY 1995 to FY 2005 has changed dramatically. We make the following observations from this chart:

- From 1995 to 2005, the interest in LPG dropped significantly.

- The interest in biodiesel has shown a steady increase since FY 1997.

- The interest in ethanol has been fairly steady over time, and a dramatic increase came about in 2005 with the passage of the Renewable Fuels Standard and EPAct 2005.

- In 2005, we see that almost three-fifths of the requests (where the fuel type was classified as part of the request) centered on biofuels or ethanol and biodiesel specifically.

- The interest in CNG probably showed the most significant decrease from FY 2004 to FY 2005, mostly because Ford stopped producing CNG vehicles.

- Hybrid interest came to the forefront in FY 2000 with the advent of Toyota's Prius and Honda's Insight. The slight decline in HEV inquiries from FY 2004 to FY 2005 probably does not reflect a declining interest, but just the fact that they were catching on as noted earlier (Figures 10 and 11) by the continued increase in HEV sales, almost on a monthly basis. 
- EV interest was relatively steady through FY 2001, then started to decline as the OEMs offered fewer and fewer options; only the GEM NEV was available in the EV market in 2006.

- Recent questions about methanol probably derived from the methyl tertiary butyl ether health concerns, as no methanol OEMs have been offered since 1997.

Figure 28 summarizes the combined historical fuel request interests from FY 1995 to FY 2005. We can see from this chart that the historical summary is not reflective of today's fuel interest. For the past 11 years, the largest proportion of fuel interest calls centered on CNG because of the large number of offerings by the OEMs, especially from 1995 to 2004. In 2005, Ford dropped out of the CNG LDV market and interest waned significantly. Over time, ethanol requests have represented about one-fifth of the requests; biofuels, biodiesel, and ethanol share one-third of the requests. LPG has garnered about one-eighth of all requests, but interest in LPG has dropped significantly in recent years, as no OEM LPG LDVs are on the market.

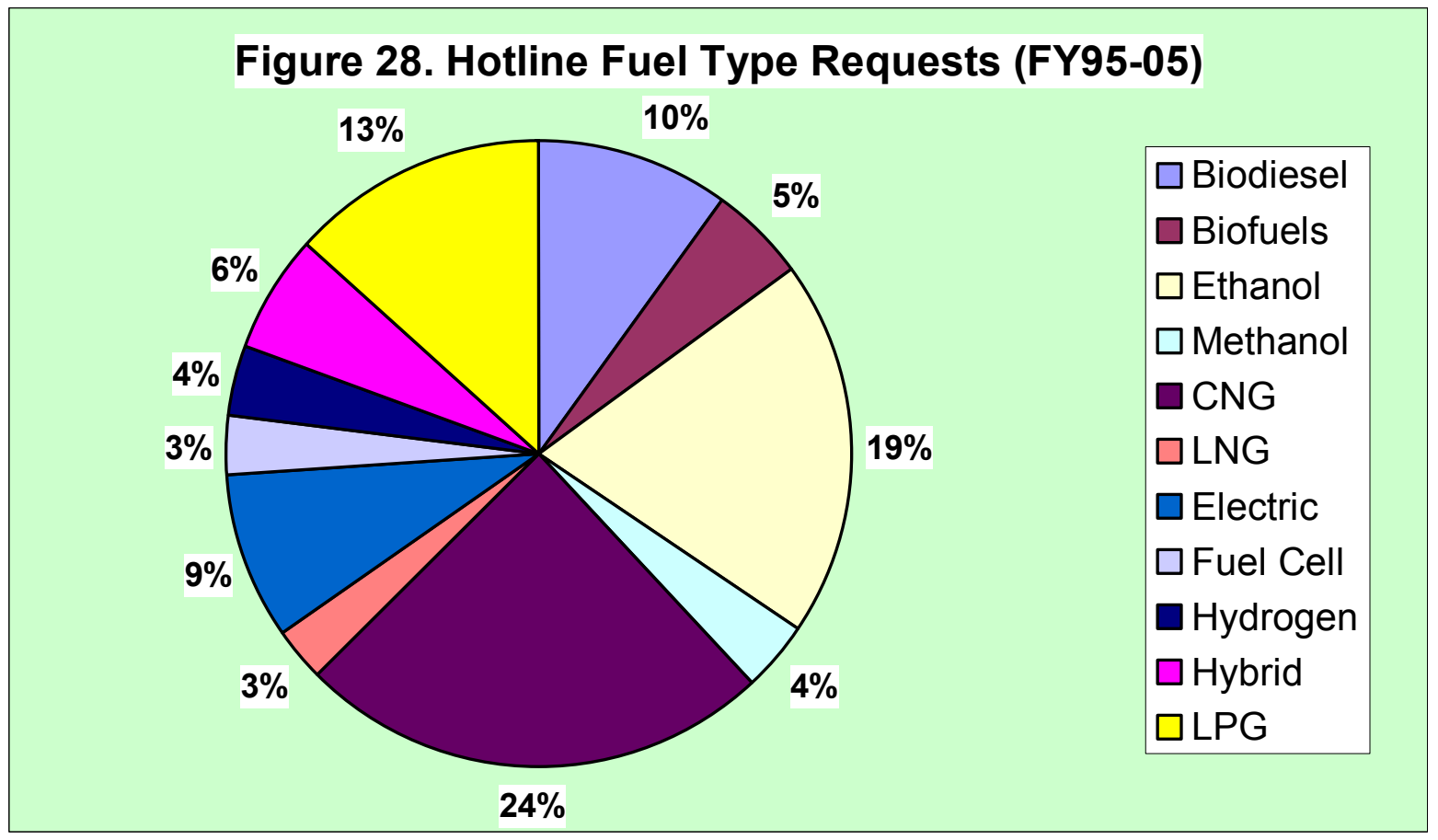

Figures 29 and 30 show the latest distribution of requests by fuel type from the last year of Hotline operation (FY 2005) and the first year of the TRS (FY 2006). The comparisons are interesting. First, we note the huge interest in ethanol with more than one-third of the requests in both FY 2005 and FY 2006. Second, and even more dramatic, is the increase in biodiesel requests from $18 \%$ to $29 \%$, which probably reflects the heavy-duty industry's need to meet the stricter emissions requirements of 2007 and the EPAct AFV credits that can be achieved for every 450 gallons of biodiesel consumed. Also, CNG interest dropped from 16\% in 2005 to only $9 \%$ in 2006 , for reasons already noted.

Appendix VI offers some information on the general types of organizations represented by callers to the Hotline. 

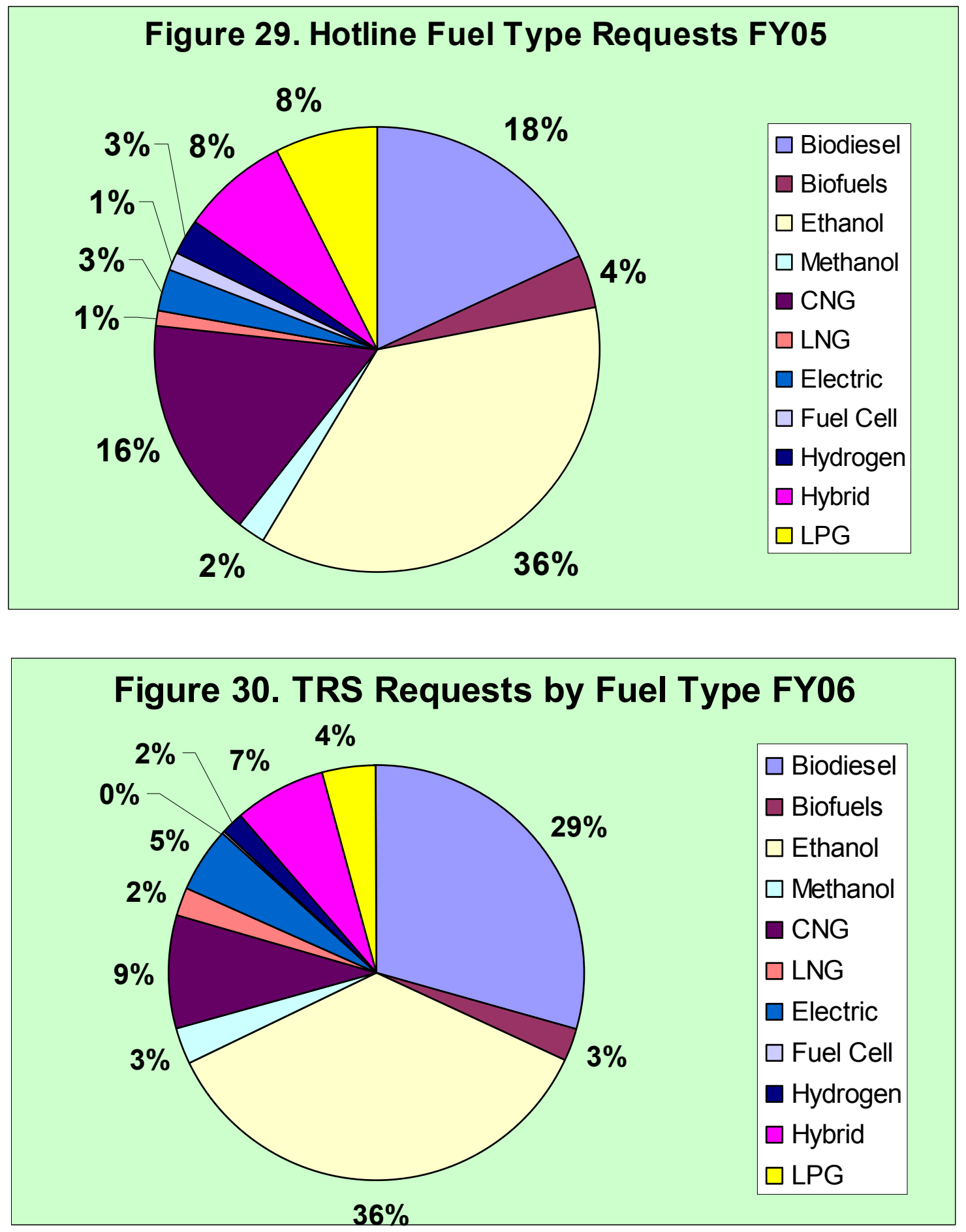

\section{Sources of Requests Received by the Hotline/Technical Response Service}

As expected, when the Hotline was first established, most queries came in via toll-free 800 phone numbers. Data on the source of the request was not added to the request processing system until FY 1997. Even so, in FY 1997, about four-fifths of the requests came in via phone; the rest were essentially e-mail requests. In FY 2000, we started differentiating pure e-mail requests from 
those being generated by Web inquiry forms, document searches, etc., on the Internet. Most of the "Other" types of requests from FY 1999 to FY 2002 pertained to the handling of FEG requests. "Other" types could also be faxes and walk-in requests. One of the most significant gleanings from Figure 31 is the continually decreasing proportion of phone inquires with the commensurate increase in electronic (e-mail and $\mathrm{Web}$ ) requests. Electronic requests accounted for about one-fifth of all requests in FY 1997, and now represent about two-thirds of all requests processed in FY 2006 by the TRS and about half in the last year of the Hotline operation in FY 2005. This was the desired trend because processing requests electronically is cheaper and more efficient.

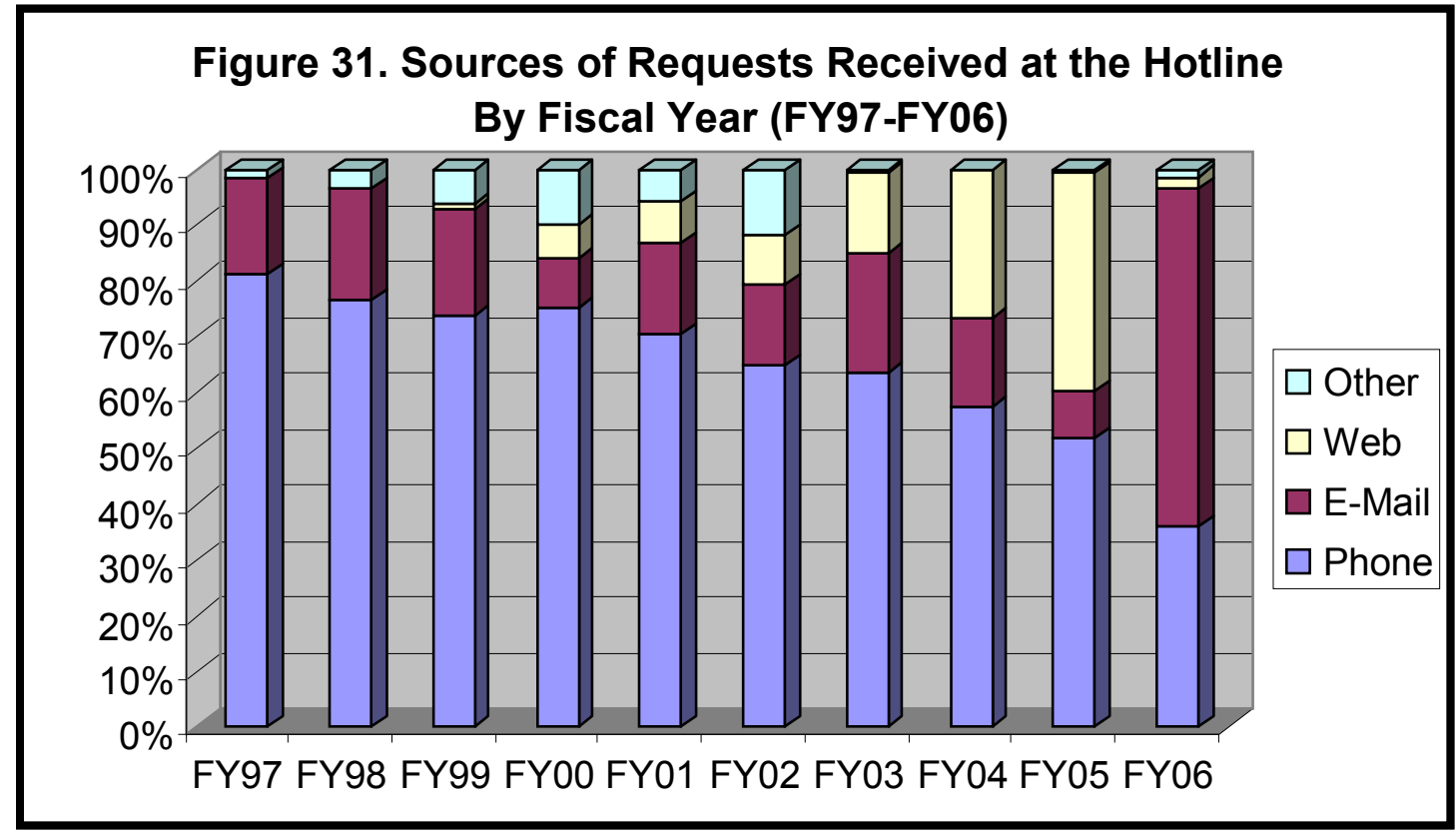

\section{Hotline Feedback}

The outstanding performance of the Hotline is reflected by direct user feedback. The overall positive feedback reflects the service provided by a staff of courteous, friendly, and knowledgeable individuals, and the thoroughness of the operators on meeting and exceeding the expectations of the users - based on the documentation sent, the answers to questions given, or the references to additional sources. With each document request from a caller, a feedback form and a postage-free return envelope were included in the package. As feedback forms were returned, the discreet answers, often in the form of letter grades, and comments were entered into a database for analysis. This database is the source for the graphs that analyze Hotline performance and service effectiveness.

Figure 32 offers a glimpse of how effective the Hotline operators have been over the years. Combining all criteria together, $92.6 \%$ of all Hotline operator and operations attributes received a grade of A; $98.6 \%$ received a grade of A or B. Only $0.4 \%$ of all grades were D or F, demonstrating huge approval ratings for operator courtesy, promptness in answering calls, understanding the needs of the callers, and timeliness and efficiency of processing the requests. 


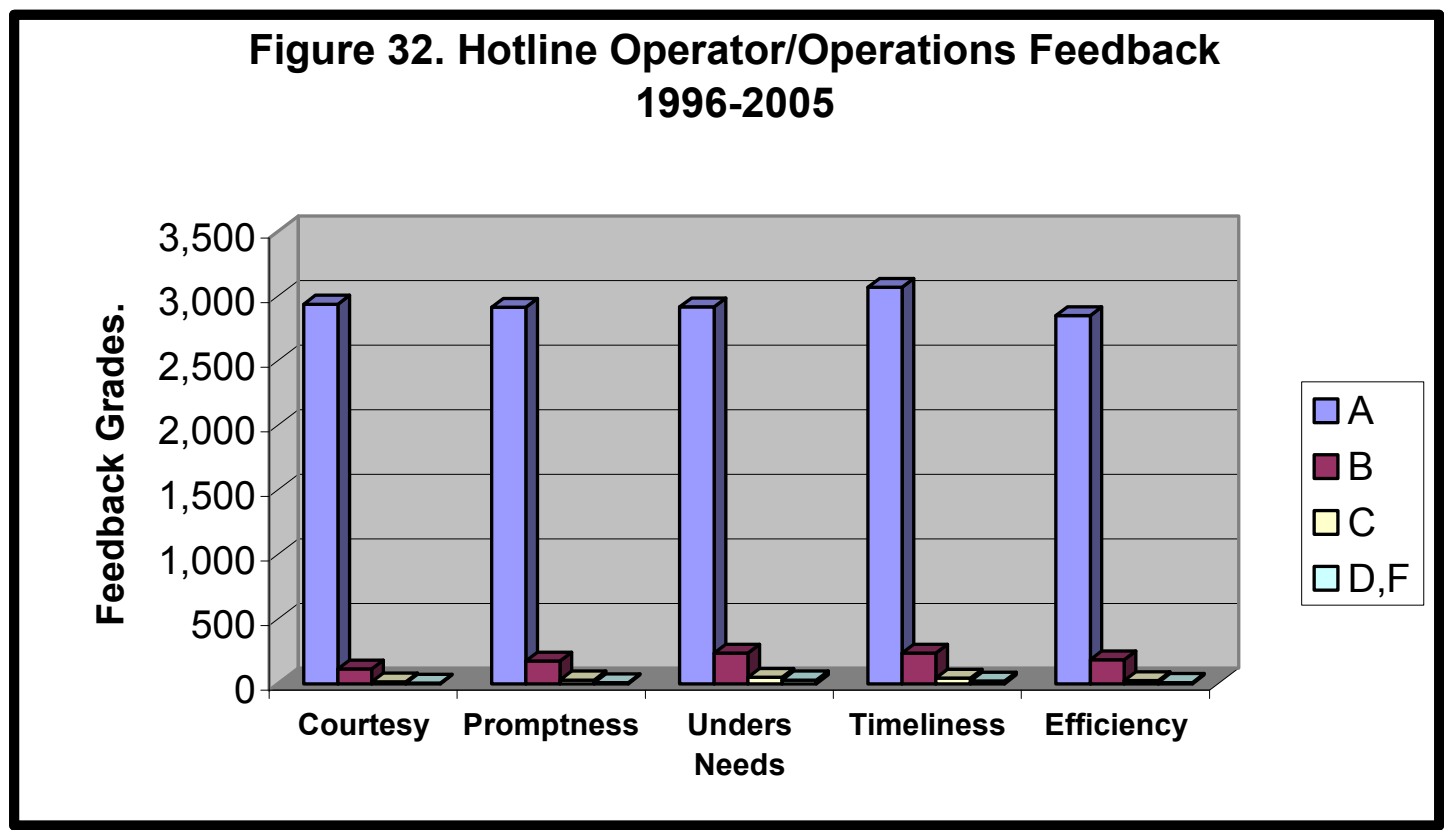

Figure 33 asks the question about whether the user needs were met by the staff of courteous, prompt, efficient operators. The chart yields an overwhelming "yes" to that answer; $42 \%$ of the expectations were not only met, but exceeded. In total $97 \%$ of the users' needs were met or exceeded, and only $3 \%$ of the needs were not met over a 10 -year period. When users' needs were not met, usually information in the form of a document or a Web search could not be found to provide a responsive answer.

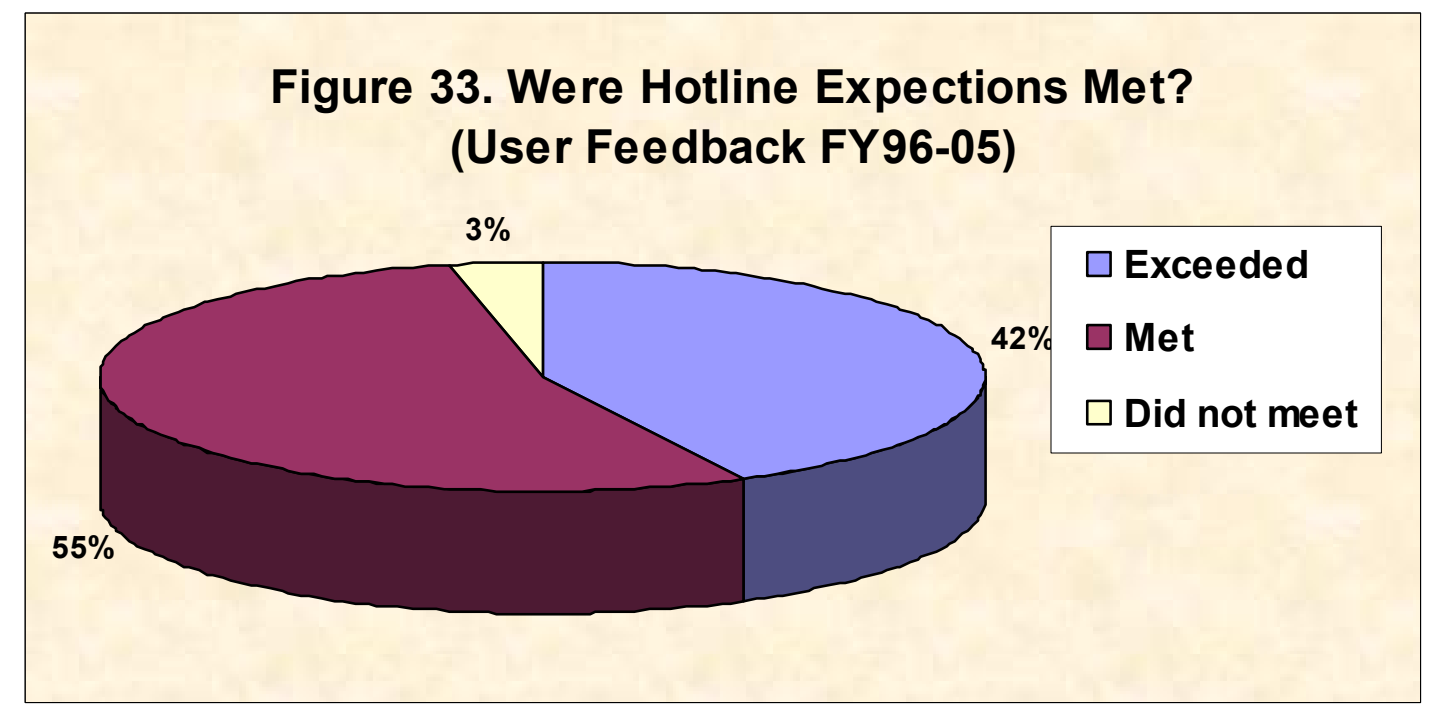

Another significant question that we asked of users was to evaluate how this Hotline compared to other Hotlines they had used. Figure 34 shows overwhelmingly that four of five responders said this Hotline was better than other services they used, and only $1 \%$ rated it worse than similar services. 


\section{Figure 34. Hotline Comparison to Other Hotlines (1996-2005)}
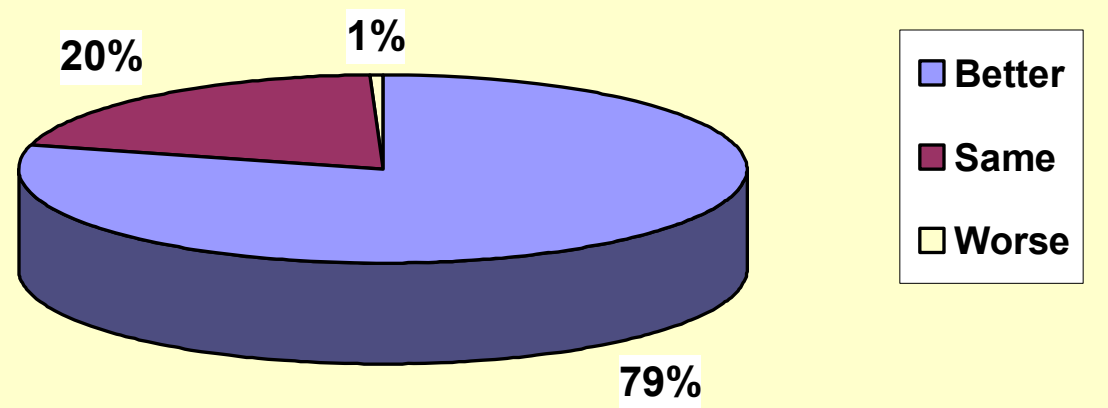

All that is well and good, but what about the documents the users received? Did they satisfy their needs? Figure 35 clearly demonstrates high grades for the documents received. They were readable, useful, well-organized, and covered the topic well. Combining these four criteria, $71 \%$ of all documents received a grade of A and $94 \%$ received a grade or A or B. Fewer than $1 \%$ received a failing grade, of 26,927 total grades reported from FY 1996 through FY 2005, when the formal publicly accessible Hotline service was discontinued.

\section{Figure 35. Grades on Documents Distributed to Hotline Users 1996-2005}

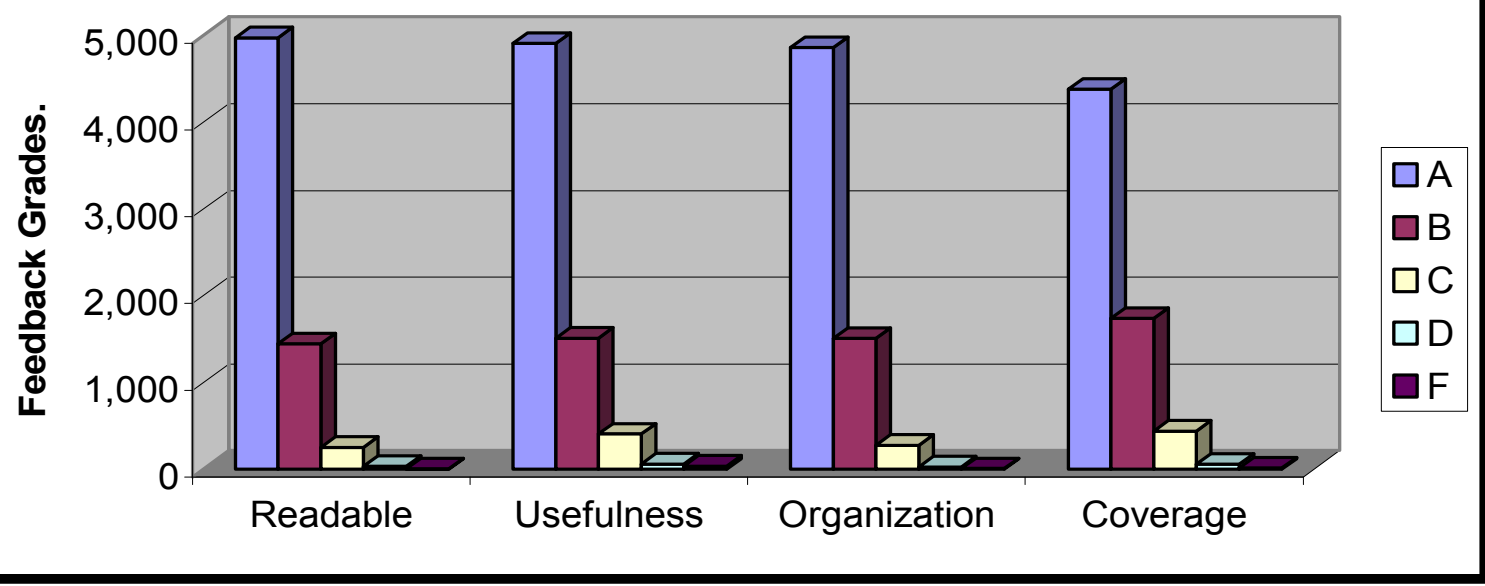

\section{Request Categories}

For each request that was logged by the Hotline, we wanted to know what the request was about. Many categories were made available to the Hotline on the request processing form, and the following notes and tables help to give a better perspective of what people were asking about when they contacted the Hotline. Two tables are provided to see how the requests over time (FY 
1991 to FY 2006) differ from the more recent request types in the past two fiscal years. The following chart (Table 1) provides the combined request data for the top 20 request categories from FY 1991 to FY 2006. Notes of interest from Table 1 are:

- These top 20 categories represent about $90 \%$ of all classified requests. Requests may also be multiply classified, so the 95,194 total request classifications would represent fewer total requests than this count reflects.

- More than one of six requests related to federal and state legislative and regulatory activities, tax incentives, the Clean Air Act Amendments, or EPAct.

- About one in six requests was for information from the AFDC, refueling sites, or OEM vehicles.

- $\quad$ One in eight requests was for FEGs, mostly between FY 1999 and FY 2003.

- About one of 16 requests was specific to Clean Cities.

- One in 16 requests was for specific documents.

- Another $7.5 \%$ of requests were related to fuel production, use, or characteristics.

The shaded categories (Conf/Events, EPAct 1992, and Technology) represent categories that did not make top 20 ranking during FY 2005 and FY 2006. EPAct 1992, of course, was old news and the Clean Cities conference registrations and related activities became much more automated in recent years.

\begin{tabular}{|c|c|c|c|c|c|c|c|}
\hline \multicolumn{8}{|c|}{ Table 1. Top 20 Most Popular Hotline Request Categories (FY 1991-2006) } \\
\hline Rank & Request Type & Total & $\%$ & Rank & Request Type & Total & $\%$ \\
\hline 1 & Fuel Econ Guide & 12,175 & $12.8 \%$ & 11 & Refueling Sites & 3,974 & $4.2 \%$ \\
\hline 2 & AFDC & 7,868 & $8.3 \%$ & 12 & Fed Legis/Prog & 3,857 & $4.1 \%$ \\
\hline 3 & Fuel Related & 7,136 & $7.5 \%$ & 13 & Fund/Grants & 3,793 & $4.0 \%$ \\
\hline 4 & $\begin{array}{l}\text { AFN/Clean Cities } \\
\text { Newsletters }\end{array}$ & 6,323 & $6.6 \%$ & 14 & Indust. Contact & 3,690 & $3.9 \%$ \\
\hline 5 & Documents & 6,306 & $6.6 \%$ & 15 & OEMs/Auto Mfg & 3,020 & $3.2 \%$ \\
\hline 6 & Clean Cities Related & 6,229 & $6.5 \%$ & 16 & State Laws/Legis & 2,640 & $2.8 \%$ \\
\hline 7 & Tax/Incentives & 5,798 & $6.1 \%$ & 17 & Emissions & 2,473 & $2.6 \%$ \\
\hline 8 & Veh. Conversions & 5,075 & $5.3 \%$ & 18 & Veh. Performance & 2,243 & $2.4 \%$ \\
\hline 9 & Conf/Events & 4,764 & $5.0 \%$ & 19 & Technology & 1,862 & $2.0 \%$ \\
\hline 10 & EPAct 1992 & 4,224 & $4.4 \%$ & 20 & Mrkt Sply/Dmnd & 1,744 & $1.8 \%$ \\
\hline & & & & & Total & 95,194 & $100.0 \%$ \\
\hline
\end{tabular}

Table 2 is provided as a contrast to the full historical request categorizations of Table 1. Again, the shaded categories represent those categories that were not in the FY 1991 to FY 2006 chart (Table 1). 


\begin{tabular}{|c|c|c|c|c|c|c|c|}
\hline Rank & Reauest Type & Total & $\%$ & Rank & Reauest Type & Total & $\%$ \\
\hline 1 & Fuel Related & 1,471 & $15.4 \%$ & 11 & Veh. Performance & 367 & $3.8 \%$ \\
\hline 2 & Fuel Econ Guide & 1,136 & $11.9 \%$ & 12 & Fund./Grants & 306 & $3.2 \%$ \\
\hline 3 & AFDC & 714 & $7.5 \%$ & 13 & Documents & 305 & $3.2 \%$ \\
\hline 4 & OEMs/Auto Mfg & 708 & $7.4 \%$ & 14 & Indust. Contact & 283 & $3.0 \%$ \\
\hline 5 & Refueling Sites & 643 & $6.7 \%$ & 15 & Mrkt Sply/Dmnd & 239 & $2.5 \%$ \\
\hline 6 & Fed Legis/Prog & 612 & $6.4 \%$ & 16 & Equipment & 200 & $2.1 \%$ \\
\hline 7 & Tax/Incentives & 594 & $6.2 \%$ & 17 & Emissions & 198 & $2.1 \%$ \\
\hline 8 & Veh. Conversions & 592 & $6.2 \%$ & 18 & Infrastructure & 155 & $1.6 \%$ \\
\hline 9 & $\begin{array}{l}\text { AFN/Clean Cities } \\
\text { Newsletters }\end{array}$ & 423 & $4.4 \%$ & 19 & $\begin{array}{l}\text { Clean Cities } \\
\text { Related }\end{array}$ & 135 & $1.4 \%$ \\
\hline 10 & State Laws/Legis & 389 & $4.1 \%$ & 20 & Niche Market & 111 & $1.2 \%$ \\
\hline & & & & & Total & 9,581 & $100.0 \%$ \\
\hline
\end{tabular}

The notes of significance about these data are:

- The top 20 categories represent about $90 \%$ of all requests, which may be multiply classified so the 9,581 total request classifications would represent fewer total requests than this count reflects.

- Compared to the total request history in Table 1, fuel-related requests during FY 2005 and FY 2006 ranked \#1 and doubled in proportion (from 7.5\% to 15.4\%).

- More than one in five requests $(21.6 \%)$ were for information from the AFDC, refueling sites, or OEM vehicles, all part of the AFDC information. This is up from the historical summary, where only one of six requests related to information in the AFDC.

- One of seven requests was for information on OEM vehicles or refueling site information, ranking these fourth and fifth versus the full historical rankings of 11 th and 15 th.

- About one-sixth of all requests fell in the regulatory/legislative interests of federal legislation, tax incentives, and state laws and legislation.

- With more than one in 10 requests, the FEGs continued to be popular, although most of the demand was in FY 2005, before the transfer to the IC. FEG requests fell from \#1 overall to \#2 in the FY 2005-2006 requests.

- Historically, one of 16 requests was specific to Clean Cities (\#6 ranking); this dropped dramatically in FY 2005 and FY 2006 to 1.2\% of requests for a \#19 ranking. One major factor was the transfer of the Clean Cities Conference to private industry and the lack of inquiries surrounding this annual conference.

- One in 16 requests was for tax incentives, the same for vehicle conversion information.

Again, the shaded categories (equipment, infrastructure, niche markets) represent categories that did not make top the 20 ranking over all time. 


\section{Fleet Managers}

Fleet managers have always been among the top clients in the AFDC with regard to Web development and documents created in the DOE/NREL searchable document database. The Buyer's Guide for Fleets morphed into the current, significantly expanded version of the Clean Fleet Guide. Many other tools have also been created for use by fleet managers (and others, of course). Knowing this, we will take a look at the number of fleet managers who have been added to the caller (requester) database and the number of requests they have made since we began to gather this information in FY 1995 (Figure 36). Early in the Clean Cities Program, the focus was to bring fleet managers into the Clean Cities fold. More than 800 fleet managers were added to the caller database; almost $90 \%$ of the additions came before 2000 . These 804 fleet managers have made a total of 1,432 requests of the Hotline, for an average of almost two inquiries per fleet manager. With the advent of the Internet, the online tools developed for fleet managers, and more managers becoming Web savvy; their need to use the Hotline has diminished since 1998. Therefore, the tools and information provided by the Internet, conferences and trade shows, and the OEMs seem to be generally satisfying fleet manager's needs in the world of alternative fuels and advanced vehicle technologies.

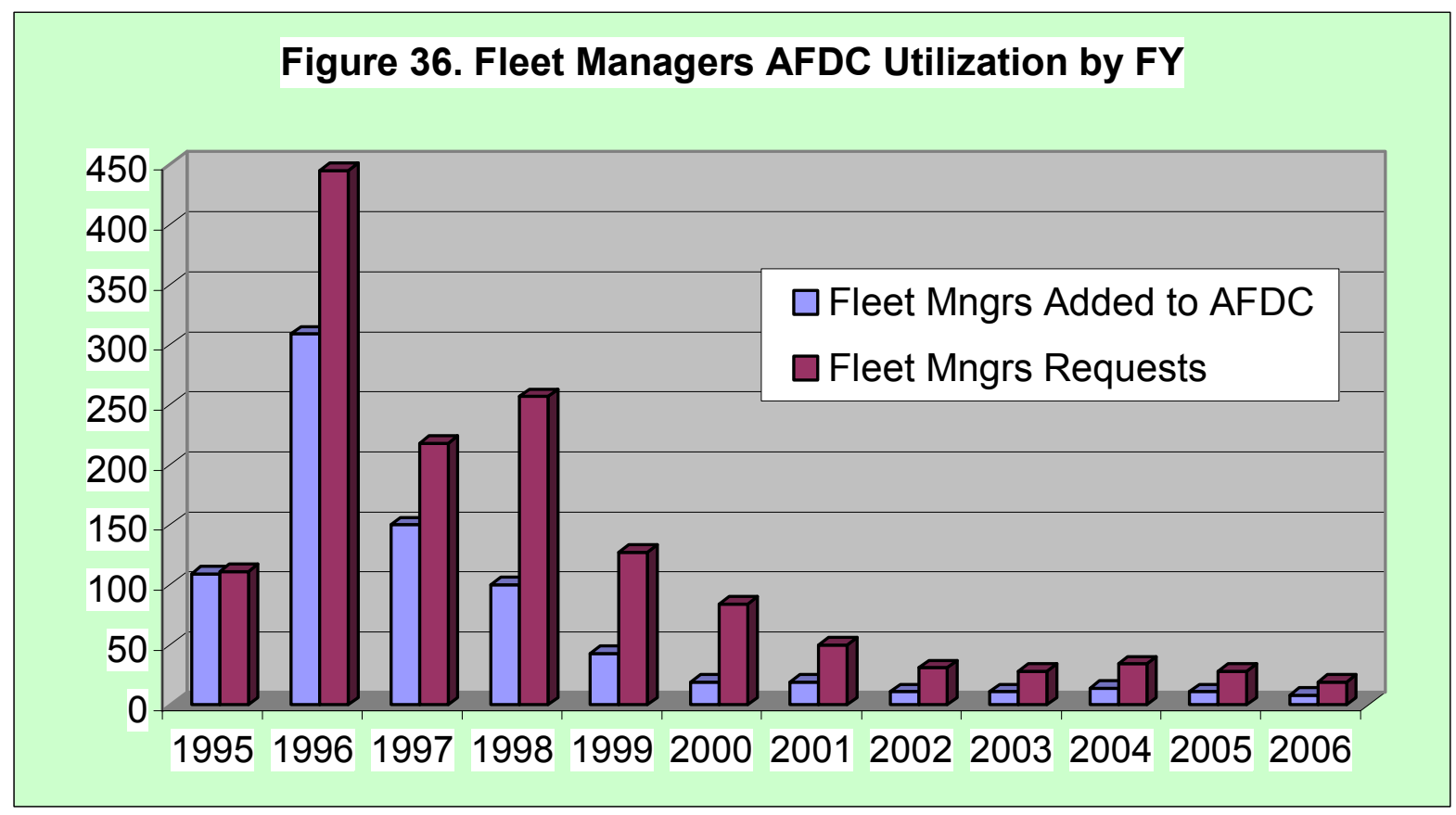




\section{Final Remarks}

We have examined a wealth of historical information from the Alternative Fuels Data Centerinformation that has not been fully analyzed in the past. We have provided a perspective on the growth of the alternative fuels industry since 1991 with regard to OEM vehicle production and have described the changing complexion of the industry from the early days of concentrations on CNG, alcohol fueled, electric, and LPG vehicles, to today's hybrids and FFVs. We have examined the refueling infrastructure and have shown the chicken-and-egg effect in the CNG industry that without sufficient support for vehicle numbers, the continued operation of public CNG stations cannot be justified. The Big Three OEMs' option to concentrate on the FFV market was a business decision that answered the question: Which comes first, the vehicles or the infrastructure? FFVs allowed the vehicles to arrive and the infrastructure to develop. Hybrids skirted this problem and offered an attractive consumer option with no refueling inconvenience.

L\&I from AMFA 1988 to EPAct 1992 and EPAct 2005, among others, have been necessary to nurture the growth of activities in the alternative fuels and advanced vehicle technology arenas that otherwise would not have occurred without the legislative stimulus and a government/ industry cooperative. And we have seen that the Clean Cities Program and the NAFH and Clean Cities Hotline have been tremendously successful in acting as the outreach and information dissemination organizations so greatly needed to ensure that all of these efforts have an impact on the nation's reduction of our dependence on imported oil. 


\section{Appendices}

Appendix I. Raw Data Used To Generate Some Original Equipment Manufacturer Figures by Models Offered and Fuel Type

Appendix Tables 1 and 2 provide the raw data used to generate Figures 1 to 4 .

\begin{tabular}{|l|r|r|r|r|r|r|r|}
\hline \multicolumn{10}{|c|}{ Table 1. AFV/HEV Models by OEM \& Fuel Type 1991-2006 } \\
\hline Fuel Type & Chrysler & Ford & GMC & Honda & Toyota & Other & \multicolumn{1}{c|}{ Total } \\
\hline CNG & 30 & 62 & 50 & 9 & 3 & & $\mathbf{1 5 4}$ \\
\hline E85 & 38 & 41 & 40 & & & 16 & $\mathbf{1 3 5}$ \\
\hline EV & 5 & 10 & 16 & 2 & 9 & 20 & $\mathbf{6 2}$ \\
\hline Hybrid & & 3 & 4 & 14 & 10 & & $\mathbf{3 1}$ \\
\hline LPG & & 18 & 3 & & & 4 & $\mathbf{2 5}$ \\
\hline M85 & 4 & 8 & 2 & & & & $\mathbf{1 4}$ \\
\hline Total & $\mathbf{7 7}$ & $\mathbf{1 4 2}$ & $\mathbf{1 1 5}$ & $\mathbf{2 5}$ & $\mathbf{2 2}$ & $\mathbf{4 0}$ & $\mathbf{4 2 1}$ \\
\hline
\end{tabular}

\begin{tabular}{|l|r|r|r|l|r|r|r|}
\hline \multicolumn{7}{|c|}{ Table 2. AFV/HEV Models by Fuel Type \& OEM 1991-2006 } \\
\hline OEM & CNG & E85 & EV & Hybrid & LPG & M85 & \multicolumn{1}{l|}{ Total } \\
\hline Chrysler & 30 & 38 & 5 & & & 4 & $\mathbf{7 7}$ \\
\hline Ford & 62 & 41 & 10 & 3 & 18 & 8 & $\mathbf{1 4 2}$ \\
\hline GMC & 50 & 40 & 16 & 4 & 3 & 2 & $\mathbf{1 1 5}$ \\
\hline Honda & 9 & & 2 & 14 & & & $\mathbf{2 5}$ \\
\hline Toyota & 3 & & 9 & 10 & & & $\mathbf{2 2}$ \\
\hline Other & & 16 & 20 & & 4 & & $\mathbf{4 0}$ \\
\hline Total & $\mathbf{1 5 4}$ & $\mathbf{1 3 5}$ & $\mathbf{6 2}$ & $\mathbf{3 1}$ & $\mathbf{2 5}$ & $\mathbf{1 4}$ & $\mathbf{4 2 1}$ \\
\hline
\end{tabular}


Appendix II. Original Equipment Manufacturer Charts Showing Models Offered by Fuel Type over Time

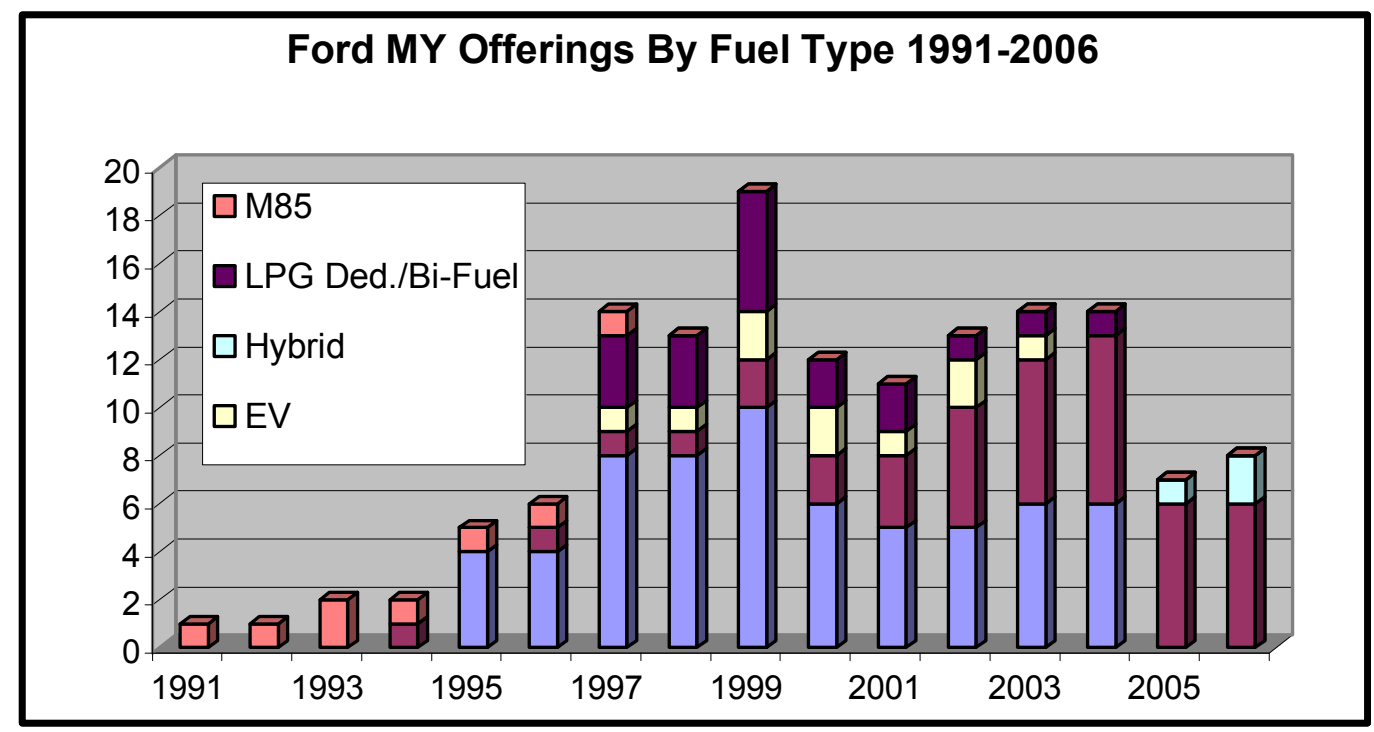

\section{Ford Notes}

- Only alcohol fuels from 1991 to 1994 (only M85 from 1991 to 1993).

- CNG vehicles offered for 10 years-1995-2004, plus some LPG vehicles and EVs.

- Now the only offerings are FFVs and hybrids.

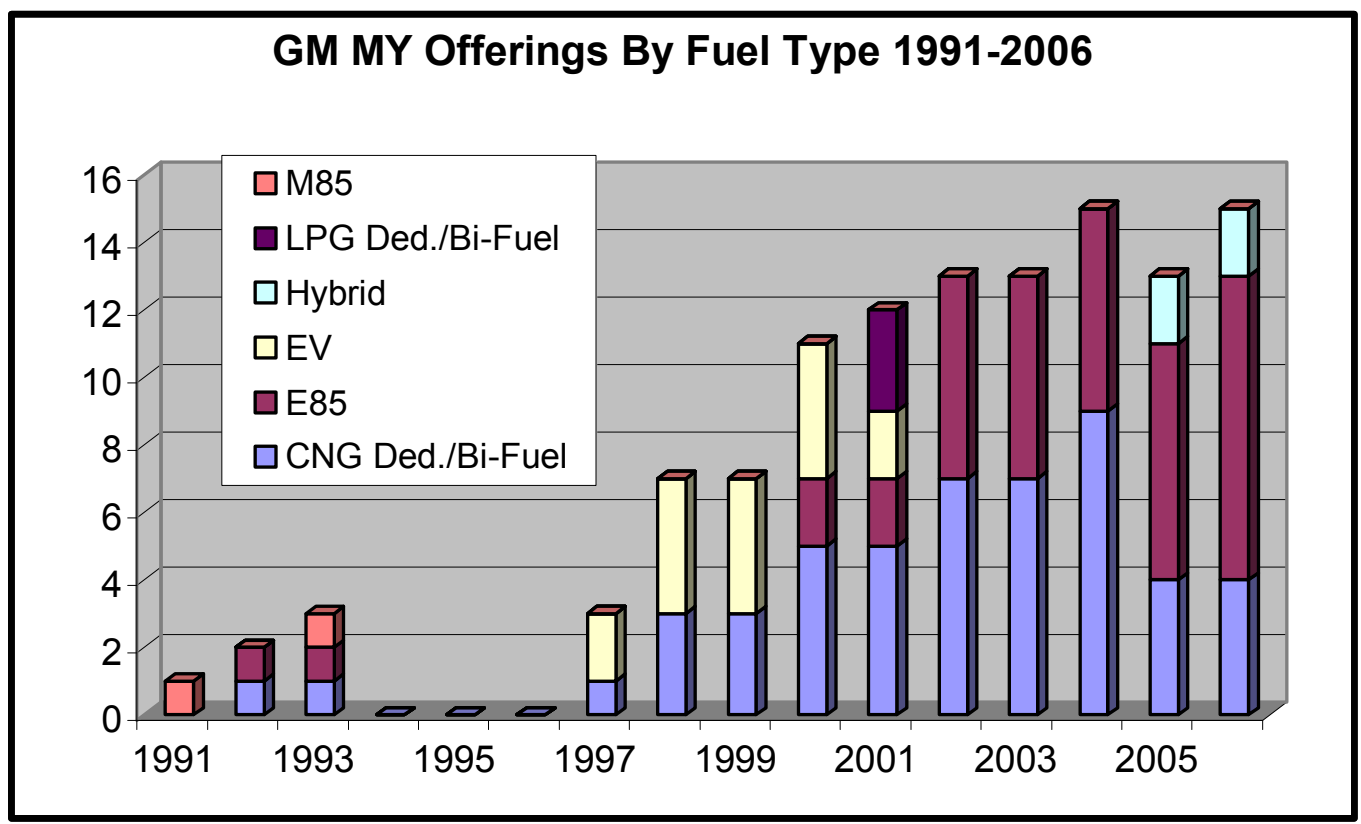

\section{GM Notes}

- GM and Honda were the only OEMs offering CNG LDVs in 2006.

- FFV offerings dominate GM menu.

- GM recently entered the hybrid market. 


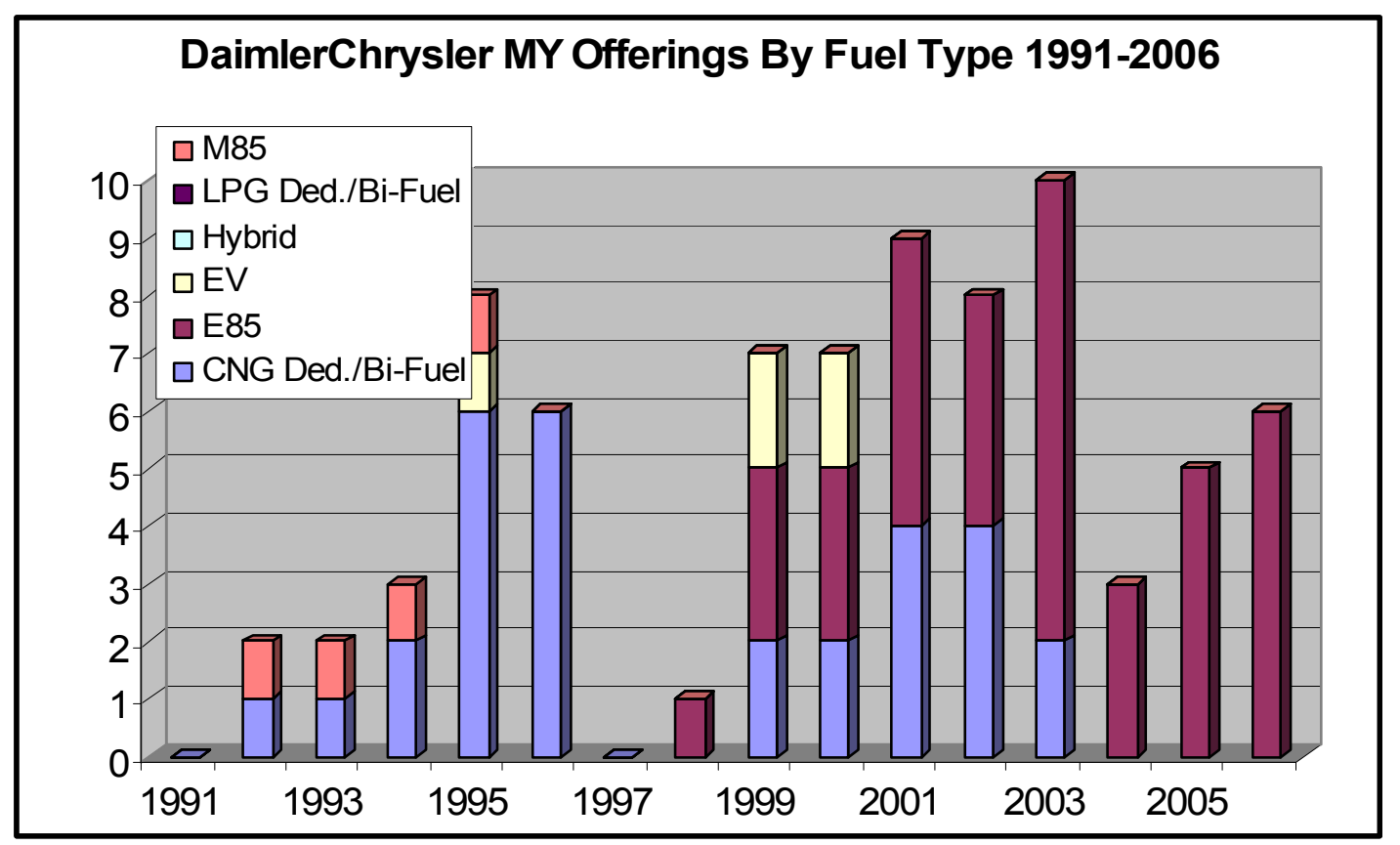

\section{DaimlerChrysler Notes}

- DaimlerChrysler was an early player in M85 and CNG, but dropped CNG in 2004.

- E85 FFVs have been its only AFV offerings for the past three years.

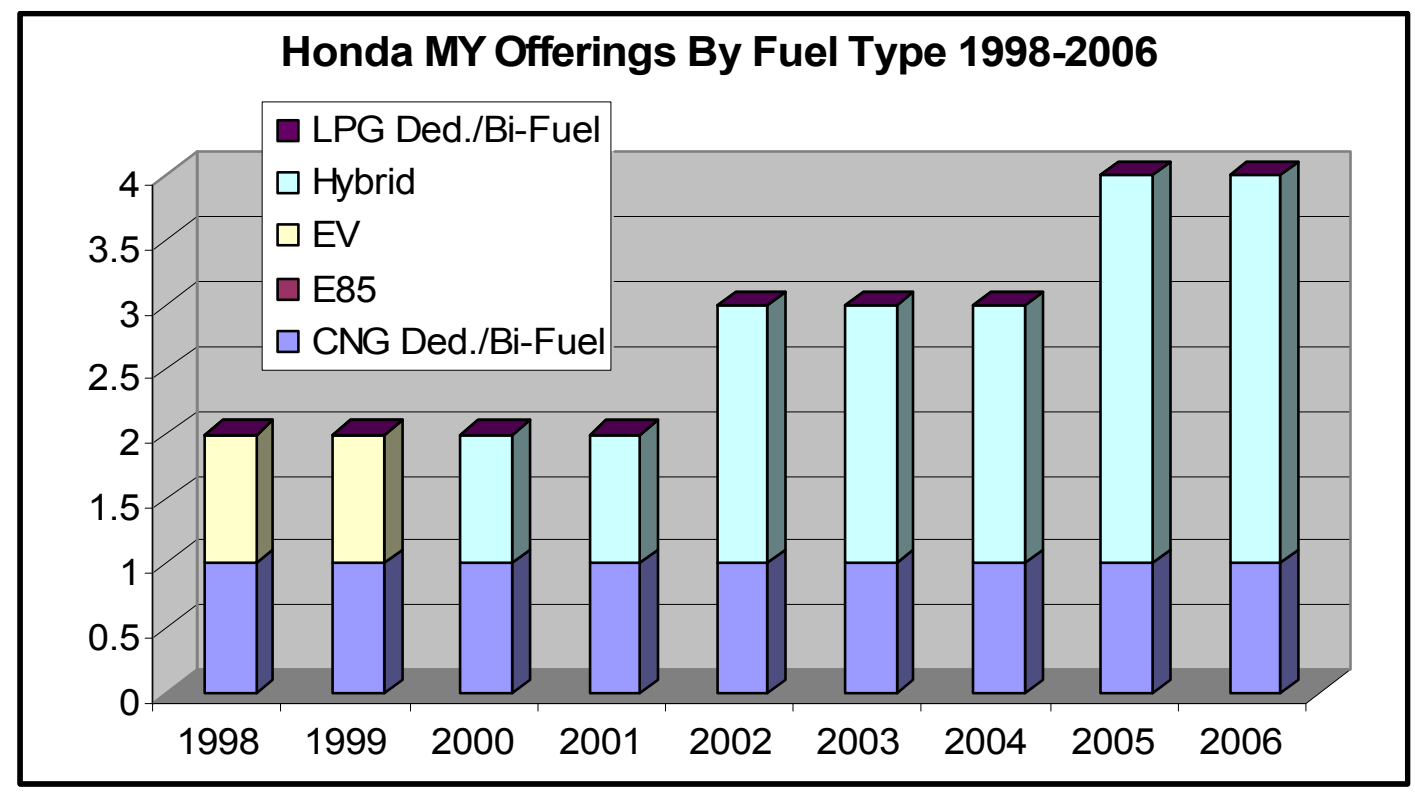

\section{Honda Notes}

- Honda entered the CNG market in 1998 with its dedicated Civic GX, which it continues to offer.

- It left the EV market in 2000 and now has offerings only in CNG and three hybrid models. 


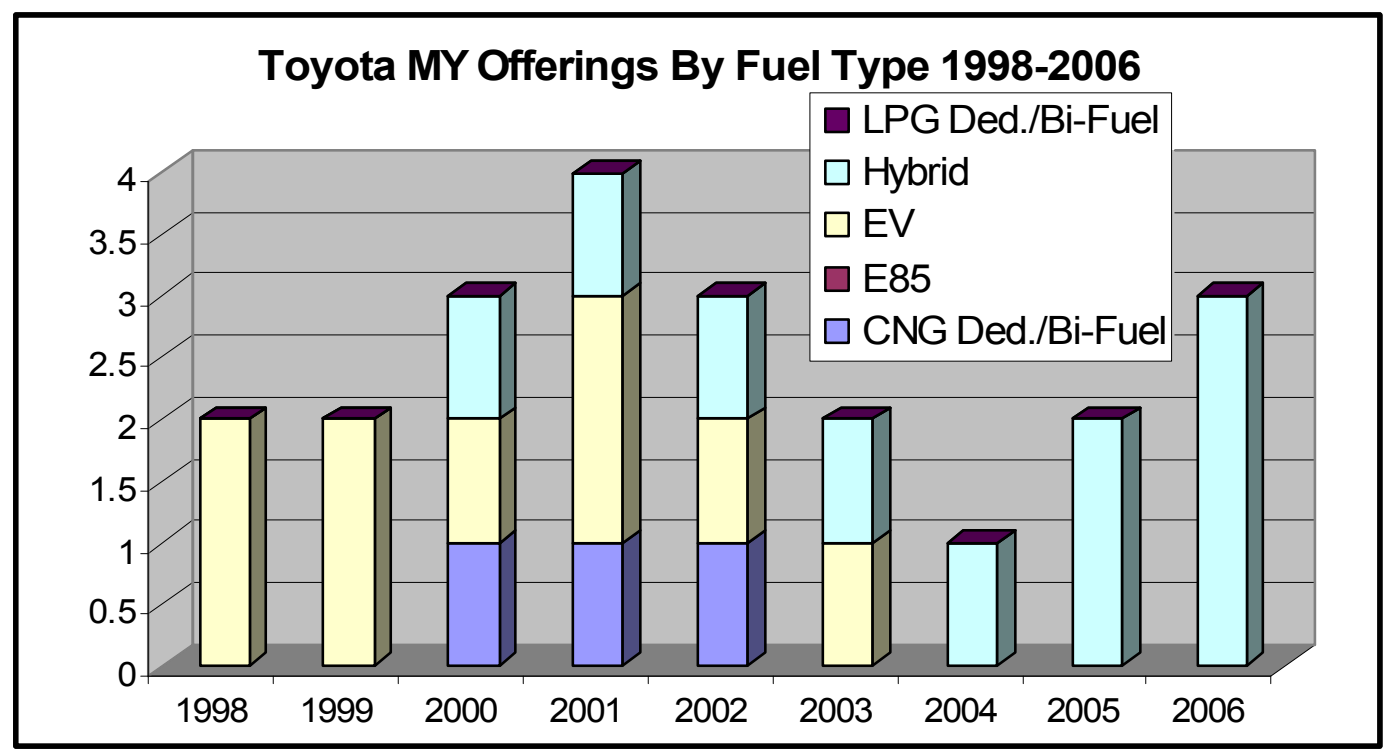

\section{Toyota Notes}

- Toyota entered the EV market in 1998, but has concentrated on the hybrid market since 2004.

- On the sales end, since being introduced in 2000, the Toyota Prius has far outperformed all other hybrid models combined with more than 500,000 of the estimated 640,000 HEVs expected to be sold by the end of 2006.

- The CNG Camry was offered for only three years. 
Appendix III. Laws and Incentives-Supplemental Information

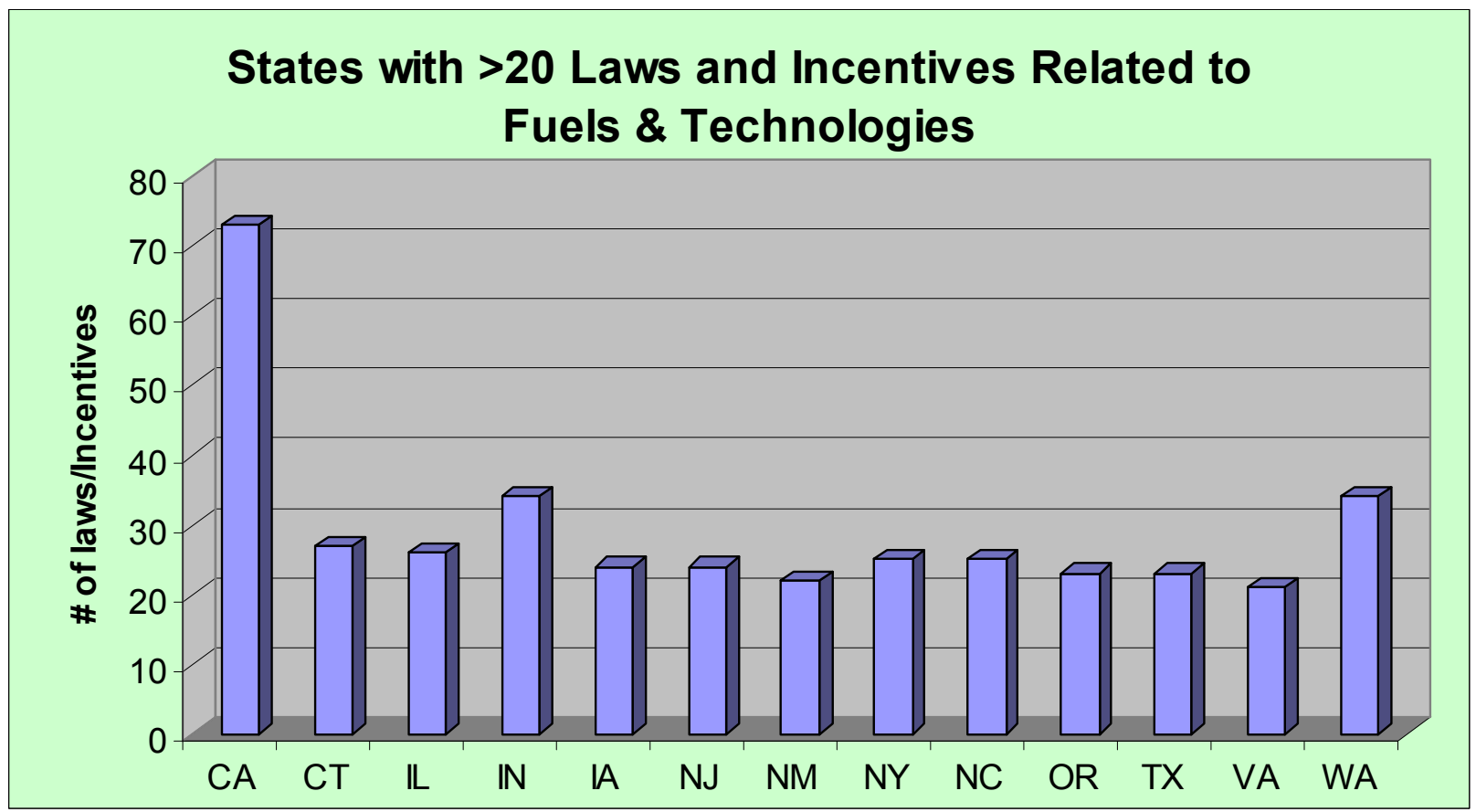

\section{Chart Notes}

- Not surprisingly, California leads the nation in the numbers of L\&I that have been passed at the state level with 73, just behind the federal total of 82 .

- Six other states have passed 18 or more L\&I, and all other states have at least one L\&I related to alternative fuel or advanced technologies.

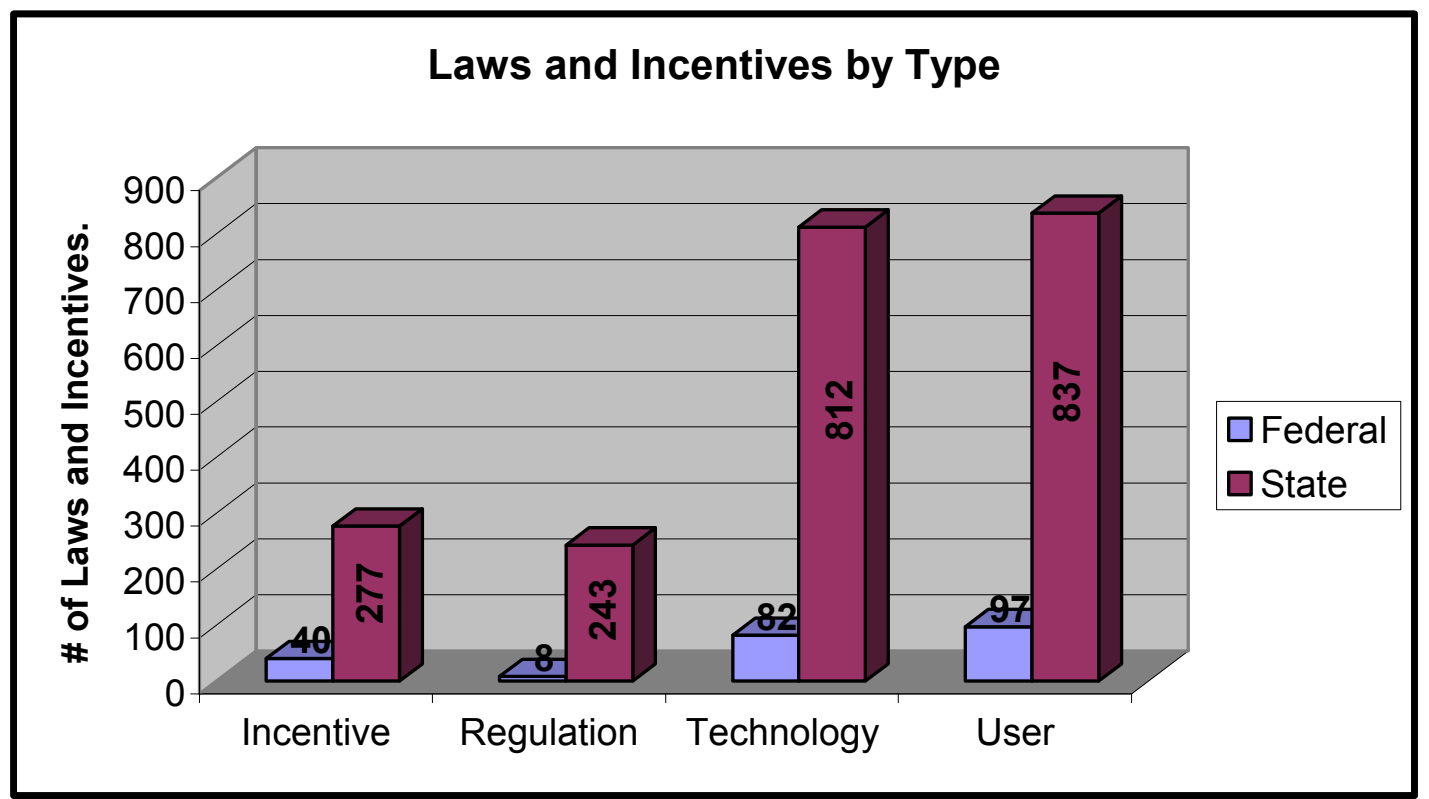

Note: Emphasis has been most significant on L\&I by fuel/technology and user type. 


\section{Appendix IV. Map of Clean Cities Coalitions}

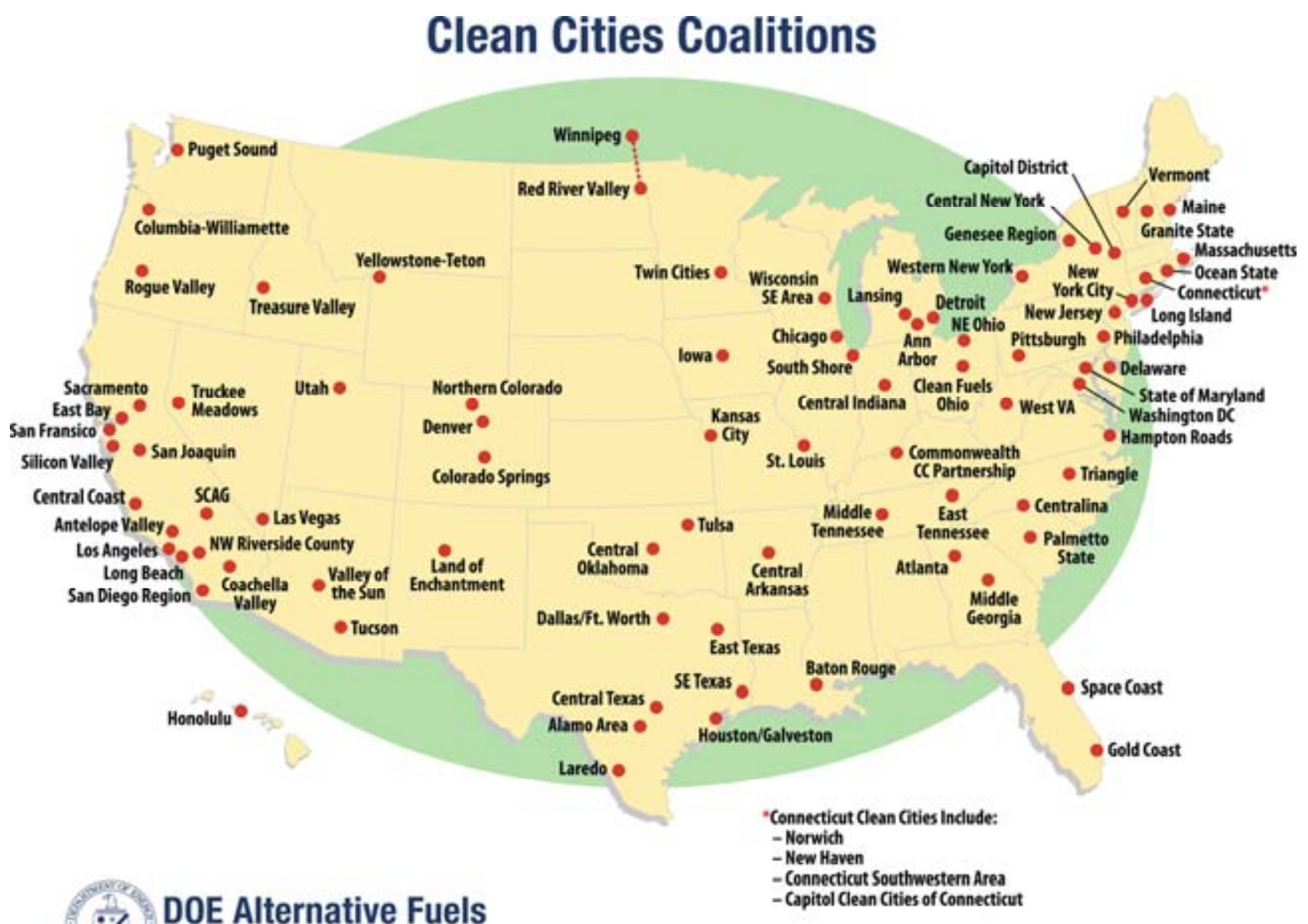

Map Date: 07.10.06 


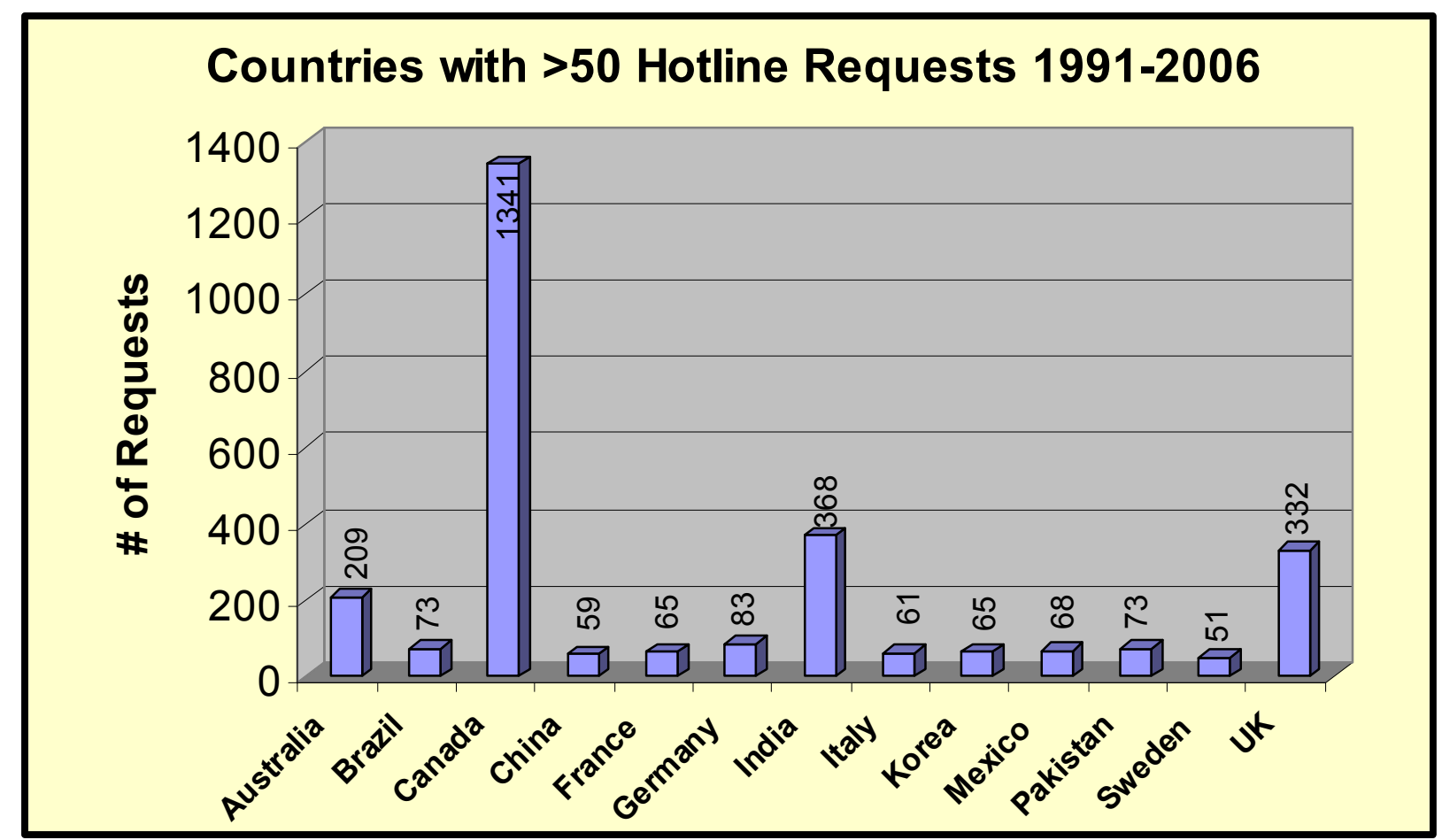

\section{Chart Notes}

- These 13 countries with more than 50 requests each represent $73 \%$ of all international calls $(3,885)$ logged by the Hotline.

- Canada represents more than one-third of all international requests.

- Not surprisingly, the four top countries (Canada, the United Kingdom, India, and Australia) are predominantly English-speaking nations. 


\section{Top 10 States $(>3,000)$ Requests 1992-2006}

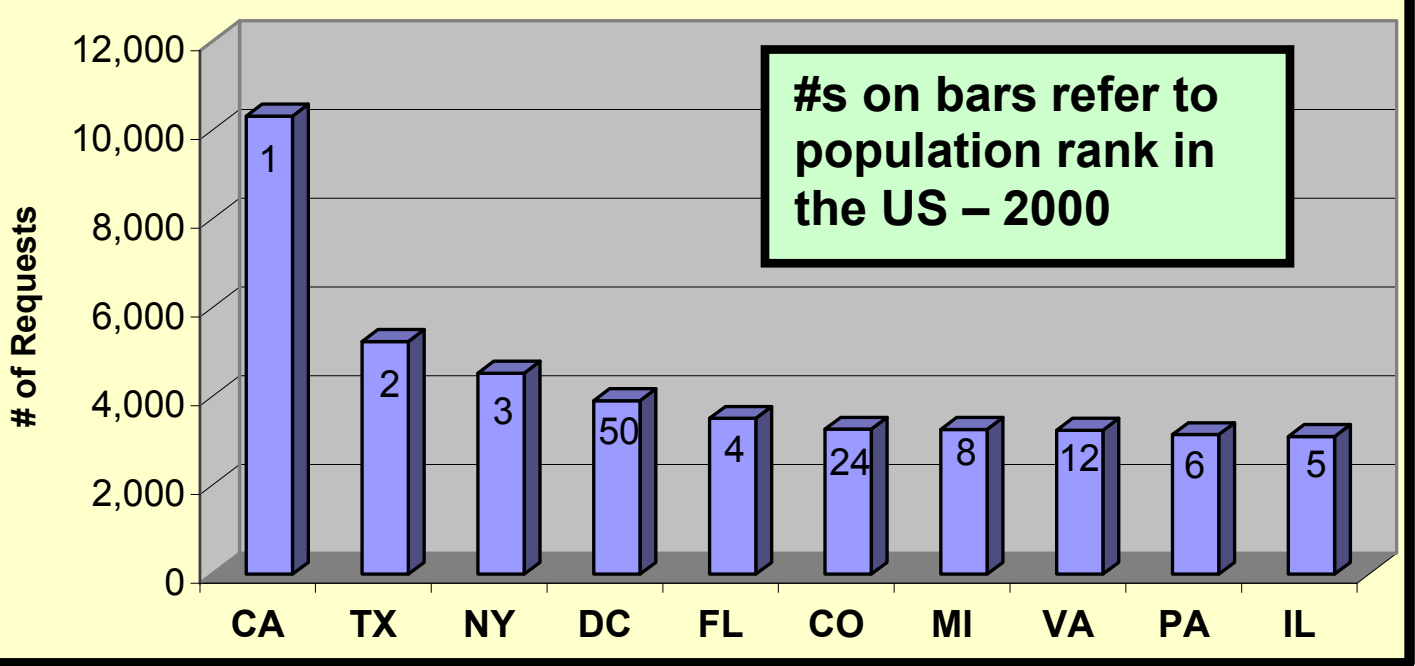

\section{Chart Notes}

- Each of these 10 states had more than 3,000 requests of the NAHF since its inception.

- Requests from these 10 states total 43,534 through July 2006 and represent almost half of all requests to the Hotline.

- The District of Columbia and Virginia are high because of the proximity to government agencies.

- Colorado is high because of the presence of NREL and the DOE Golden Field Office in Golden, and the Federal Center in Lakewood, Colorado.

- The 10,322 requests from California represent about one in nine of all requests to the Hotline. 


\section{Appendix VI. Organization Type of Hotline Users}

These next two charts depict the general organization types of users of the Hotline/TRS services from FY 1996 to FY 2006.

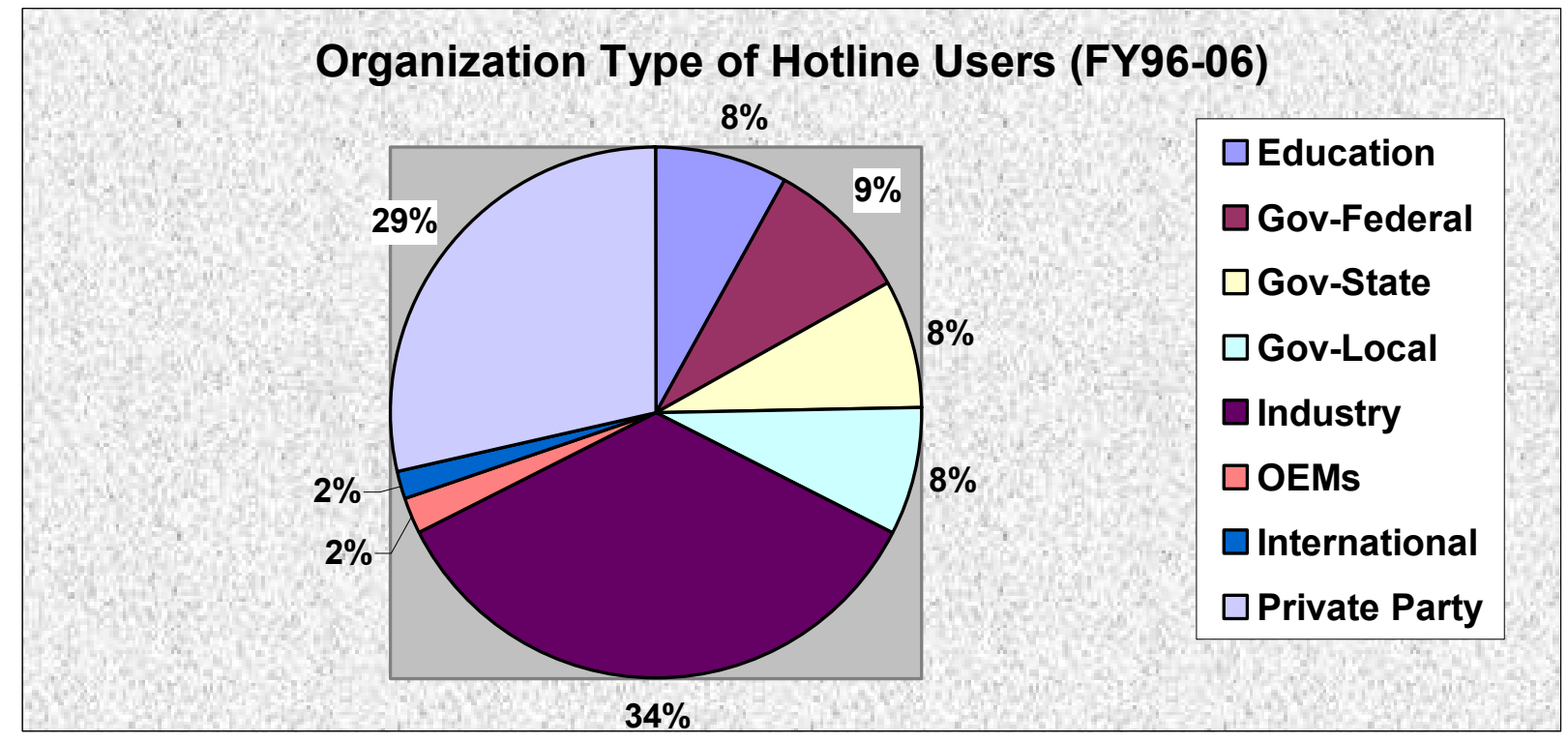

\section{Chart Notes}

- One of six Hotline requests was from federal/state government and one-fourth of all requests originated from all government types.

- Another one-third of all requests came from industry and private organizations.

- One in 12 requests came from education institutions.

- More that one-fourth stemmed from private individuals. 


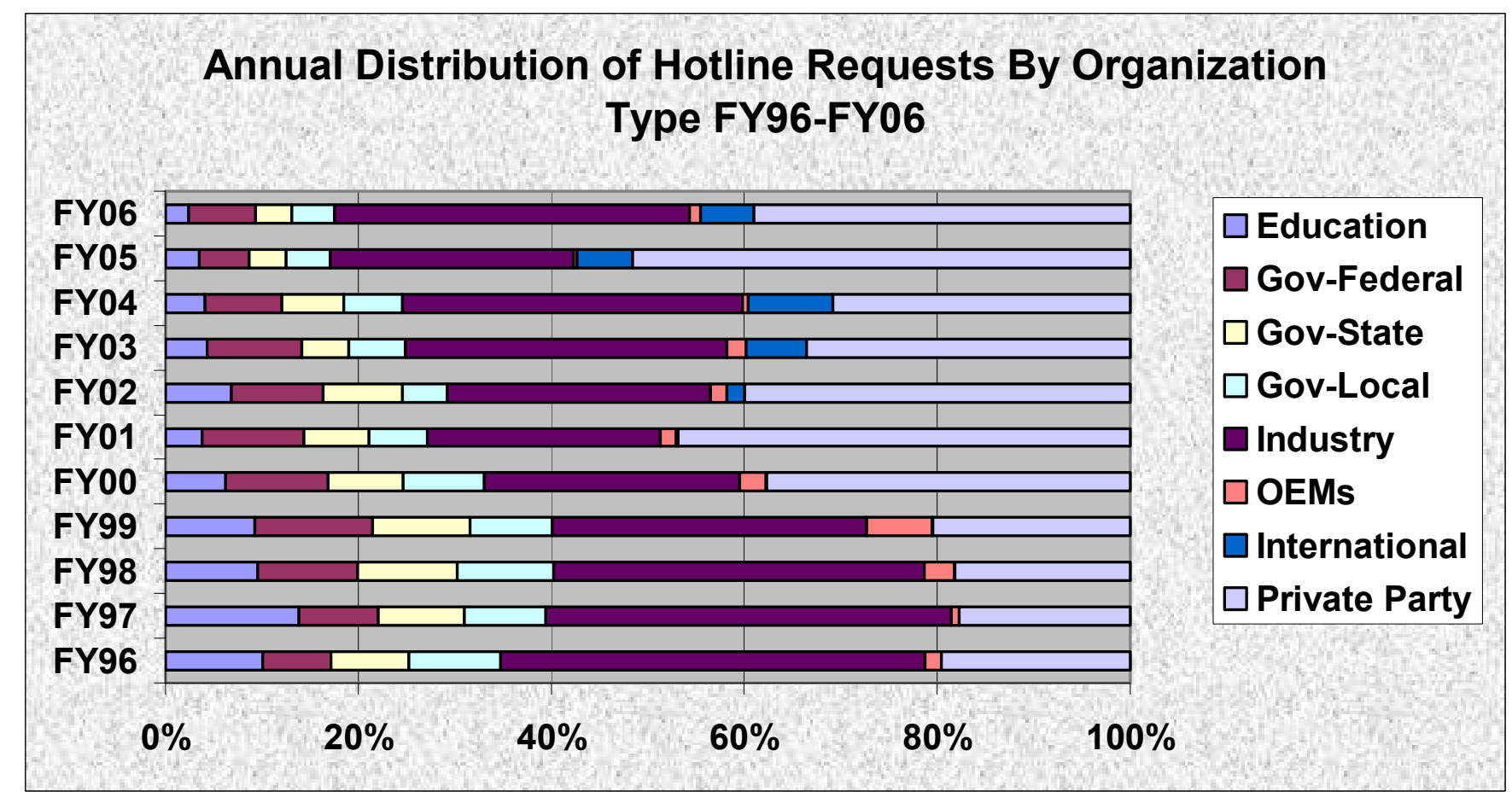

\section{Chart Notes}

This chart provides supplementary details on the Hotline requests by organization type over time. We can see the general dominance of industry and private individual requests over the 11-year period. 


\section{REPORT DOCUMENTATION PAGE}

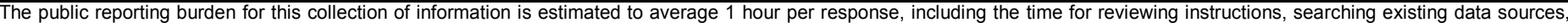

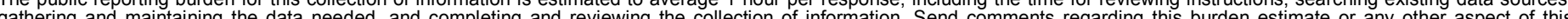

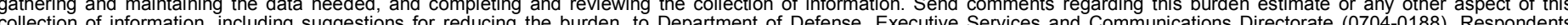

should be aware that notwithstanding any other provision of law, no person shall be subject to any pena

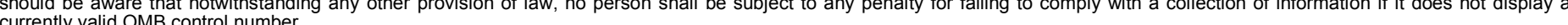

PLEASE DO NOT RETURN YOUR FORM TO THE ABOVE ORGANIZATION.

\begin{tabular}{l|l|l|l} 
1. REPORT DATE $(D D-M M-Y Y Y Y)$ & 2. & REPORT TYPE & 3. DATES COVERED (FrOm - TO)
\end{tabular}

September 2007

Technical Report

4. TITLE AND SUBTITLE

Historical Perspective of Clean Cities and Alternative Fuels Data

Center Trends 5a. CONTRACT NUMBER

DE-AC36-99-GO10337

5b. GRANT NUMBER

5c. PROGRAM ELEMENT NUMBER

5d. PROJECT NUMBER

NREL/TP-540-41069

5e. TASK NUMBER

FC070023

5f. WORK UNIT NUMBER
7. PERFORMING ORGANIZATION NAME(S) AND ADDRESS(ES)

National Renewable Energy Laboratory

1617 Cole Blvd.

Golden, CO 80401-3393
8. PERFORMING ORGANIZATION REPORT NUMBER

NREL/TP-540-41069

9. SPONSORING/MONITORING AGENCY NAME(S) AND ADDRESS(ES)

10. SPONSOR/MONITOR'S ACRONYM(S) NREL

11. SPONSORING/MONITORING AGENCY REPORT NUMBER

12. DISTRIBUTION AVAILABILITY STATEMENT

National Technical Information Service

U.S. Department of Commerce

5285 Port Royal Road

Springfield, VA 22161

13. SUPPLEMENTARY NOTES

14. ABSTRACT (Maximum 200 Words)

This document draws on the wealth of information housed in the U.S. Department of Energy's Alternative Fuels Data Center at the National Renewable Energy Laboratory. Trends and analyses are examined from data as far back as 1991. The findings of those trends and salient features are summarized.

15. SUBJECT TERMS

data mining; afdc; alternative fuels data center; clean cities

\begin{tabular}{l}
\hline \multicolumn{3}{|l|}{ 16. SECURITY CLASSIFICATION OF: } \\
\hline \begin{tabular}{l|l|l|} 
a. REPORT & b. ABSTRACT & c. THIS PAGE \\
Unclassified & Unclassified & Unclassified \\
& & \\
\hline
\end{tabular} \\
\hline
\end{tabular}

\begin{tabular}{|c|c|}
\hline $\begin{array}{l}\text { 17. LIMITATION } \\
\text { OF ABSTRACT }\end{array}$ & $\begin{array}{l}\text { 18. NUMBER } \\
\text { OF PAGES }\end{array}$ \\
\hline UL & \\
\hline
\end{tabular}

19a. NAME OF RESPONSIBLE PERSON

19b. TELEPHONE NUMBER (Include area code) 